DOE/NE/44139-80

Distribution Category UC-510

\section{DEVELOPMENT OF ANALYTICAL CELL SUPPORT FOR VITRIFICATION AT THE WEST VALLEY DEMONSTRATION PROJECT}

Topical Report

By

F. H. Barber

T. T. Borek

J. Z. Christopher

W. J. Connors

A. C. Feuz

J. H. Marlow

December, 1997
RECEIVED JUN 261998

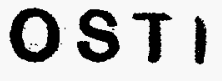

Work Performed Under Contract No. DE-AC24-81NE 44139

Prepared for

U.S. Department of Energy

Assistant Secretary for Nuclear Energy

Prepared by

West Valley Nuclear Services Co., Inc.

P.O. Box 191

West Valley, NY 14171-0191

DISTABUTION OF THIS DOCUMENT IS UMLMITED

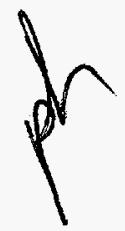




\section{DISCLAIMER}

This report was prepared as an account of work sponsored by an agency of the United States Government. Neither the United States Government nor any agency thereof, nor any of their employees, makes any warranty, express or implied, or assumes any legal liability or responsibility for the accuracy, completeness, or usefulness of any information, apparatus, product, or process disclosed, or represents that its use would not infringe privately owned rights. Reference herein to any specific commercial product, process, or service by trade name, trademark, manufacturer, or otherwise, does not necessarily constitute or imply its endorsement, recommendation, or favoring by the United States Government or any agency thereof. The views and opinions of authors expressed herein do not necessarily state or reflect those of the United States Government or any agency thereof.

This report has been reproduced directly from the best available copy.

Available to DOE and DOE contractors from the Office of Scientific and Technical information, PO Box 62, Oak Ridge, TN 37831; prices available from (615) 576-8401, FTS 626-8401.

Available to the public from the National Technical Information Service, U. S. Department of Commerce, 5285 Port Royal Road, Springfield, VA 22161. 


\section{DISCLAIMER}

Portions of this document may be illegible electronic image products. Images are produced from the best available original document. 
DEVELOPMENT OF ANALYTICAL CELL

SUPPORT FOR VITRIFICATION AT THE

WEST VALLEY DEMONSTRATION PROJECT

Topical Report

By

F. H. Barber

T. T. Borek

J. Z. Christopher

W. J. Connors

A. C. Feuz

J. H. Marlow

December, 1997

Work Performed Under Contract No. DE-AC24-81NE 44139

Prepared by

West Valley Nuclear Services Co., Inc.

P.O. Box 191

West Valley, NY 14171-0191 



\section{TABLE OF CONTENTS}

Section

LIST OF TABLES

LIST OF FIGURES

ABSTRACT

2.0 ANALYSIS REQUIREMENTS AND TURNAROUND TIME (TAT) LOGIC ........................................5

2.1 Sample Types 5

2.2 Development of Turnaround Time (TAT) and Layout of Equipment in the ACs

3.0 ANALYTICAL CELL MOCKUP UNITS AT THE VITRIFICATION TEST FACILITY

3.1 Regulatory Considerations

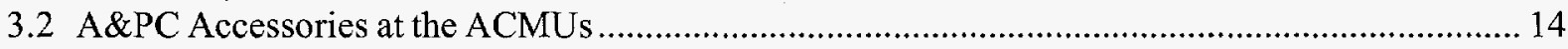

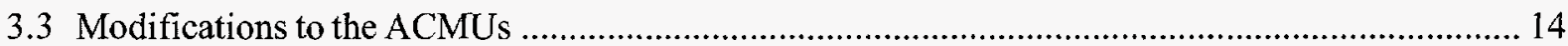

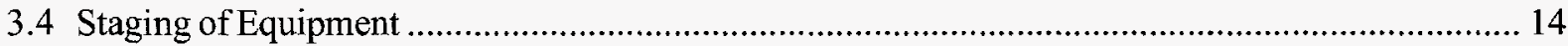

4.0 DEVELOPMENT OF REMOTE ANALYTICAL METHODS, APPARATUS, AND CELL TOOLS ...... 15

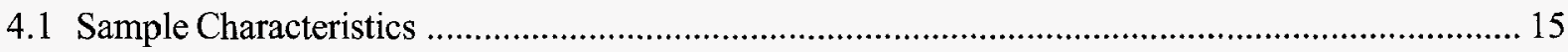

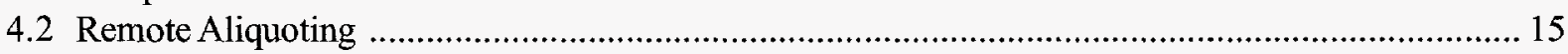

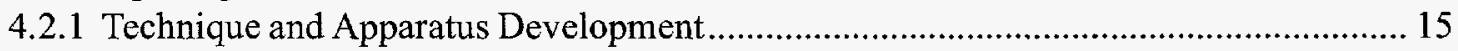

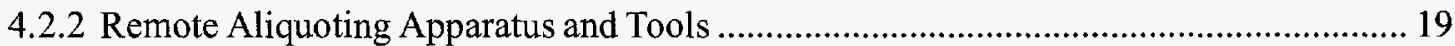

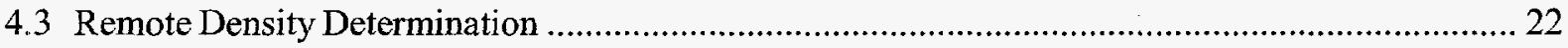

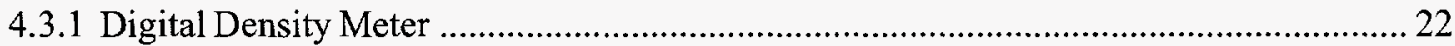

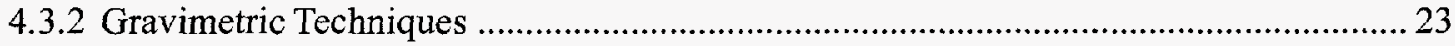

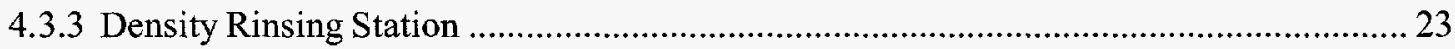

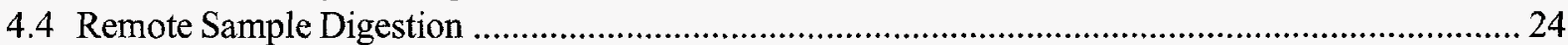

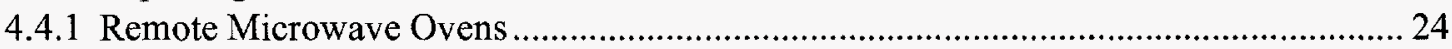

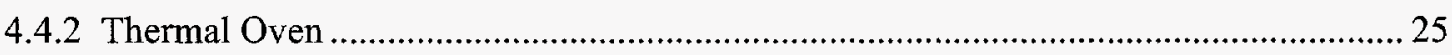

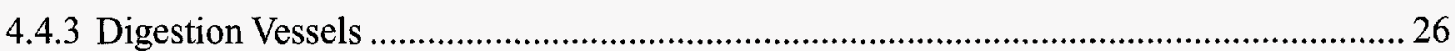

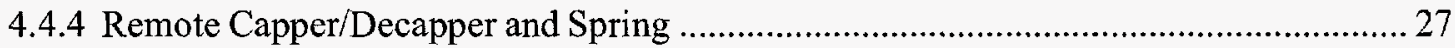

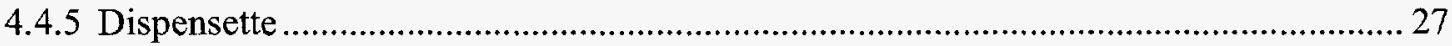

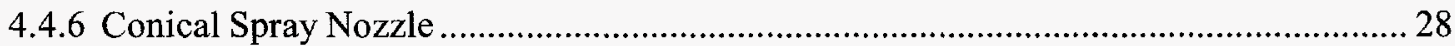

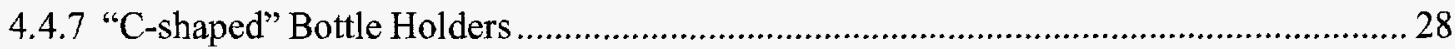

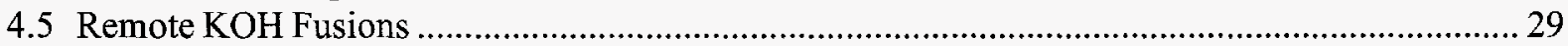

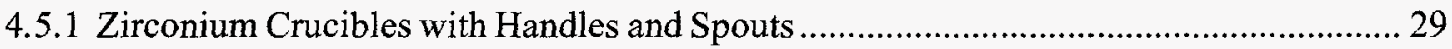

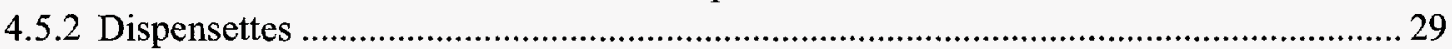

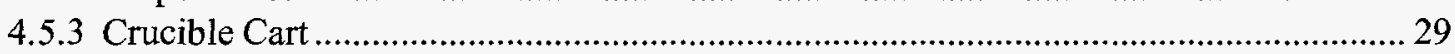

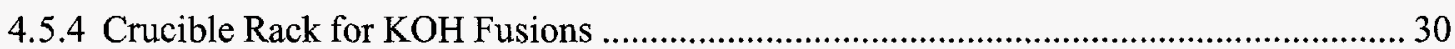

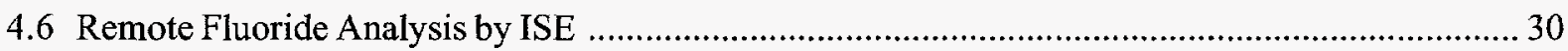

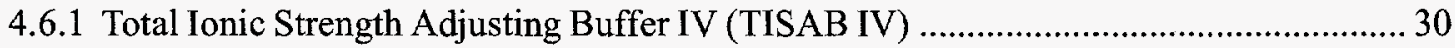

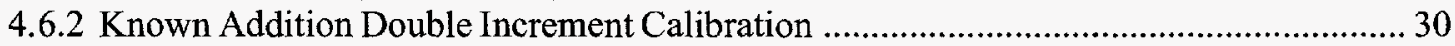

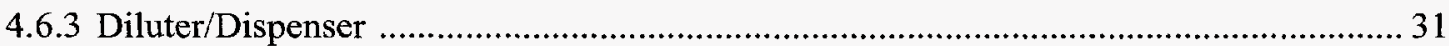


Section

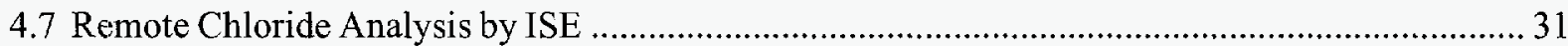

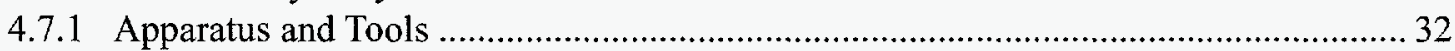

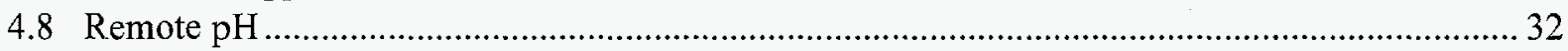

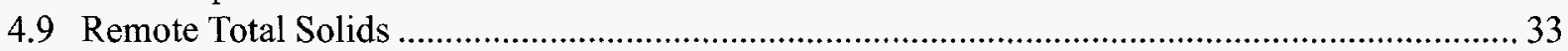

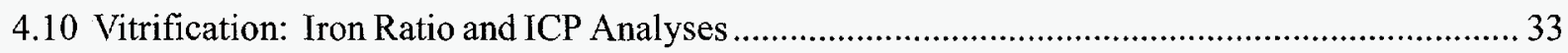

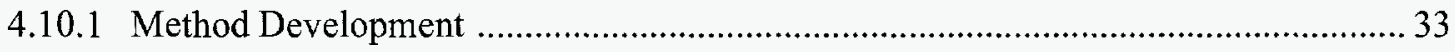

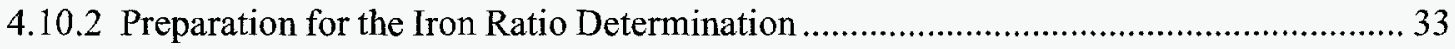

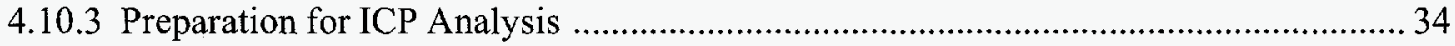

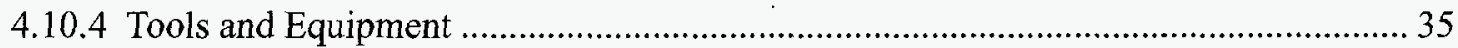

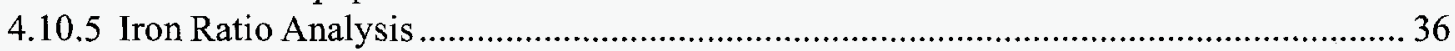

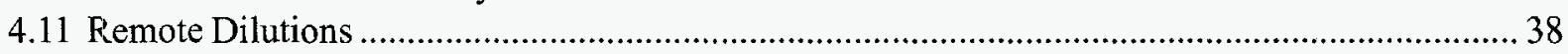

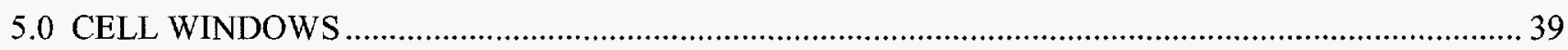

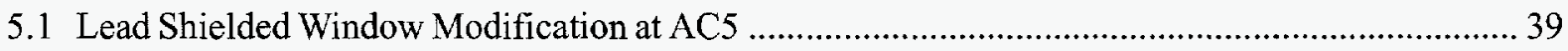

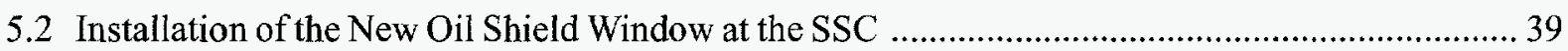

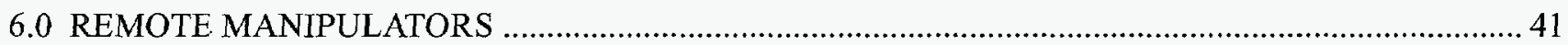

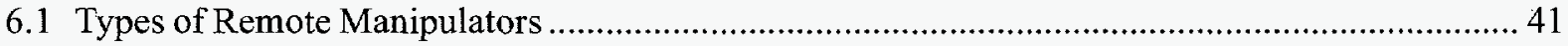

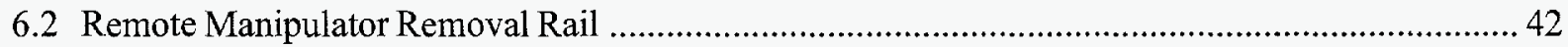

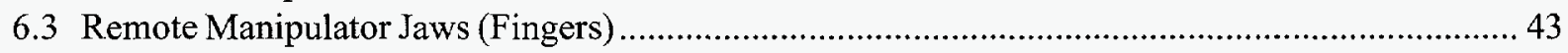

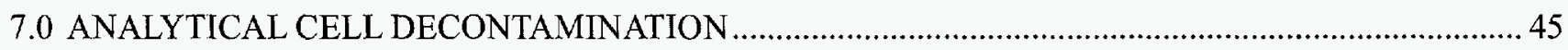

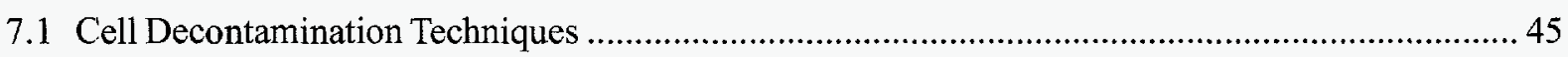

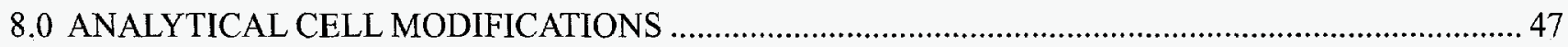

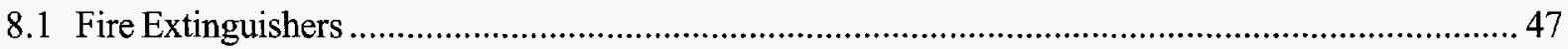

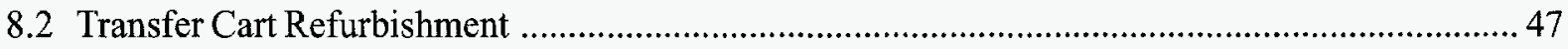

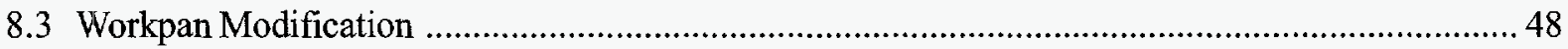

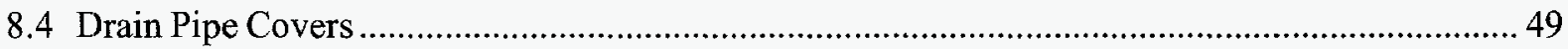

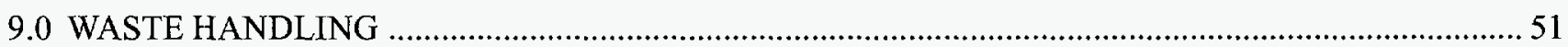

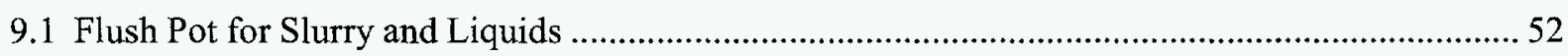

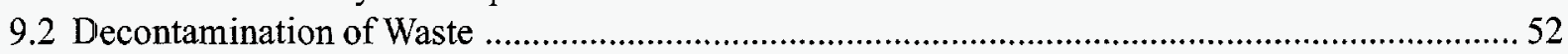

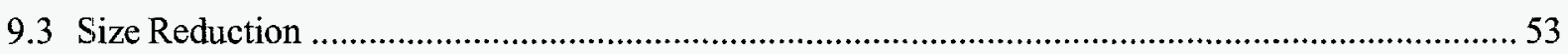

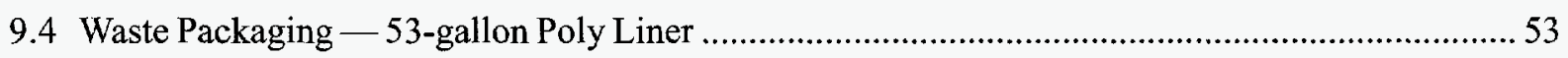

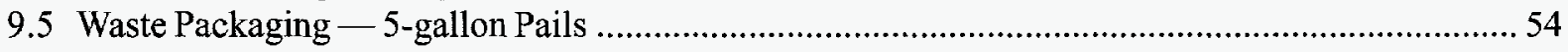

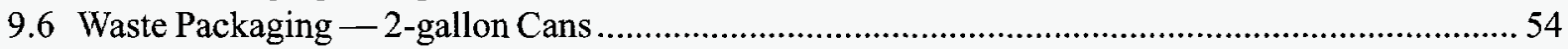

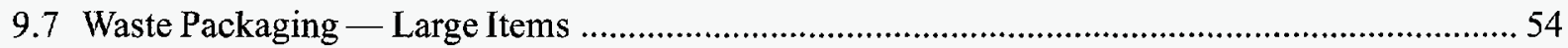


Section

10.0 SAMPLE STORAGE CELL (SSC)

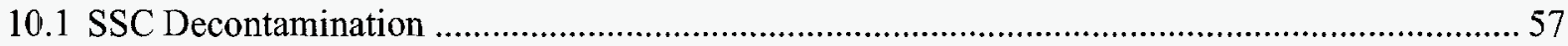

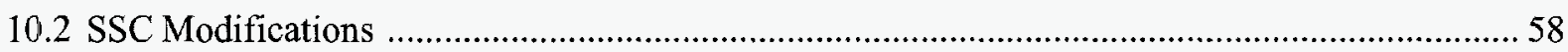

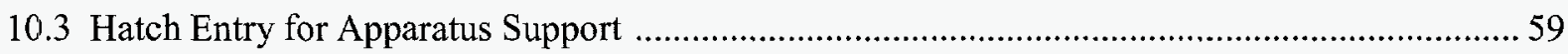

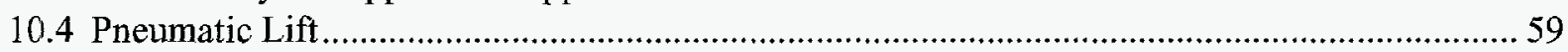

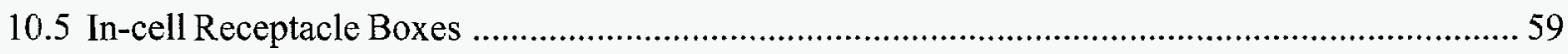

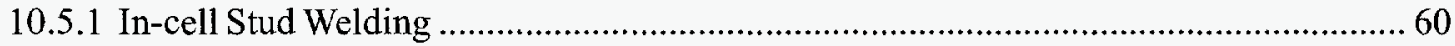

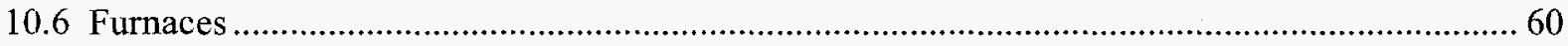

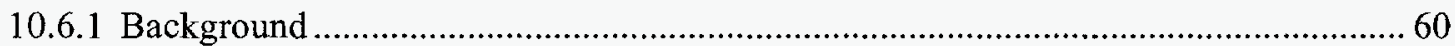

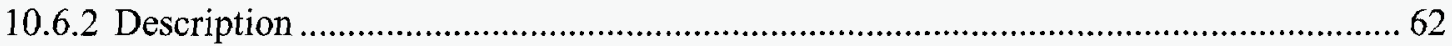

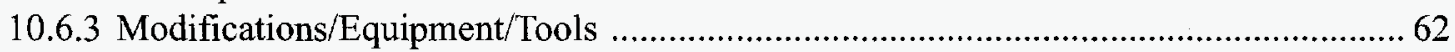

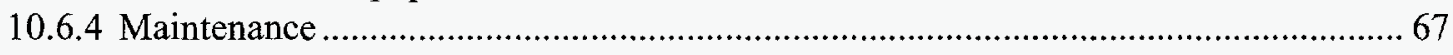

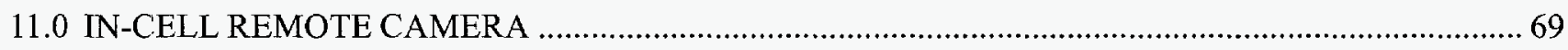

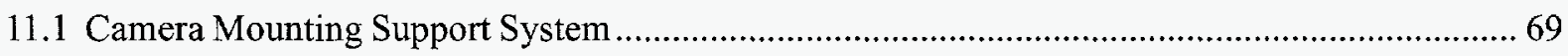

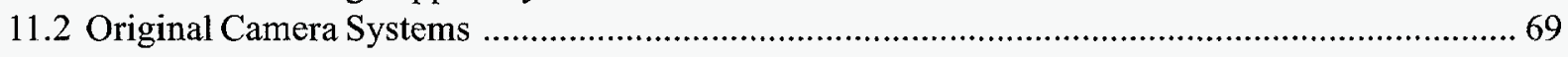

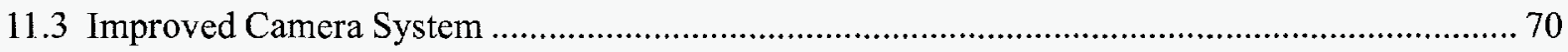

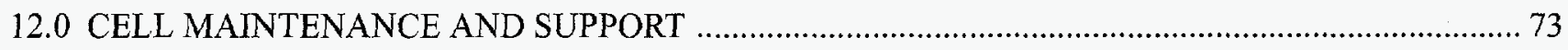

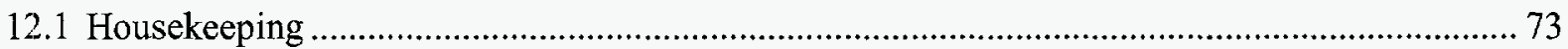

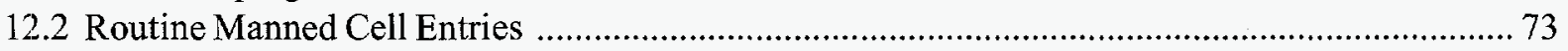

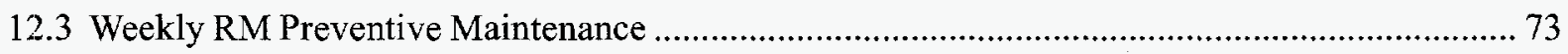

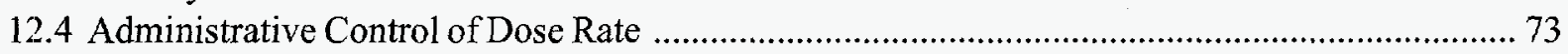

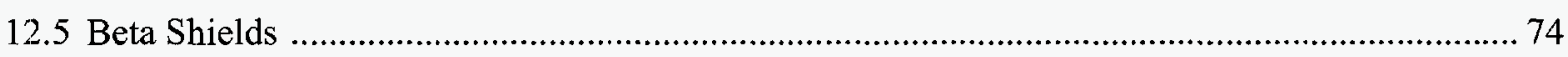

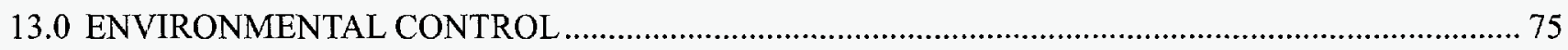

13.1 Analytical Decontamination Aisle (ADA) Heating, Ventilation, and

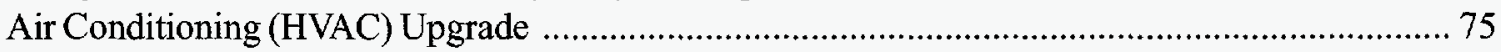

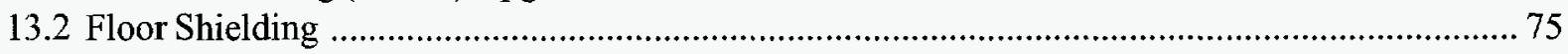

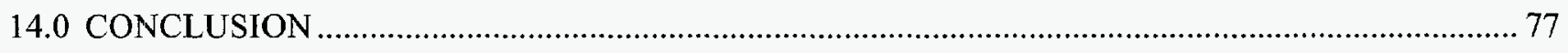

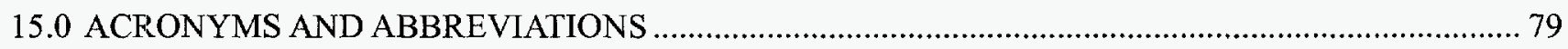




\section{LIST OF TABLES}

Table

Table 1. 1992 Analytical Parameters 5

Table 2. 1996 Analytical Parameters 6

\section{LIST OF FIGURES}

Figure

Figure 1. Schematic of Analytical \& Process Chemistry (A\&PC) Laboratories, Analytical Cells, and 2 Sample Storage Cell

Figure 2. Analytical Aisle Glovebox (Located Between Cells 4 and 5), Front View 3

Figure 3. Analytical Aisle Glovebox (Located Between Cells 4 and 5), Side View 3

Figure 4. Analytical Cell 1 (AC1) 8

Figure 5. Analytical Cell 2 (AC2) 9

Figure 6. Analytical Cell 3 (AC3) 9

Figure 7. Analytical Cell 4 (AC4) 10

Figure 8. Analytical Cell 5 (AC5) 10

Figure 9. Sample Storage Cell (SSC) 11

Figure 10. Analytical Cell Mockup Units (ACMUs) 12

Figure 11. Remote Diluter/Dispenser 17

Figure 12. Remote Controller with Remote Balance Controller 17

Figure 13. Remote Aliquoting Apparatus in Analytical Cell (Remote Balance, Pneumatic Lift with 17 Counterweight and Rod, Remote Pipetter, Sliding Base, and Center Positioning Plate)

Figure 14. Commercial Pneumatic Lift (CPL) with Counterweight and Rod 20

Figure 15. Pneumatic Lift 20

Figure 16. Sliding Base with Magnetic Stirmotor, Center Positioner, and Single RBG Bottle Holder 21

Figure 17. Single Scintillation Vial Holder and RBG Bottle Holders 21

Figure 18. Density Rinsing Station, Open 24 


\section{LIST OF FIGURES (continued)}

Eigure

Figure 19. Density Rinsing Station, Closed

Figure 20. Digestion Vessel with Pressure-relief Valve in Cap

Figure 21. Remote Capper/Decapper

Figure 22. Remote Capper/Decapper Spring

Figure 23. Dispensette Outside Analytical Cell

Figure 24. Conical Spray Nozzle at End of Water Line in Analytical Cell 28

Figure 25. C-shaped Bottle Holder with $60 \mathrm{~mL}$ Bottle 28

Figure 26. Zirconium Crucibles with Handles and Spouts; Original and Modified 29

Figure 27. Crucible Rack with Detachable Angled Handle 29

Figure 28. Crucible Cart 30

Figure 29. Crucible Cart with Rack and Crucibles ..... 30

Figure 30. Extension Tool and Inconel ${ }^{\mathrm{TM}}$ Crucible Rack 34

Figure 31. Pear-shaped Quartz Crucible with Secondary $100 \mathrm{~mL}$ Crucible 34

Figure 32. Sample Crusher with Tray 35

Figure 33. Mixer/Mill 36

Figure 34. Tungsten Carbide Grinding Vials 36

Figure 35. Remote Manipulator (RM) Used at A\&PC Hot Cells and ACMUs 41

Figure 36. SC-2 and AC1-5: Eleven Remote Manipulators (RMs) in Working Positions 41

Figure 37. View of SSC with Six RMs in Working Positions. 42

Figure 38. RM Removal Rails 42

Figure 39. Ten-inch Fingers (Jaws) 43

Figure 40. Dry Chemical Extinguisher System 47

Figure 41. Transfer Cart 47

Figure 42. Transfer Tray 48

Figure 43. Hinged Work Pan 49 


\section{LIST OF FIGURES (continued)}

Figure

Figure 44. Work Pan Lifting Tool

Figure 45. Work Pan Rollers

Figure 46. Flush Pot 52

Figure 47. Ultrasonic Bath 52

Figure 48. Cell Entry - Radiation Protection to Remove Drum Liner... 53

Figure 49. Five-gallon Plastic Pail 54

Figure 50. Two-gallon (Stainless Steel) Waste Can 54

Figure 51. Example of Removal of a Large Item 55

Figure 52. Transfer Tube, Ex-cell .58

Figure 53. Transfer Tube, In-cell 59

Figure 54. SSC Cord Brackets and Receptacle Box 59

Figure 55. Furnace on Stainless Steel Cart, Front View 61

Figure 56. Furnace on Stainless Steel Cart, Front View, Door Open 61

Figure 57. Furnace on Stainless Steel Cart, Side View 61

Figure 58. Electrical Connections Atop the Furnace 62

Figure 59. Molybdenum Disilicide Heating Elements with Lifting Apparatus 62

Figure 60. Heating Element Lifting Apparatus 63

Figure 61. Thermocouples and Receptacle Box on Rear of Furnace 63

Figure 62. 50 Amp Connector with RM Grip. 64

Figure 63. Seven-inch Thermocouple and Thermowell 64

Figure 64. Stainless Steel Cooling Rack 65

Figure 65. Cardboard and Foam Wrapped Around Heating Elements 65

Figure 66. Furnace Cart Brake Tool 66

Figure 67. Modified RM Fingers for Furnace Pinch Clamps 66

Figure 68. Socket Tool for RM Use 66 


\section{LIST OF FIGURES (continued)}

Figure

Figure 69. Spill Tray Removal Tool 67

Figure 70. Camera View of Passageway from SSC through AC1-5 69

Figure 71. Charged Coupled Device Camera and 10X TV Zoom Lens 69

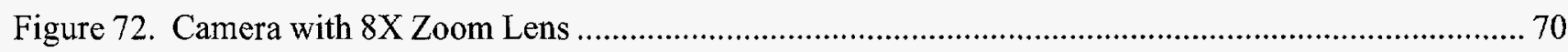

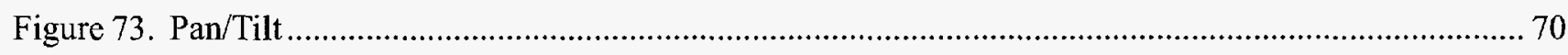

Figure 74. Camera Remote Controller Used with Camera System in SSC and SC2 _................................ 70

Figure 75. Present Camera Setup with Bracket Used in SSC for Surveillance of Passageway ..................... 71

Figure 76. Bracket to Support Camera System in SC2 on Rails .......................................................... 71

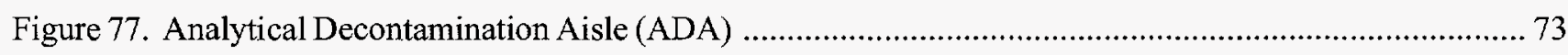

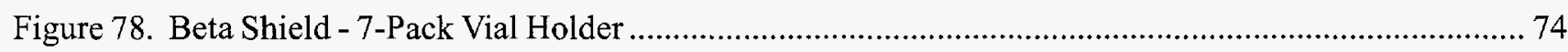

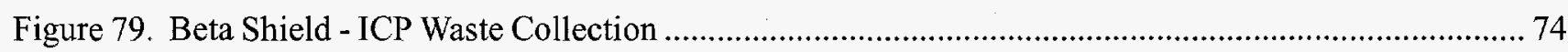

Figure 80. Beta Shield - Ion Chromatography (IC) Auto Sampler Vial Holder ............................................ 74 


\section{ABSTRACT}

Analytical and Process Chemistry (A\&PC) support is essential to the high-level waste vitrification campaign at the West Valley Demonstration Project (WVDP). A\&PC characterizes the waste, providing information necessary to formulate the recipe for the target radioactive glass product. High-level waste (HLW) samples are prepared and analyzed in the analytical cells (ACs) and Sample Storage Cell (SSC) on the third floor of the main plant. The high levels of radioactivity in the samples require handling them in the shielded cells with remote manipulators.

The analytical hot cells and third floor laboratories were refurbished to ensure optimal uninterrupted operation during the vitrification campaign. New and modified instrumentation, tools, sample preparation and analysis techniques, and equipment and training were required for A\&PC to support vitrification.

Analytical Cell Mockup Units (ACMUs) were designed to facilitate method development, scientist and technician training, and planning for analytical process flow. The ACMUs were fabricated and installed to simulate the analytical cell environment and dimensions. New techniques, equipment, and tools could be evaluated in the ACMUs without the consequences of generating or handling radioactive waste. Tools were fabricated, handling and disposal of wastes was addressed, and spatial arrangements for equipment were refined. As a result of the work at the ACMUs the remote preparation and analysis methods and the equipment and tools were ready for installation into the ACs and SSC in July 1995. Before use in the hot cells, all remote methods had been validated and four to eight technicians were trained on each. Fine tuning of the procedures has been ongoing at the $\mathrm{ACs}$ based on input from $\mathrm{A} \& \mathrm{PC}$ technicians. Working at the $\mathrm{ACs}$ presents greater challenges than had development at the ACMUs.

The ACMU work and further refinements in the ACs have resulted in a reduction in analysis turnaround time (TAT). High quality data is consistently provided by A\&PC for vitrification operations, usually within 15 to 30 hours of sample receipt (representing a 50\% reduction from the original 30 to $62 \mathrm{hr}$ TAT). The high degree of proficiency demonstrated by A\&PC personnel at the analytical cells, combined with excellent tools, streamlined remote cell techniques, and analytical chemistry procedures, are the underlying factors in the improved TATs. The excellence in safety culture among A\&PC personnel is exemplified by the skill displayed in handling radioactive samples. 


\subsection{INTRODUCTION}

In 1981 West Valley Nuclear Services Co., Inc. (WVNS) was awarded a contract by the Department of Energy (DOE) to solidify high-level waste (HLW) at the West Valley Demonstration Project (WVDP) and WVNS began work in 1982. The HLW was generated by Nuclear Fuel Services, Inc. (NFS) while reprocessing spent nuclear reactor fuel from 1966 to 1972 . The HLW consisted of precipitated sludge and an alkaline supernatant stored in Tank 8D-2. WVNS has successfully decontaminated the supernatant using zeolite to remove cesium 137 (Cs-137) and solidified the resulting low-level liquid waste as cement in drums. The Cs-137-contaminated zeolite was added to the remaining sludge and the mixture is being vitrified to produce HLW glass suitable for storage in a federal repository.

The Analytical and Process Chemistry (A\&PC) Department performs the chemical analyses to support the vitrification process and to characterize the HLW form. The A\&PC staff includes several scientists and four crews of technicians on rotating shifts, providing support 24 hours every day. HLW process samples are prepared and/or analyzed in the analytical cells (ACs) because of their high levels of radioactivity. The resulting data is used by Slurry Acceptance Engineers (SAEs) in the Vitrification Process Engineering Department and by the Waste Qualification Report (WQR) personnel to prepare recipes, accept batches, control the process, and characterize the HLW glass product.

The analytical hot cells consist of ACs (1-5), a Sample Storage Cell (SSC) and Sample Cell 2 (SC2). Each $\mathrm{AC}$ has internal dimensions of 6' $\mathrm{L} \times 6^{\prime} \mathrm{W} \times 9^{\prime} \mathrm{H}$. Each cell is equipped with a zinc bromide $\left(\mathrm{ZnBr}_{2}\right)$ or a leaded glass/oil immersion shield window. The back wall, roof, and front wall above the bottom of the shield window are composed of $3^{\prime}$ thick concrete. The bottom and the front wall up to the bottom of the shield windows are composed of $2^{\prime}$ thick high-density concrete. The interior walls between adjacent cells are $18^{\prime \prime}$ thick. A removable stainless steel work pan is mounted on supports in the side walls of the cell approximately 42 " above the cell floor. The work pan has a center trough to collect waste liquid that is routed through a tube to the cell floor drain. A sliding hatch in the work pan is provided to gain access to a transfer cart. Rear access doors provide an opening of 3 ' $\mathrm{W} \times 6^{\prime} \mathrm{H}$ to each cell. The $\mathrm{l}^{\prime}$ thick doors are made of steel and concrete, mounted on hinges, and manually operated. Access to the SSC is by a roof hatch. Four $120 \mathrm{~V}$ outlets and one $208 \mathrm{~V}$ outlet are provided in each cell, each with a separate switch outside the cell. Four 1.5" ID conduits connect each cell interior to an instrument shelf located under the cold side of the shield window. An intercell transfer cart is available to transport objects from SC2 through the ACs to the SSC and back. Two transfer drawers, located between $\mathrm{SC} 2$ and $\mathrm{AC} 1$ and between $\mathrm{AC} 4$ and $\mathrm{AC} 5$, are available to pass materials into and out of the cells. In-cell access to the drawers is from $\mathrm{AC} 1$ and $\mathrm{AC} 5$, respectively. Access to the AC5 transfer drawer is obtained via glovebox.

The SSC contains an outlet for the sample pneumatic transfer system. Radioactive samples are sent from the Vitrification Facility and from the Integrated Radwaste Treatment System (IRTS) facility by two separate branches of the system that converge at a diverter. Sample bottles are placed inside polyethylene "rabbits." These specialized secondary containers fit the pneumatic tubes and are propelled by variations in air pressure. An pneumatic transfer control panel is located outside the SSC. Upgrades were made to this system in 1995. In-cell tools for removal of sample bottles from the rabbits were also developed. All HLW Waste Initial (WI), Waste plus Glass Formers (WGF), Elemental Shim (ES), and Glass Shard (SHD) samples are received in the hot cells in rabbits via the SGN system.

The ACs have been essential to sample preparation and analysis throughout the waste processing campaigns. The interior surfaces of the cells were initially decontaminated to facilitate refurbishment of the $\mathrm{ZnBr}_{2}$ shield windows in 1984. Some of the AC's remote manipulators (RMs) were replaced at this time. The intercell 
transfer cart underwent repairs and preventive maintenance and work pan modifications were made to allow greater remote manipulator access to the cart and tracks. Equipment and tools were modified for remote handling and in-cell use.

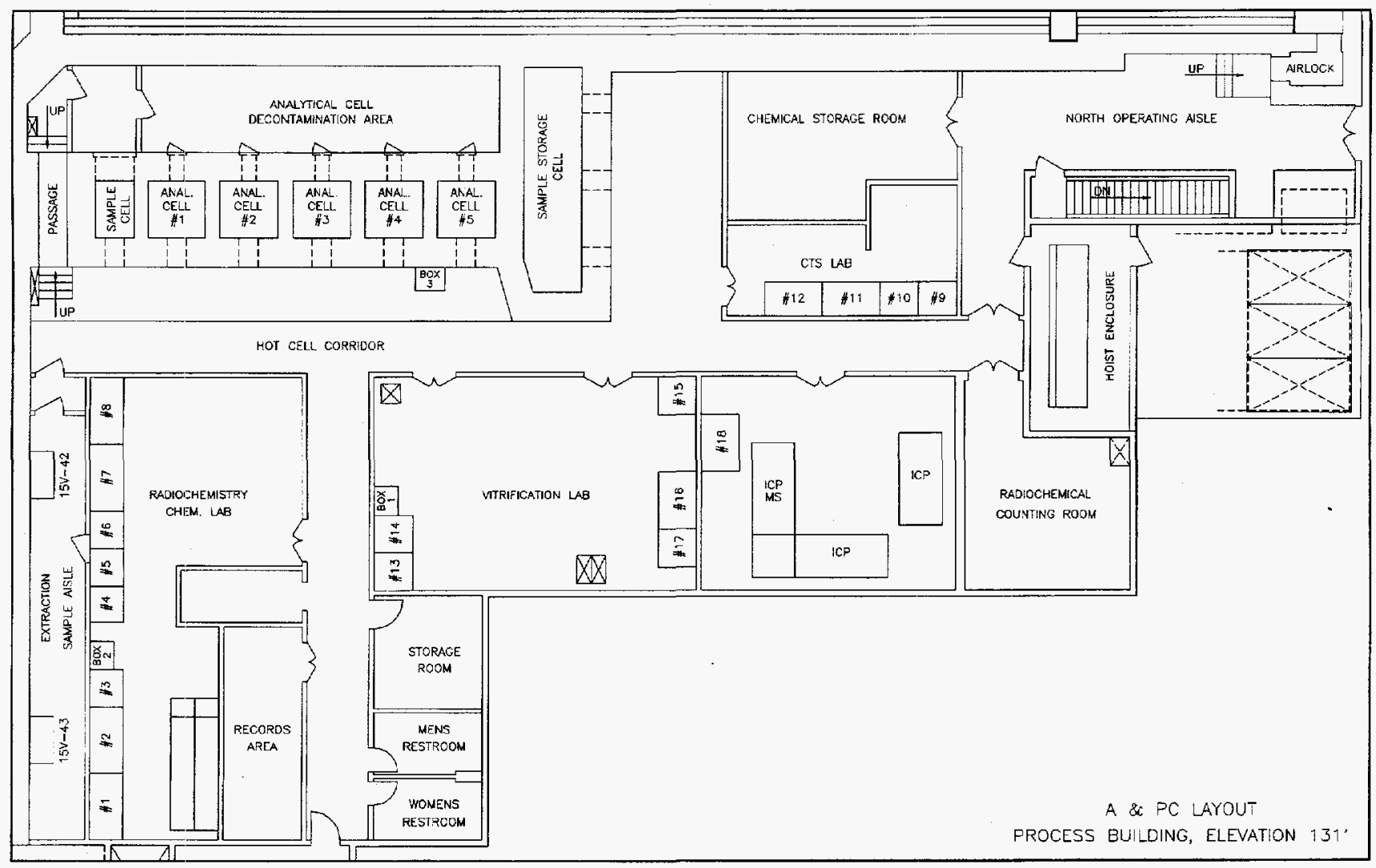

Figure 1. Schematic of Analytical \& Process Chemistry (A\&PC) Laboratories, Analytical Cells, and Sample Storage Cell

Figure 1 is a schematic diagram of the A\&PC Laboratory areas and the Analytical and Sample Storage Cells. The cells were refurbished in 1986 and 1987 to support the IRTS Facility which was brought on-line in 1988. The IRTS included the Supernatant Treatment System (STS) and Cement Solidification System (CSS). One objective of the IRTS treatment was to remove high concentrations of sulfate $\left(\mathrm{SO}_{4}{ }^{2-}\right)$ ions. These ions from the HLW cause undesirable characteristics in glass.

The major external modification to the analytical cells was made in 1987 by installation of the Analytical Cell Glovebox between AC4 and AC5 (see figures 2 and 3). The existing cell door was removed and replaced with a new door filled with lead shot to provide shielding. The glovebox incorporates a tong extender to remove samples and insert items into the cells through the drawer opening platform.

In-cell modifications in preparation for IRTS sample analysis were made in the fall/winter of 1987/1988. A reagent/cable rack was installed in AC2 to support the remote density meter. The remote density meter required external cooling, rinse valve sequencing, and remote sample uptake located on an ex-cell support cart. The remote initial diluter/dispenser, conductivity system, and $\mathrm{pH}$ meter were also installed in $\mathrm{AC} 2$. The first process samples received for preparation and analysis in the cells were from the IRTS. 


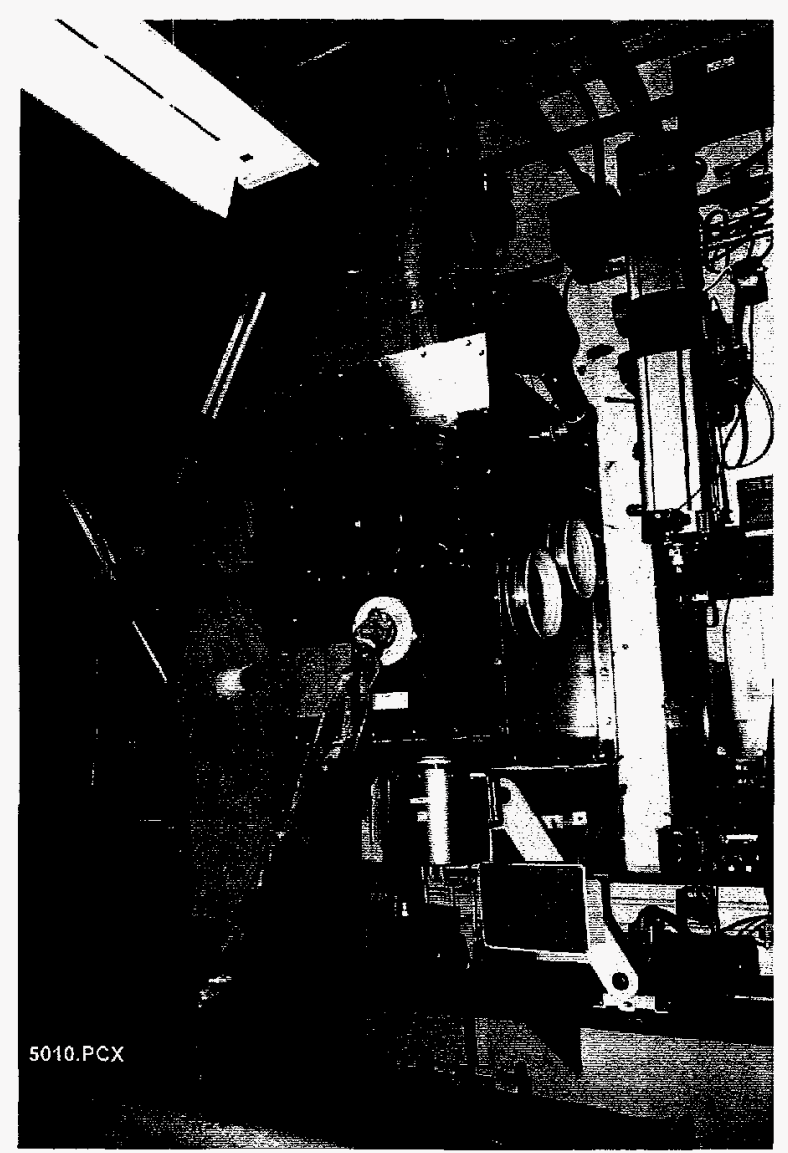

Figure 2. Analytical Aisle Glovebox (Located Between Cells 4 and 5), Front View

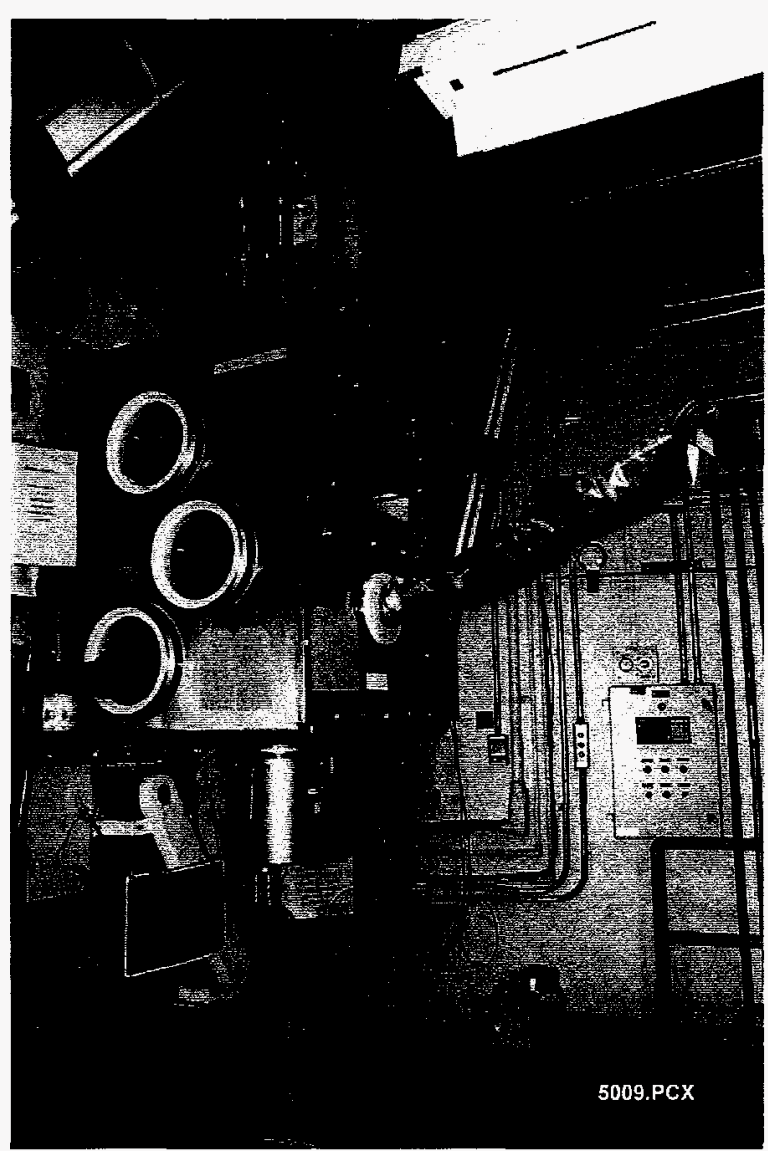

Figure 3. Analytical Aisle Glovebox (Located Between Cells 4 and 5), Side View

The HLW contained strontium-90 (Sr-90), Cs-137, and transuranic (TRU) waste components, as well as excess sulfate ions. In 1988, the IRTS began processing the supernatant portion of the HLW to remove the high concentration of Cs-137 using zeolite columns. This was followed by the sludge wash process which removed sulfate ions.

At the time of the sludge wash process, provisions had not been made for removal of cell waste, which led to its accumulation on and under the pans in AC3. Segregation, characterization, and decontamination of waste items were required in order to clean out AC3. This was accomplished by installing a 55-gallon drum liner in AC5 for low-level waste $(<100 \mathrm{mR} / \mathrm{hr})$ and fabricating shielded concrete 55 -gallon drums that held two 2-gallon containers for $>100 \mathrm{mR} / \mathrm{hr}$ and $<2 \mathrm{R} / \mathrm{hr}$ material.

The vitrification campaign was anticipated to begin in the fall of 1995 after completion of the IRTS. The highly radioactive sludge would be mixed with glass-forming chemicals and fed into a melter. Over a period of 30 to 40 months, about $2752^{\prime} \mathrm{OD} \times 10^{\prime} \mathrm{H}$ stainless steel canisters of the radioactive glass are expected to be filled and ultimately transferred to a federal repository. The vitrification process is more complex than the IRTS, requiring more chemical analysis support, unique analytical techniques, and shorter analysis turnaround time (TAT).

In 1993 A\&PC personnel evaluated the requirements for the remote methods and technology needed to receive, prepare, and analyze process samples from the vitrification campaign. The highly successful mockup technique was implemented with the establishment of the Analytical Cell mockup units (ACMUs), which mimic the dimensions and layout of the ACs. RMs, conduit, cell work pans, and other features of the ACs were installed. New methods for remote sample preparation (aliquoting, vitrification, acid digestion, and alkaline fusion) and 
analyses (density, fluoride, chloride, iron ratio, and $\mathrm{pH}$ ) were developed, evaluated, and validated at the ACMUs. Prototypical tools for remote handling were invented, manufactured, and refined. The round-bottomed glass (RBG) bottles presented a challenge, requiring various racks and holders to keep them upright during preparation and analysis. Instrumentation and equipment modified for remote use were tested and evaluated, and modifications were recommended for future versions. Equipment arrangements for efficient sample manipulation and throughput were developed. Technicians were trained in the use of remote manipulators and in the new preparation/analysis procedures. Preliminary estimates of TATs were determined at the ACMUs. Tools for remote sample preparation, analysis, handling, and transportation were evaluated. The ACMUs were used to create mockup hardware modifications of the cell pans, walls, penetrations, carts, and analytical apparatus. Technician participation in the development process has been invaluable.

A layout of the ACs and SSC was staged in the Control Room of the Main Plant in July 1995 to configure the equipment developed at the ACMUs for installation into the hot cells via personnel entry. At this time some of the layouts were modified for optimal utilization of AC floor space and technician access.

While ACMU development work was progressing, the hot cells were being decontaminated in preparation for personnel entries to upgrade the cells and position new equipment. Decontamination methods were developed to remove high levels of alpha and beta contamination from the cell pans and walls. Debris was vacuumed from the floors and drains of the ACs and SSC. The $\mathrm{ZnBr}_{2}$ window in AC5 had become deteriorated and was replaced with a new leaded glass/oil immersion window, which has allowed the use of the cell for the vitrification campaign. The SSC area was completely refurbished by adding a third window (oil-filled) and penetrations for electrical cables, reagents, a fire suppression system, and remote manipulators.

The SSC, due to its large area, was the only practical cell in which to locate the furnaces required for vitrifying the slurry $\left(1150^{\circ} \mathrm{C}\right)$. Vitrification was required for an iron ratio determination and to determine elemental composition from a "whole bottle aliquot" (which might be the only way to obtain a representative sample). The furnace was also required for potassium hydroxide $(\mathrm{KOH})$ fusion of the slurry $\left(500^{\circ} \mathrm{C}\right)$ and for calcining $\left(500^{\circ} \mathrm{C}\right.$; whole bottle aliquot). The consideration of the heat generated by the furnaces led to controlling the temperature of the SSC.

The SSC was equipped with two furnaces that were craned in through the SSC hatch. One furnace is for primary use and one is a spare. A drying oven was also incorporated into this area for use in the preliminary steps of fusion, vitrification, and calcination.

For the refurbishment to support the vitrification campaign, an Inductively Coupled Plasma (ICP) spectrometer with a glovebox was installed in the Mass Spec Lab along with a backup ICP spectrometer with a second glovebox. The bottom of each glovebox has a $190 \mathrm{~mm}$ double door canister installed for transferring samples to the hoods and other gloveboxes with similar double door flanges. Vitrification process samples typically require digestion or fusion in the ACs followed by extensive dilution prior to introduction to the ICP glovebox for analysis. Sample shielding containers have been included for the sample transfer from the cells to the hoods and ICP gloveboxes. 


\subsection{ANALYSIS REQUIREMENTS AND TURNAROUND TIME (TAT) LOGIC}

In $1992 \mathrm{a}$ list of the required analytes for processing the HLW sludge was obtained from the Vitrification Process Engineering Department. These initial analytical parameters were required as supporting documentation of glass durability, which has previously been correlated with composition, for the waste repository. Some of the parameters are used to determine processability by generating the appropriate recipes to produce durable glass and others to help regulate the process. Radioactive analytes are used to track the processing of the waste in terms of curies.

Table 1 lists the parameters that were initially stipulated in 1992. These analytes are based on results obtained during the series of Functional and Checkout Testing of Systems (FACTS) tests conducted on the full-scale melter Component Test Stand (CTS) during the 1984-1989 period. Not all analyses are required on all sample types.

Table 2 lists the analyses that support the present vitrification process. Some of the analyses on the 1992 list are no longer needed in 1996.

\subsection{Sample Types}

Sample types for analysis are as follows:

- "Waste Initial" or "WI," the HLW slurry composed of the thorium extraction (THOREX) waste solution (from Tank 8D-4), Cs-137-loaded zeolite, plutonium uranium reduction extraction (PUREX) waste sludge (from Tank 8D-2), and submerged bed scrubber (SBS) suspension. The analysis of WI samples provides information that is used to create the recipe for the glass formers (GF), below.

- "Glass Formers" or "GF," a mixture of nonradioactive chemicals added to the WI to make the feed slurry.

Table 1. 1992 Analytical Parameters

$\mathrm{Al}, \mathrm{B}, \mathrm{Ba}, \mathrm{Ca}, \mathrm{Ce}, \mathrm{Cr}, \mathrm{Fe}, \mathrm{K}, \mathrm{Li}, \mathrm{Mg}, \mathrm{Mn}, \mathrm{Na}, \mathrm{Nd}, \mathrm{Ni}, \mathrm{P}, \mathrm{Ru}, \mathrm{S}, \mathrm{Si}, \mathrm{Sr}, \mathrm{Th}, \mathrm{Ti}, \mathrm{U}, \mathrm{Zn}$, and $\mathrm{Zr}$ by inductively coupled plasma atomic emission spectroscopy (ICP-AES or ICP)

Radioactive analysis: Cs-137, Sr-90

Anions $\left(\mathrm{NO}_{3}^{-}, \mathrm{NO}_{2}^{-}, \mathrm{Cl}^{-}, \mathrm{F}^{-}, \mathrm{SO}_{4}^{-2}\right.$, and $\left.\mathrm{PO}_{4}^{-3}\right)$ by ion chromatography (IC)

$\%$ total solids (\%TS)

Total organic carbon (TOC) and total inorganic carbon (TIC)

Density

$\mathrm{pH}$

Iron ratio $\left(\mathrm{Fe}^{2+} / \mathrm{Fe}^{3+}\right)$ 
$\mathrm{Al}, \mathrm{B}, \mathrm{Ba}, \mathrm{Ca}, \mathrm{Ce}, \mathrm{Cr}, \mathrm{Fe}, \mathrm{K}, \mathrm{Li}, \mathrm{Mg}, \mathrm{Mn}, \mathrm{Na}, \mathrm{Nd}, \mathrm{Ni}, \mathrm{P}, \mathrm{Ru}, \mathrm{S}, \mathrm{Si}, \mathrm{Sr}, \mathrm{Th}, \mathrm{Ti}, \mathrm{U}, \mathrm{Zn}$, and $\mathrm{Zr}$ by ICP

Radioactive analysis: Cs-137, $\mathrm{Sr}-90$

Anions $\left(\mathrm{NO}_{3}^{-}\right.$and $\left.\mathrm{NO}_{2}^{-}\right)$by $\mathrm{IC}$

Anions $\left(\mathrm{Cl}^{-}\right.$and $\left.\mathrm{F}^{-}\right)$by ion-selective electrode (ISE)

$\%$ TS

TOC

Density

$\mathrm{pH}$

- "Waste plus Glass Formers," or "WGF," the mixture of WI and GF that contains the desired components for the feed slurry in terms of metals or elements. This composition must be documented for the repository records.

- "Elemental Shim," or "ES," a second iteration of the WGF in cases where the desired recipe was not confirmed by analysis and certain components needed to be added. This composition must be documented for repository records.

- "Sugar Feed," or "SF," the final product fed to the melter. It consists of WGF with sugar added. Analytical results are used for process control.

- "Glass Shard," or "SHD," glass shards taken from the upper level of a cylinder filled with glass. This data is used to confirm the glass composition, thus documenting its acceptability for the repository records.

All of the sample types contain high percentages of dissolved and undissolved solids. The slurry samples (WI, WGF, ES, SF) may contain more than $50 \%$ total solids. The glass shards are solid glass. All sample types require dissolution and dilution in the ACs in order to analyze the metals and the radioisotopes. Remote sample preparation in the cells by digestion and/or fusion required a major technology development.

\subsection{Development of Turnaround Time (TAT) and Layout of Equipment in the ACs}

Schematic drawings of the ACs and proposed equipment layout drafted in July of 1993 resulted in an initial estimated sample TAT of 83 hours. The TAT includes 20 hours of waiting due to sample queues that form in the cells awaiting processing on the singular piece of remote equipment (e.g., waiting for the balance to be free, waiting for the oven to be free).

The following objectives were pursued in August of 1994 to decrease the 83-hour TAT:

- Increasing the duplication of equipment in the cells to avoid "choke points" in sample preparation caused by sample queues. 
- Specialization in each cell providing for one preparation or analysis function to minimize cell-to-cell transfers.

- Utilizing the Sample Storage Cell (SSC) which provides significant space for sample preparation and analysis.

- Minimizing the number of samples and analyses required by Vitrification Process Engineering personnel.

- Using the Analytical Cell Mockup Units (ACMUs) to develop remote sample preparation and analysis procedures and apparatus.

A second appraisal of cell equipment layouts was performed. The layouts were modified, resulting in a corresponding decrease in analysis TAT. Expected time savings were based on the following assumptions:

- Maximum slurry particle size will be approximately 325 mesh ( $<50$ microns), which would allow wet slurry aliquots to be taken directly from the RBG bottles.

- The microwave oven, balance, dispenser, stirrer, and capper for acid digestion/dissolution will be located in $\mathrm{AC} 3$.

- The furnaces for vitrification, fusion, and calcination will be located in the SSC.

- A four-crucible furnace rack will be used for vitrification of four samples at a time (needed for iron ratio determination) rather than one sample at a time.

- Reagent heating for iron ratio sample preparation will take place in the microwave oven in $\mathrm{AC} 3$.

- Iron ratio measurements will be performed in AC2 using a fiber optic dip probe.

- Additional samples will be obtained for various analyses to minimize intercell RBG sample bottle transfer instead of performing several analyses from the same bottle.

- Fluoride and chloride ions are analyzed in-cell by ion-selective electrodes (ISEs).

- Slurry samples are subjected to alkali fusion in preparation for titanium (Ti) analysis in addition to acid digestion for other analyses.

- Thorium and ruthenium can be digested by existing acid digestion or alkali fusion methods abrogating the requirement for special method development.

Estimates at this point indicated a TAT of approximately 61 hours, including shift changes, primary digestion/ dilution, fusion, secondary dilution, and ICP analyses. The study was based on the operations and time required for each of the three sample preparation branches: digestion, fusion, and secondary dilution. The feed batch makeup cycle time, which totaled $204 \mathrm{hrs}$ on the vitrification logic diagram, included a 60-hr TAT for A\&PC.

If the maximum slurry particle size (WI, WGF, ES) is much larger than 325 mesh, it may not be possible to take a representative small aliquot of the wet slurry. Quantitative whole bottle aliquoting followed by drying and calcination or vitrification may be required. This would involve additional steps before the dissolution for elemental analysis could be started, including: 
- Weighing the full RBG bottle.

- Transferring the bottle contents quantitatively to an evaporating dish, with rinsing.

- Drying the slurry at $110^{\circ} \mathrm{C}$ for a minimum of 16 hours.

- Drying the empty RBG bottle (and the cap), weighing them.

- Transferring dried slurry to a suitable crucible (either gold-platinum or glassy carbon) for either calcining at $500^{\circ} \mathrm{C}$ or vitrification at $1150^{\circ} \mathrm{C}$ for two hours.

- Removal of the product from the crucible and grinding.

The whole bottle aliquoting additional work, if required, is expected to add a minimum of 22 hours to the TATs for the subject samples, yielding a preliminary estimated turnaround time of 83 hours. The ability to take a wet slurry aliquot is critical to minimizing TAT.

In 1995 the apparatus and equipment were staged for setup in the hot cells as shown in figures 4 through 9. The figures also identify cables, cell and equipment functions, and the additional lines required to support this operation.

The most recent TAT in September 1996 is 30 hours for the WI samples, 15 hours for the GF samples, and 30 hours for the WGF samples. At this time, the iron ratio determination analysis is not required and there is no TAT specified for the SF or SHD analyses. The new TATs are based on A\&PC performance during the first stages of HLW vitrification.

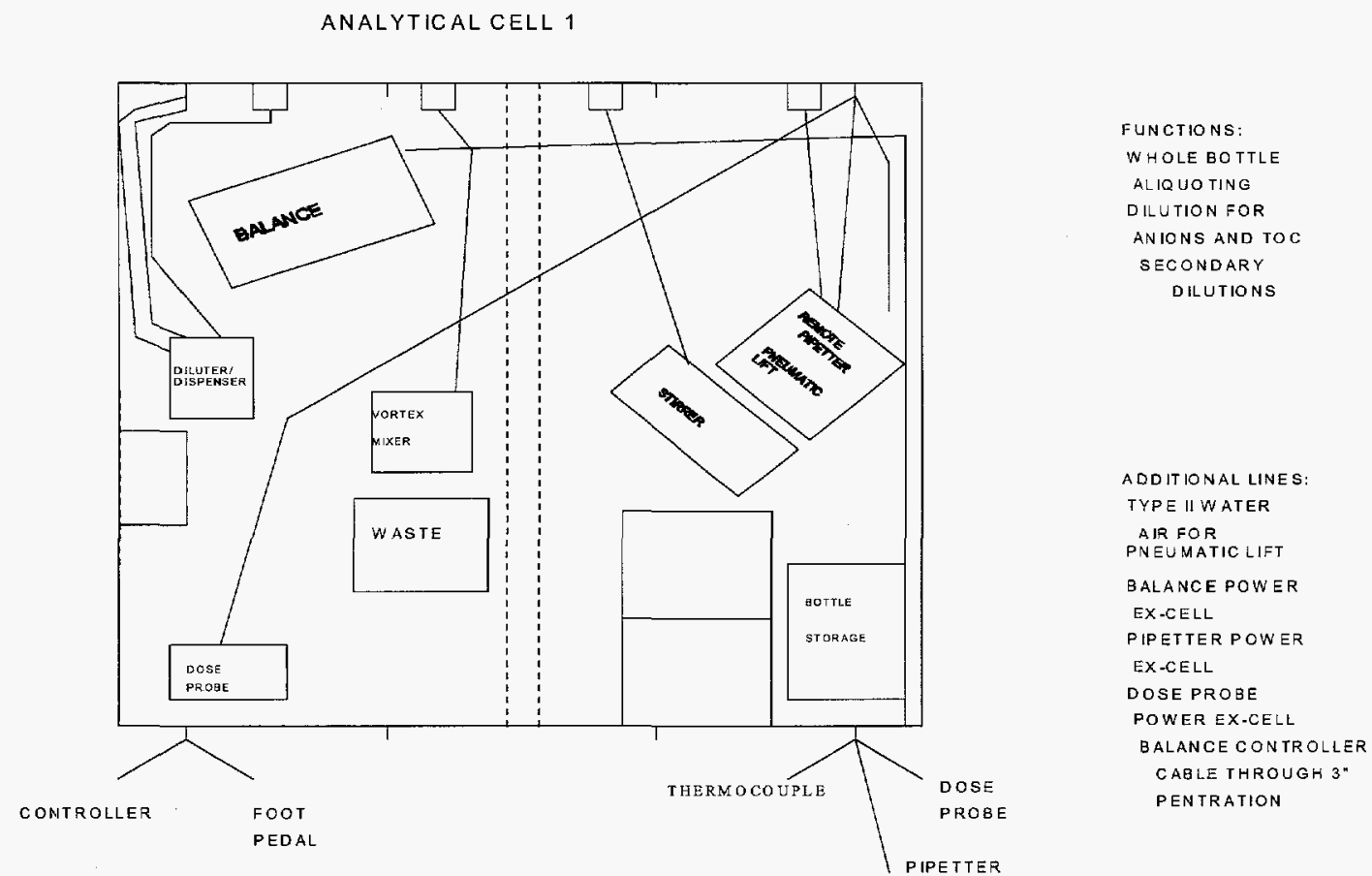

Figure 4. Analytical Cell 1 (AC1) 
ANALYTICAL CELL 2

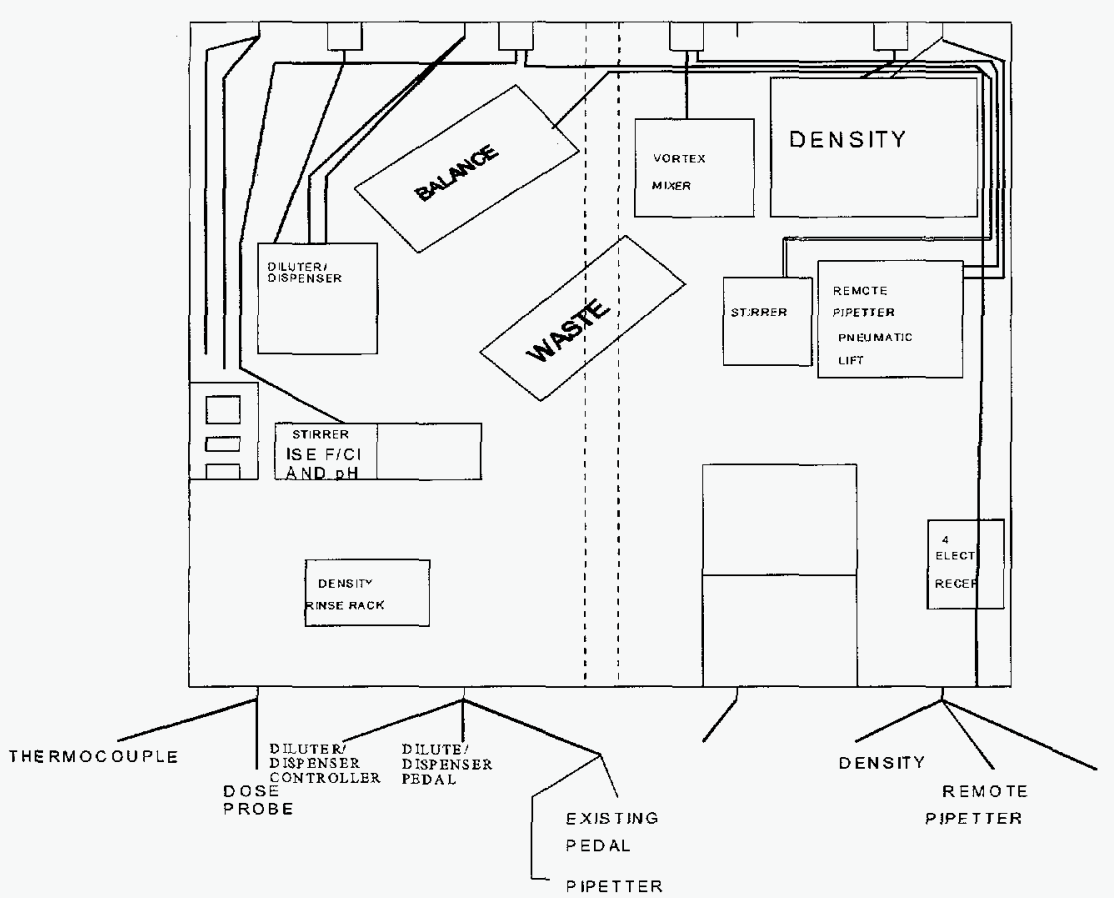

FUNCTIONS:

$\mathrm{PH}$

OENSITY

ISE FLURIOE (F)

ISE CHLORIDE (CI)

ALIQUOTING

ADOITIONAL LINES:

PHITITRATION POWER

EX-CELL

TYPE ॥ WATER

DONSTHY CELL COOLING LINES - 2

ELL POWER

SE CICABLE
SE F CABLE

POWER CABLE FOR 4 IN-CELL RECEPTACLE

QALANCE CONTROLLER THROUGH

Figure 5. Analytical Cell 2(AC2)

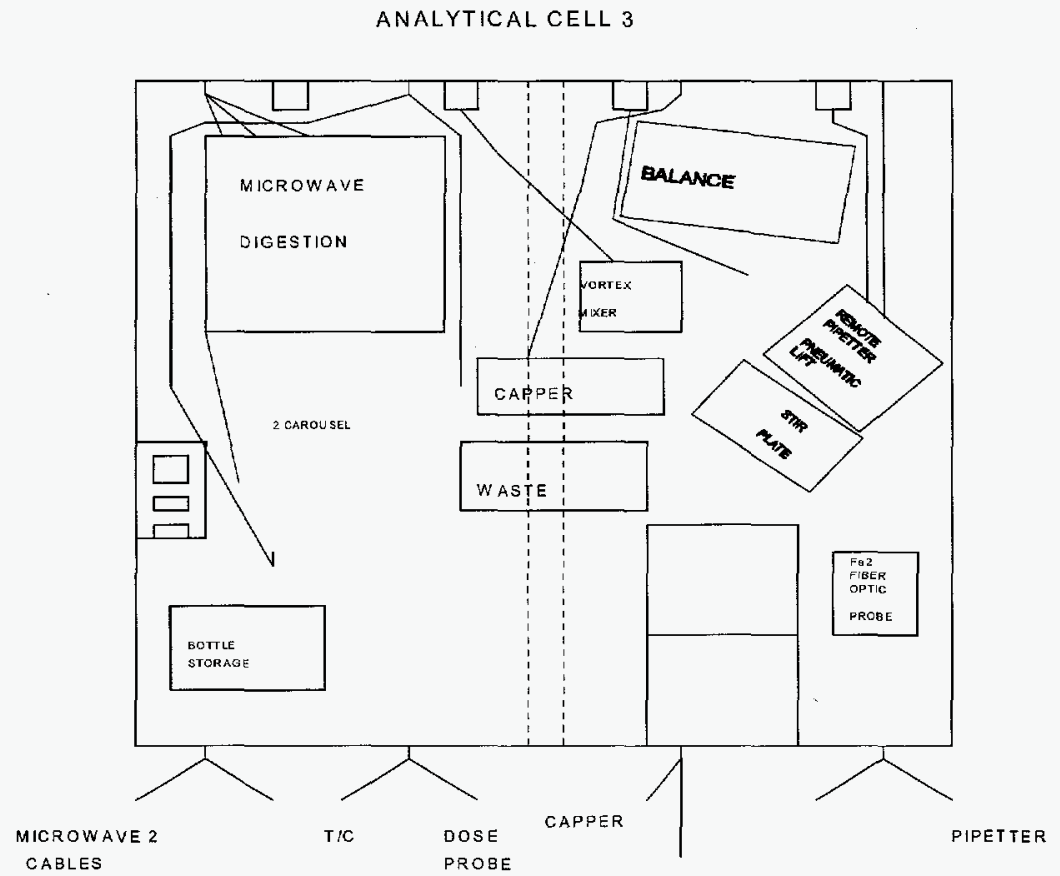

Figure 6. Analytical Cell 3 (AC3) 
ANALYTICAL CELL 4

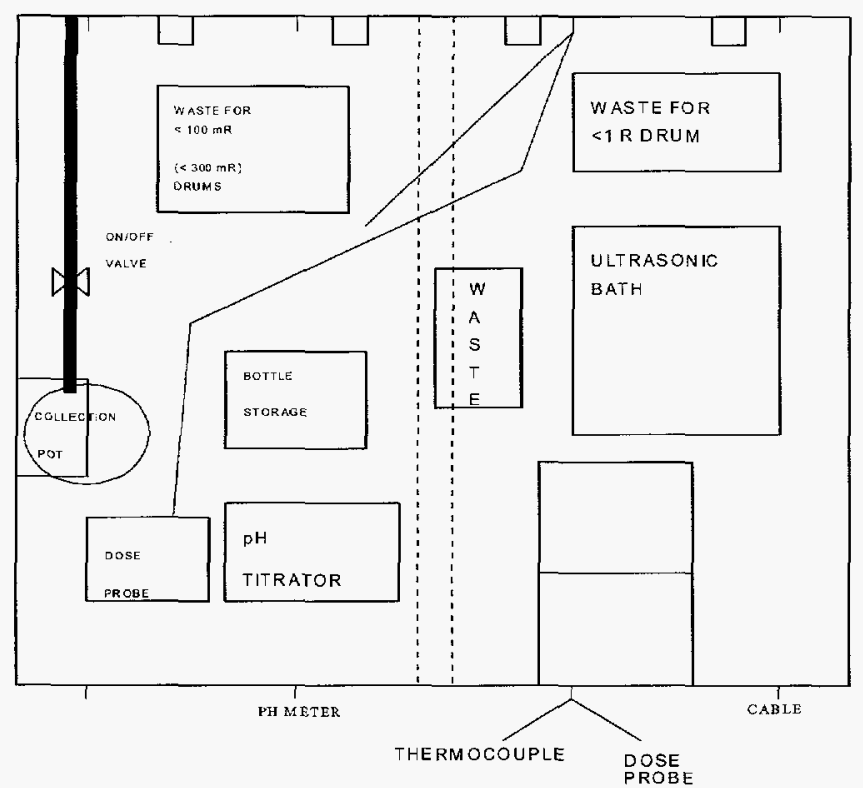

FUNCTIONS:

SEPARATION OF

WASTE $<100 \mathrm{mR}$

FROM $>100 \mathrm{mR}$

RINSING SLURRY

BOTTLES

- COLLECTION OF

WASTE FROM CELLS $1-5$

AND SSC

- ULTRASONIC BATH

FOR CLEANUP

ASSURING DOSE

LIMITS BY PROBE

ITEMS $>100 \mathrm{mR}$ GO

TO $<1$ R BIN

- COLLECTION OF

WASTES TO POT

- NEU TRALIZATION OF

WASTE STREAMS

FROM ANALY TICAL

CHEMISTRY METHODS

PH

-MOLARITY

ADDITIONAL LINES:

PH SENSOR CABLE

TITRATION CABLE

PH/TITRATION POWER

EX-CELL

Figure 7. Analytical Cell 4 (AC4)

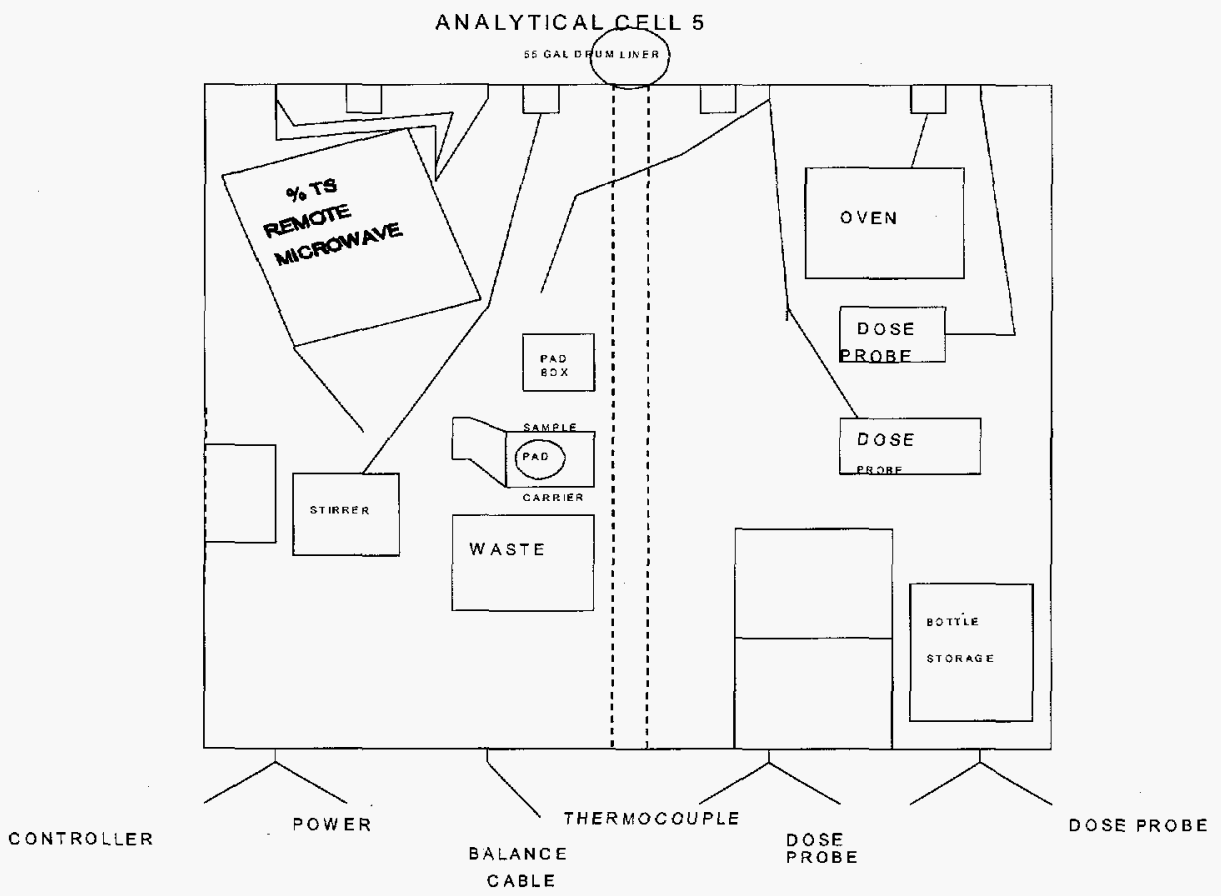

FUNCTIONS:

DRYING OVEN FOR

SLURRY

\% TOTALSOLIDS

DISPOSAL OF $<100$

MR WASTE TO 55

GAL ORUM LINER

TRANSFERRING

SAMPLES EX-CELL

ADDITIONALLINES:

DOSEPROBE

POWER EX-CELL

MICROW AVE POWER

EX-CELL.

Figure 8. Analytical Cell 5 (AC5) 
DEFINE STATUS OF HLW

SAMPLING IN $9 / 95$ PERIOD

BYSGN OR CASKET BETWEEN
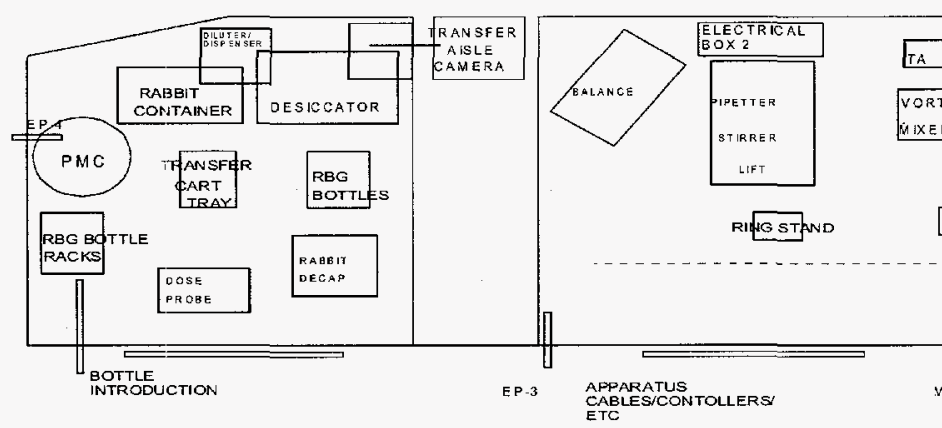

ADOITIONAL LINES:

BALANGE

PIPETTER

STIRRER

PNEUMATIC LIFT -AIR \& AIR ACTUATOR POWER

DISPENSER/PEDAL POWER CONTROLLER

FURNACES $\{2\}$-EA FAN AND POWER \& 2 T/C

DRYING OVEN POWER \& T/C

TYPE II W ATER, K 2C204

DOSE PROBE CABLE \& POWER EX-CELL

CELL THERMOCOUPLE DESICCATOR \& CAMERA \& GRINDER

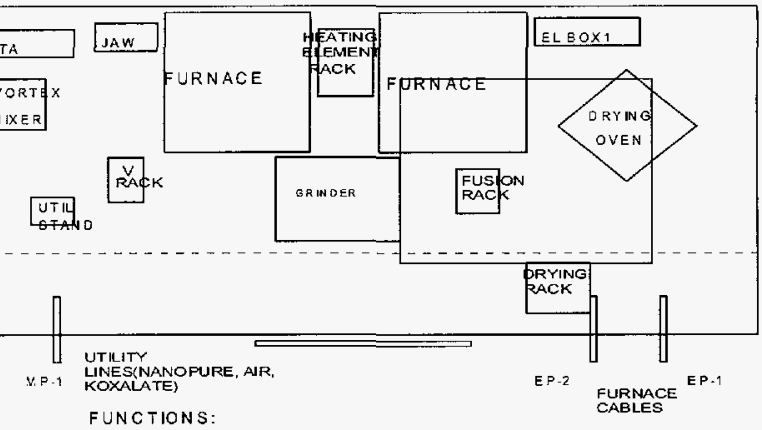

FUNCTIONS:

WHOLE BOTTLE ALIQUOTING AND DRYING

GRINDING

CALCINING WHOLE BOTTLE

FUSION TI/SO4/FO4

VITRIFYING-WHOLE BOTTLEIRRON RATIO

SAMPLE DRYING 105-150 C

\% TOTAL SOLIOS

DOSE RATE MEASUREMENTS

Figure 9. Sample Storage Cell (SSC) 


\subsection{ANALYTICAL CELL MOCKUP UNITS AT THE VITRIFICATION TEST FACILITY}

In the fall of 1993, construction of the Vitrification Test Facility (VTF) was completed. The VTF houses mockups of several operations necessary to support the HLW vitrification process, including two analytical cell mockup units (ACMUs). The need for ACMUs had been established in the fall of 1991. The ACMUs were designed to duplicate the interior dimensions, power outlets, lighting requirements, and pan and opening requirements of ACs 1-5. Personnel entry was possible from the back of the ACMUs to mimic entry to the hot cells through the Analytical Decontamination Aisle (ADA).

The exterior dimensions, conduits, 3" chamber penetrations, shelves, RMs, operator height proportions, and window dimensions also duplicated those in the hot cells. Due to the corrosive nature of the zinc bromide solution used for the hot cell shield windows, three-feet-thick, oil-filled windows were installed in the ACMUs. The ACMUs were interconnected via a 6"ID manifold vent to a common exhaust fan. Each ACMU had an effective volume of $216 \mathrm{ft}^{3}$ and was exhausted at $150 \mathrm{cfm}$.

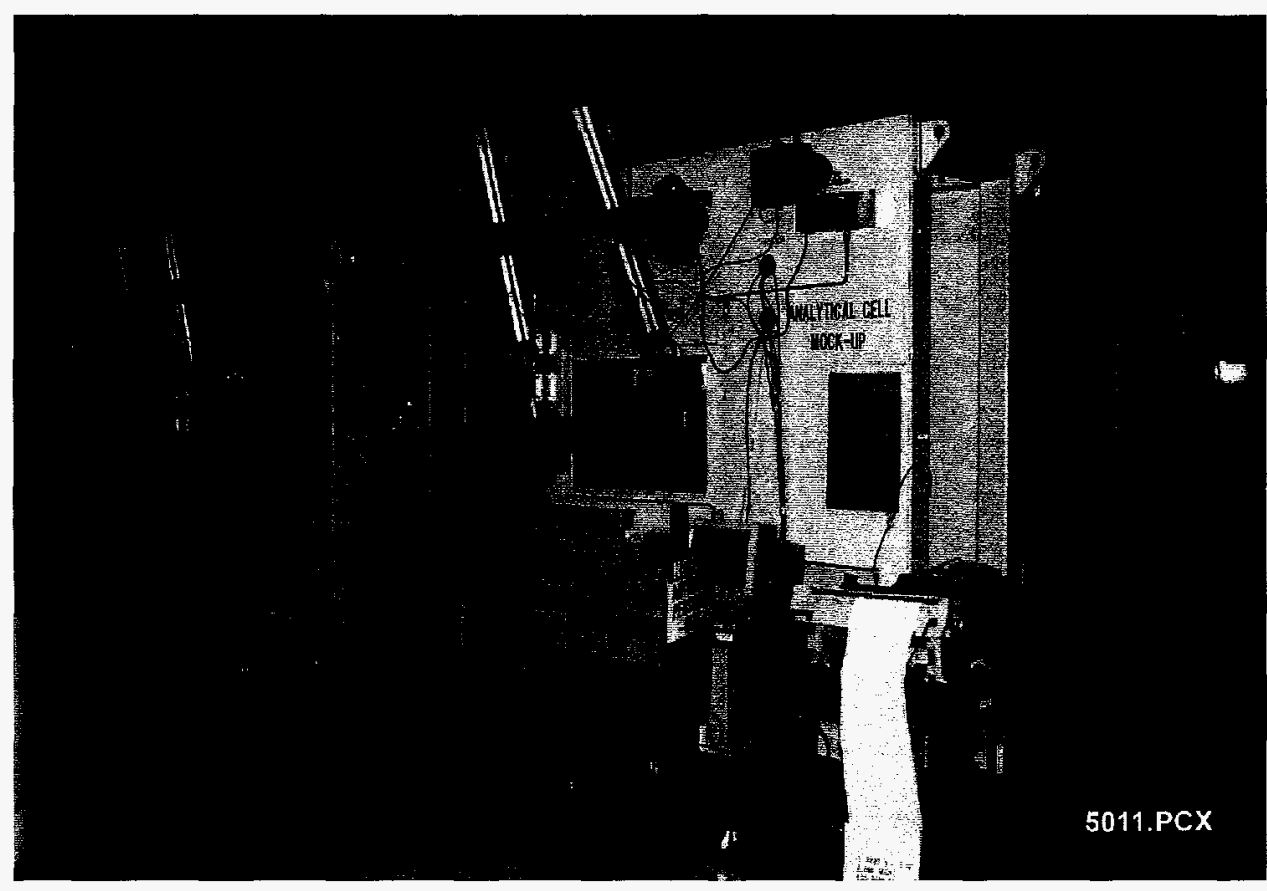

Figure 10. Analytical Cell Mockup Units (ACMUs)

The exhaust flow rate was $300 \mathrm{cfm}$ to the outside atmosphere at a height of 37 feet. Scrubbers, filters, or collectors were not required. The design of the ACMUs allowed ready circulation of ambient air around the pans through numerous small openings (see figure 10).

A wide variety of remote analytical techniques were initially developed and further refined at the ACMUs. In order to successfully perform remote operations using RMs, conventional "off the shelf" equipment must be modified. Power and controller connections may need to be provided from outside the cell. In many cases this necessitates electrical modifications to the equipment, such as replacing hardwired electrical cords with 30-foot extension cables with remotely removable connectors. Modified equipment was initially tested in the ACMUs and sometimes further modifications were recommended after preliminary evaluation. When the equipment, tools, and remote handling techniques were refined to A\&PC's satisfaction, the next step was to set up the equipment in the decontaminated analytical cells.

\subsection{Regulatory Considerations}

A\&PC's purposes at the ACMUs included the use of chemicals for remote method development. Permission to use chemicals in the ACMUs required an Environmental Checklist application for possible exhaust of chemicals through the blower. A state air permit was also required in order to use the ACMUs for analysis of nonradioac- 
tive samples with chemical reagents. Generous requirements for the monthly analysis of samples ( 1200 for inorganics and 100 for organics [which were never used]) were specified so that there would not be any question at a later date whether or not various experiments would be permitted. In spite of the high estimates, the calculated exhaust quantities were negligible. While permits were being granted to work with chemicals in the ACMUs, testing of remote procedures and apparatus proceeded using water.

\subsection{A\&PC A.ccessories at the ACMUs}

A 30" self-contained hood with absorbent filters was employed in the VTF for the transfer of small volumes of reagents (up to 1-L bottles) to smaller secondary containers. Reagents were used for sample dissolutions by digestion and fusion, for development of $\mathrm{pH}$ and ion selective electrode (ISE) methods for chloride and fluoride analyses, and for development of remote iron ratio analysis techniques. Evaluation and testing of the hood exhaust by Industrial Health \& Safety (IH\&S) during typical chemical manipulations verified that monitoring requirements were met. Use of the hood eliminated many transfers of reagents from other laboratories by personnel on foot, improved safety conditions (the VTF is approximately a quarter of a mile from the Main Plant), and sped up the method development process.

The A\&PC area of the VTF also contained chemical storage cabinets designated for acids, bases, and flammables. For several months during method validation in 1995, two shifts of technician coverage were provided.

\subsection{Modifications to the ACMUs}

The ACMUs have proven useful in performing mockup activities for new equipment use and for simulating manned entries into the analytical cells. Some of the mockup activities required modifications to the original design of the ACMUs. The mockup activities included remote stud welding that was necessary for refurbishment of the SSC. Transfer cart rails were installed into one of the ACMUs where previously there had been only a chute. This facilitated development of a remote means for replacing the intercell transfer cart on its rails if the transfer cart should derail. Candidate tools and techniques for removal of debris from the transfer cart rails were developed. New hinged workpans were placed in the ACMUs to determine how well they increased access to the transfer cart and new lighter covers were placed on the openings to the transfer cart. The cell entries that were required to install the new workpans and covers were rehearsed at the ACMUs, as was the removal of the defunct remote microwave oven from AC3.

\subsection{Staging of Equipment}

The remote equipment and associated components, including power cords and controllers, were set up in the staging area in the Main Plant Control Room prior to installation in the hot cells. The purpose of the staging area was to confirm that the proposed equipment arrangement was optimally configured, and to power up and confirm operation of all equipment and components prior to placement in the cells. The staging area was proportioned to duplicate the five ACs and the SSC using tape on the floor to delineate each cell. The positions of shield windows, cell entry doors, and penetrations were included.

In the staging area it became apparent that in some cases, a more efficient configuration was needed, therefore the equipment was rearranged. After the exact configurations of the eight in-cell work areas ( $5 \mathrm{ACs}$, three areas within the SSC) were confirmed, the in-cell components were connected to ex-cell controllers and energized to prove correct operation. Any components that failed were repaired or replaced immediately.

Once correct operation was confirmed, the components were disassembled and staged for installation in-cell. 


\subsection{DEVELOPMENT OF REMOTE ANALYTICAL METHODS, APPARATUS, AND CELL TOOLS}

Many of the procedures needed for sample preparation and analysis to support vitrification were well-established laboratory benchtop methods used during FACTS testing. Most of the remote preparation and analysis methods are chemically similar to previously existing benchtop methods, with the exceptions of fluoride and chloride analysis using ISEs, which were initiated at the ACMUs.

Modifications in equipment, apparatus, and technique were needed to adapt the methods for remote analysis. In some instances alternate reagents were substituted to make the transition from the laboratory benchtop to the analytical cells more effective and user-friendly. Additional training and fine-tuning were needed after the apparatus was set up in the radioactive cells.

The most important aspects of remote technique development and apparatus selection are durability, simplicity and ease of use, ability to decontaminate, reproducibility, and ease of disposal. Many of the in-cell tools for analysis were developed during ACMU method development work, and many are refinements of the original tools. Engineering drawings for all tools are on file for future manufacture.

\subsection{Sample Characteristics}

The liquid samples requiring analysis by A\&PC for support of HLW vitrification consist of approximately $30-50 \%$ solids, including settleable zeolite particles. The sample types present a challenge for removal of homogeneous aliquots. Remote aliquoting, sample preparation, and analysis techniques were developed at the ACMUs for the WI and feed slurry using simulants provided by the Vitrification Process Engineering Department. As a "worst case," a simulant representing the SF was used in development work for analyses TR which were eventually defined for the WGF. All analytical techniques were developed and validated using WI and SF simulants.

Radioactive glass is another important sample type requiring preparation for analysis in the analytical cells. It needs to be ground remotely and a representative sample accurately weighed and dissolved. The buoyancy of the ground glass presents unique challenges in remote handling.

\subsection{Remote Aliquoting}

The ability to remove a small representative aliquot of slurry from a RBG bottle is of central importance to A\&PC support of the vitrification process. Early method development at the ACMUs was performed using simulants supplied by the Vitrification Process Engineering Department. The slurry was expected to contain approximately $50 \%$ solids, with a significant fraction of large settleable zeolite particles. The dissolution of a small wet slurry aliquot takes much less time than quantitatively drying, solidifying, and grinding the entire contents of each bottle first. The contents of the RBG sample bottle are kept well-mixed by placing a tiny teflon-coated magnetic stirbar inside the RBG bottle. The bottle is then shaken on a vortex mixer for several minutes and placed in a holder on the center of a magnetic stirmotor. The stirmotor is turned to a high setting and the spinning of the stirbar keeps the slurry well mixed.

\subsubsection{Technique and Apparatus Development}

Several slurry aliquoting techniques were investigated at the ACMUs. Of primary concern was the homogeneity of a small (approximately 0.1 to $1.0 \mathrm{~g}$ ) aliquot of slurry removed from a RBG bottle. In the analytical cells, all quantities are weighed using remote analytical balances with ex-cell electronics. Reproducibility studies were 
performed initially by weighing aliquots of water while approval for use of chemicals at the ACMUs was being sought. The ease of remote use of the various equipment was also evaluated. Prototypical single RBG bottle and scintillation vial holders, and the capper/decapper spring were made from $1 / 8$ " stainless steel tubing during evaluation.

Ultimately, experiments were performed where both types of simulant slurry were aliquoted, digested, and analyzed by ICP for the specified elements. Various aliquoting techniques were evaluated by digesting aliquots of simulated slurry, performing elemental analysis by ICP, then statistically analyzing the resultant data. Influential factors included bore size and material composition (surface properties) of the aliquoting device and volume of the aliquot (minimum $100 \mu \mathrm{L}$ ).

Aliquoting of ground glass proved to be more of a challenge in the ACs than was indicated during ACMU testing, mostly due to the "wind" in the hot cells and the stiffness of the RMs. A suspension of ground glass in water is prepared to prevent radioactive contamination in the cells due to airborne glass powder. The suspension also assures that all the glass that is weighed for digestion is inside the vessel, not on the outer threads, which had been a problem when dry aliquots were taken.

Paragraphs $\mathrm{A}, \mathrm{B}$, and $\mathrm{C}$ that follow describe the three major techniques and apparatuses that were tested at the ACMUs for taking small aliquots of liquid slurry.

Paragraph D summarizes small aliquot testing while paragraph E summarizes whole bottle aliquoting and, finally, paragraph $\mathrm{F}$ describes glass aliquoting.

\section{A. Disposable Transfer Pipets}

The obvious first choice for aliquoting is the disposable (eye dropper) transfer pipet. The $1.5 \mathrm{~mL}$ capacity pipet has a very narrow tube which becomes clogged with the zeolite particles in the simulant, even when the tapered end of the tip has been cut off. A large capacity $(3.0 \mathrm{~mL})$ pipet was tried, but elemental analysis of digested aliquots taken this way indicated inhomogeneity. The ability to draw up only the amount needed and expel the entire aliquot is essential to obtaining a homogeneous aliquot of HLW slurries. The transfer pipet is likely to allow settling of zeolite particles in the pipet and expulsion of a nonhomogeneous aliquot. It is also difficult to obtain uniformity of aliquot volume or weight using this type of pipet. Aliquots would most likely be large enough to require extensive dilution prior to analysis, adding to the TAT. Disposal would require either rinsing each pipet by drawing and expelling water, or by cutting each one for cleanup in the ultrasonic bath.

\section{B. Diluter/Dispenser}

The diluter/dispenser can be used to aspirate a predetermined volume of slurry through a piece of tubing, similar to using a small straw, and then expel the aliquot into the desired container. Teflon tubing was tried initially in anticipation of its ability to totally expel all the aliquot due to teflon's non-stick properties.

However, the necessity for rinsing between aliquots immediately became apparent because residue remained in the tubing.

The end of the tube was placed in the slurry and the desired volume was aspirated. The aliquot was dispensed into the previously weighed receiving container and the aliquot weight was recorded to the nearest $0.1 \mathrm{mg}$. Water was then aspirated into the sample tubing and expelled into a waste collection vessel. Eight $\mathrm{M}$ nitric acid was next aspirated/expelled, and several water rinses were performed. The tubing was finally ready for another aliquot. After several uses, the end of the tubing could be cut off and disposed, leaving a fresh piece of tubing 
for aliquoting. This technique was very time-consuming and homogeneity studies showed that it was not quite as reproducible as the remote pipetter (see figure 11).

\section{Remote Pipetter}

A commercial pipetter was modified for remote use in the ACMUs. The plunger/barrel (liquid end) unit was separated from the programming and control unit and was connected with a 30 -foot cable with removable connectors at each end. This is the typical modification required for equipment to be used in the hot cells for preservation of integrated circuits, which can be damaged by radiation. The pipetter is programmable by volume and uses disposable tips. An updated version of the remote Rainin pipetter is currently in use in the analytical cells (see figures 12 and 13).

Various volume delivery ranges are available on the pipetter. The $1000 \mu \mathrm{L}$ liquid end has been chosen because it allows removal of 100 to $1000 \mu \mathrm{L}$ aliquots. The same pipetter may be used to take aliquots for digestions, fusions, and fluorides $(100 \mu \mathrm{L})$; for chlorides and total solids $(500 \mu \mathrm{L})$; for Total Organic Carbon (TOC) and Ion Chromatography (IC) in-cell dilutions (100 to $1000 \mu \mathrm{L})$; and for other miscellaneous applications.

A $250 \mu \mathrm{L}$ liquid end was used in development work. One advantage to the $250 \mu \mathrm{L}$ liquid end is the availability of "wide bore" disposable tips, which is not the case for the $1000 \mu \mathrm{L}$ liquid end. The larger opening is necessary in case large particles are present in the slurry.

The disposable pipet tips ( $1000 \mu \mathrm{L}$ size $)$ are cut to increase the size of the orifice, so that if extremely large particles are present in

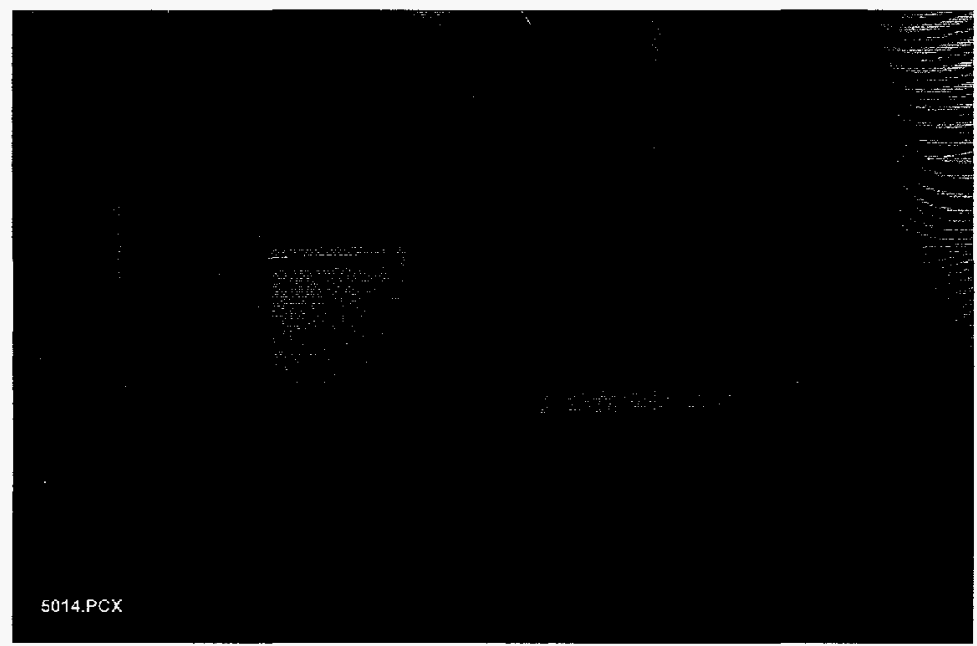

Figure 13. Remote Aliquoting Apparatus in Analytical Cell (Remote Balance, Pneumatic Lift with Counterweight and Rod, Remote Pipetter, Sliding Base, and Center Positioning Plate)

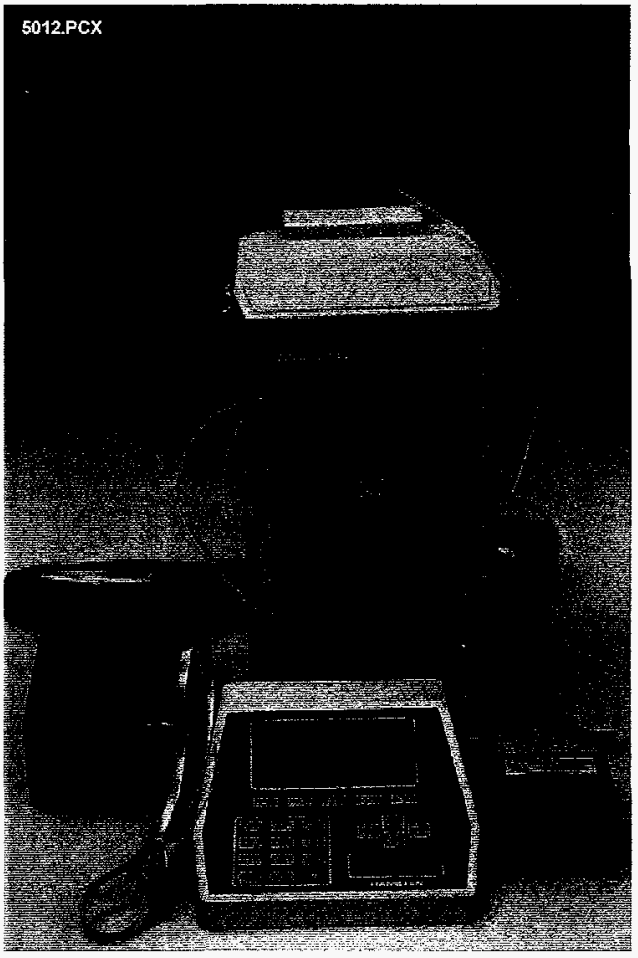

Figure 11. Remote Diluter/Dispenser

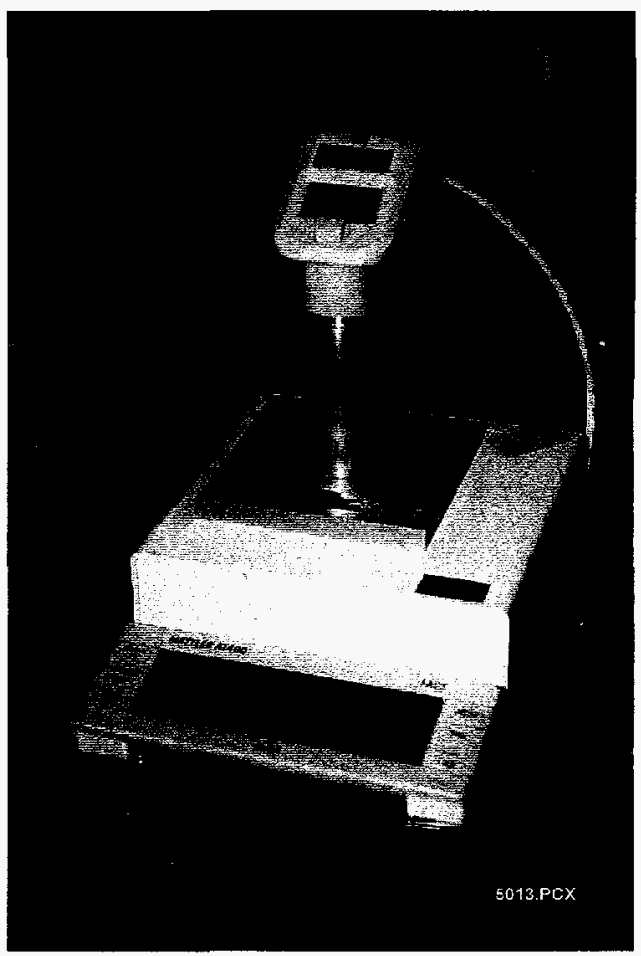

Figure 12. Remote Controller with Remote Balance Controller 
the slurry they may be included in the aliquot without plugging the tip. About $1 / 4$ " is cut off from the tip at about a 30 angle. A modified wire cutter was invented for this purpose, with a guide to hold the tip in place for uniform length and angle. Cuts may also be made using a sharp pair of scissors or a razor blade.

For remote use, disposable tips must be defined. Particular brand tips do not hold a good seal on the remote pipetter when applied using the RMs, do not have an easy grip for the RM, and are slightly curved. The curve makes it difficult to position the pipetter over the sample bottle in a consistent manner using the remote aliquoting equipment. The defined tips seal very well to the remote pipetter when applied using the RMs, perhaps because of the rather thick, ridged collar on the tips. The tips are also perfectly straight and, therefore, easily positioned above the sample bottle. The tips are made of a high-density polyethylene from which the slurry is easily expelled and they are easily decontaminated for disposal.

\section{Small Aliquots}

It has been found that the best aliquot size for slurry digestions and fusions (preparations for elemental analysis by ICP) is $100 \mu \mathrm{L}$, which weighs anywhere from 0.075 to $0.200 \mathrm{~g}$, although the usual weight is approximately 0.12 to $0.15 \mathrm{~g}$. The dissolved aliquot is then diluted to a total weight of approximately $100 \mathrm{~g}$, resulting in primary dilution factors of 600 to 1000 , which has been found to be optimal. Concentration is maximized for ICP analysis, while radioactive dose level is minimized for removal from the cells; both are usually within working ranges. WI samples sometimes require a 150 to $200 \mu \mathrm{L}$ aliquot to reach ICP minimum quantifiable limits for certain elements; the minimum volume for homogeneity is $100 \mu \mathrm{L}$. Secondary dilutions may be performed as needed, either in the analytical cells or in the laboratory, depending on the radioactive dose.

Fluoride analysis also uses a $100 \mu \mathrm{L}$ aliquot. This is the maximum allowable volume due to high concentrations of interferents in the slurry and the minimum aliquot volume for homogeneity.

For chloride analysis, a $500 \mu \mathrm{L}$ aliquot has been found to be optimal. It is large enough to provide detection and small enough to minimize interferences. Larger or smaller aliquots may be used if needed.

Aliquots from 100 to $1000 \mu \mathrm{L}$ may be used for IC/TOC dilutions and total solids analysis, depending on radioactive dose rates and analytical detection.

\section{E. Whole Bottle Aliquoting}

Whole bottle aliquoting (i.e., the aliquot consists of the entire contents of a RBG bottle) was developed as a backup technique. It is meant to be used in the event that the waste and feed slurries cannot be handled using in small homogeneous liquid aliquots because of extremely large particles. It is an extremely time-consuming process.

This technique involves weighing the RBG bottle containing the sample, pouring the contents into a preweighed container, rinsing the RBG bottle into the container using water, drying the clean (empty) RBG bottle and cap and weighing them. The weight of the slurry taken from the RBG bottle is determined by the difference in weight of the full minus the empty RBG bottle.

The collected slurry is then dried in an oven and either calcined $\left(500^{\circ} \mathrm{C}\right)$ or vitrified $\left(1150^{\circ} \mathrm{C}\right)$ in a furnace, ground, and aliquoted for digestion and/or fusion for elemental analysis. Taking aliquots of glass as an aqueous suspension is also quite time-consuming. Also see section 4.10, Vitrification. 


\section{F. Glass}

Glass presents some special aliquoting problems. It is generally either received as small shards in RBG bottles or vitrified in-cell as discussed in section 4.10 . The glass is ground using a commercial mixer/mill with tungsten carbide grinding vial sets. After grinding, the glass is collected in a plastic bottle using a plastic funnel with a stainless steel screen set in its mouth. The screen collects the grinding ball while allowing the finely ground glass to pass through. See section 4.10 for more information.

Aliquoting dry, ground glass has proven to be difficult in the analytical cells. Often the elemental analyses did not add up to the mass of glass that was analyzed. Individual aliquot results showed the correct relative proportions of elements; this hinted at weighing difficulties. It is presumed that glass powder was dropped on the threads of the digestion vessel where it was weighed or static charge caused some type of holdup; in either way the material was never either digested or analyzed. The most successful technique for dry aliquoting was removal of glass from a scintillation vial in a tilted holder, using a small spatula or "shovel" and great care.

The technique that has proven to be preferable involves making an aqueous suspension of the ground glass. Approximately 1 to $2 \mathrm{~g}$ of ground glass is added to approximately $5 \mathrm{~mL}$ of water in a vial and a teflon-coated magnetic stirbar is added. The digestion vessel is predried and weighed to constant weight $( \pm 0.0005 \mathrm{~g})$, which is recorded. The suspension is stirred and aliquots are taken using the remote pipetter. An aliquot of the glass/ water suspension is added to the vessel, which is placed in a drying oven for about one hour. The vessel is removed from the oven, allowed to cool, and weighed. It is heated/cooled again until constant weight $( \pm 0.0005$ $\mathrm{g}$ ) is achieved. The weight of the empty vessel is subtracted and the result is the weight of glass. The glass is then digested as usual. This technique results in excellent elemental recovery of the amount of glass digested.

\subsubsection{Remote Aliquoting Apparatus and Tools}

The aliquoting apparatus consists of a remote pipetter mounted to a rod on a pneumatic lift using a WVNS rectangular clamp. The lift is either a commercial pneumatic lift (CPL) or a WVNS custom model. Beneath the pipetter is a sliding base with a brake, upon which is a magnetic stirmotor equipped with a center positioning plate for the single RBG bottle holder. The sample is placed in the holder, the stirmotor is slidunderneath the pipetter, and the lift is lowered. The aliquot is taken, the lift is raised, and the stirmotor is slid away. The receiving container is held beneath the pipetter and the aliquot is dispensed into it.

\section{A. Remote Pipetter}

The pipetter is made remote by separating the electronic control pad and components from the plunger and barrel. A commercial slide and lock connector at the top of the in-cell portion (plunger and barrel) attaches to a 30-foot extension cable. (These connectors were thought to be ideal for use on remote equipment because they slide on and "lock." The drawback is their lack of durability at the soldered internal wire-to-pin connection.) The ex-cell end of the cable attaches to the controller, which has been mounted upon an aluminum stand for stability and for ease of use.

\section{B. Commercial Pneumatic Lift with Counterweight and Rod}

At the ACMUs, two CPLs were used. The magnetic stirmotor was placed on the lower lift and the pipetter was clamped to a ring stand on the upper lift. The weight of the ring stand base served as a counterbalance to the weight of the pipetter hanging over the edge of the lift. Each CPL allows a 3" vertical range. Therefore, two 
lifts allowed a $6 "$ range. This was useful because it allowed the digestion vessel to fit into the space between the pipette tip and the sample bottle for transfer of the aliquot.

Unfortunately, it was determined that the "footprint" of two CPLs was too large for the Analytical Cell. For this reason the WVNS pneumatic lift was created and placed in the SSC. Difficulty of manufacture and the expense drove the development of the sliding base for use with one CPL per cell.

ACS 1-5 use the single CPL with counterweight and rod for aliquoting. A stainless steel rod is welded to the platform of the CPL and a counterweight is placed on top to balance the weight of the overhanging pipetter. The remote pipetter is then clamped to the rod as described later (see figure 14).

\section{Pneumatic Lift}

A heavier duty custom pneumatic lift was designed and manufactured for use in the SSC. It was custom made for WVNS, must be installed or removed from the SSC via the hatch, and is functionally equivalent to the CPL with sliding base because it has a 6 " vertical range instead of the CPL 3" range (see figure 15). A spare lift of this type is on hand in case of failure.

\section{Rectangular Clamp}

To hold the remote pipetter in place on the rod, a common laboratory 3-finger clamp was originally used. However, this clamp was easily twisted, afforded no support to the top of the pipetter, and was difficult to readjust. A rectangular clamp was invented and fabricated at WVNS with supporting strips for the top of the pipetter. This new clamp holds the remote pipetter securely.

\section{E. Sliding Base}

For ACs 1-3, a sliding base (WVNS design) was placed underneath the pipetter, with the magnetic stirmotor centered on its platform. The base is positioned so that one end of its sliding range places the sample bottle directly beneath the pipetter.

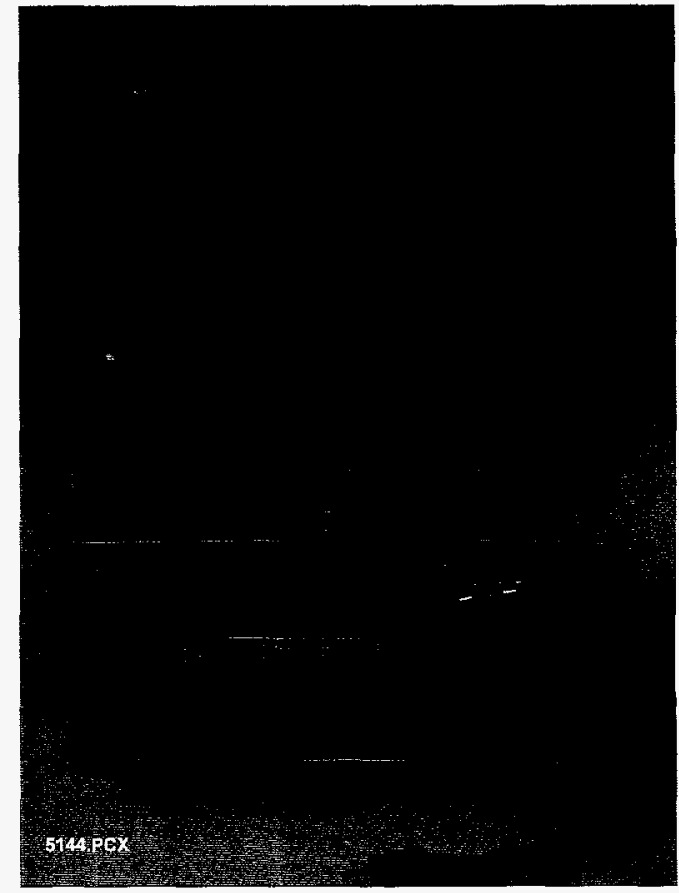

Figure 14. Commercial Pneumatic Lift (CPL) with Counterweight and Rod

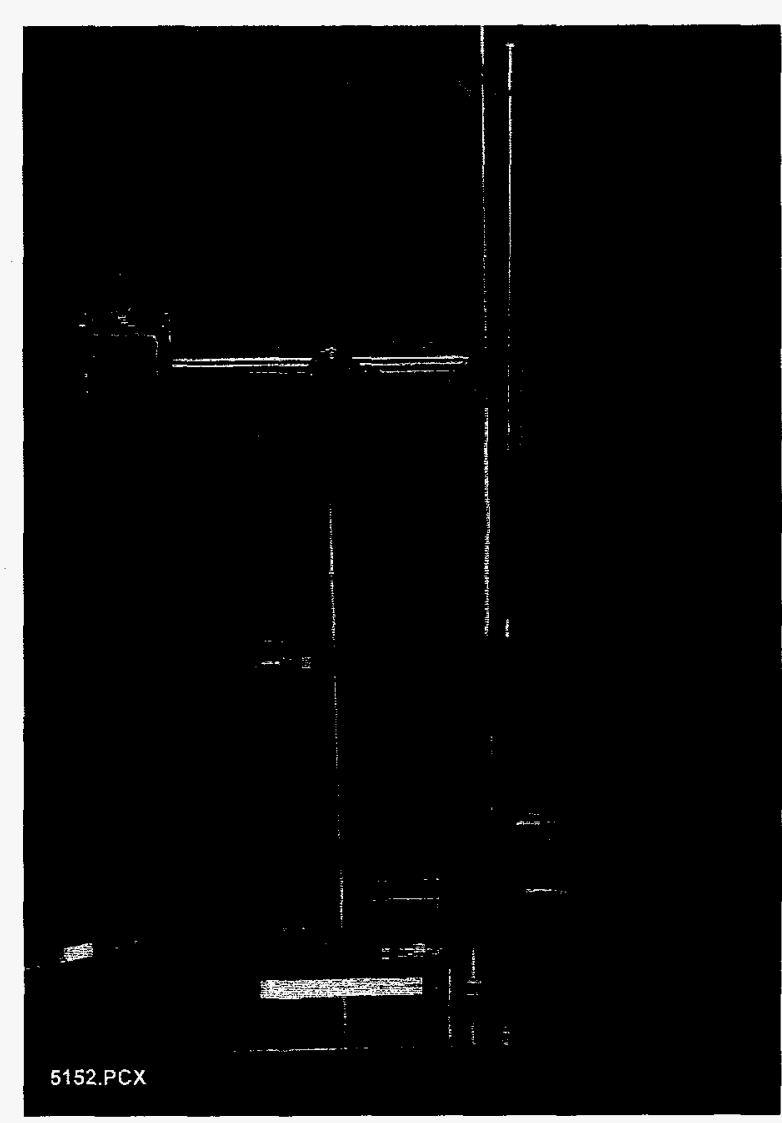

Figure 15. Pneumatic Lift 
The sliding base incorporates a radial load linear motion rail and guide to provide smooth positioning. A platform made to fit the stirmotor is mounted on the rail so that the stirmotor may be moved from one end of the rail to the other. A large steel base underneath the rail provides overall stability (see figure 16). This invention allows the use of one CPL lift for aliquoting instead of a more expensive WVNS pneumatic lift or two CPLs.

\section{F. Stirrer Center Positioning Plate}

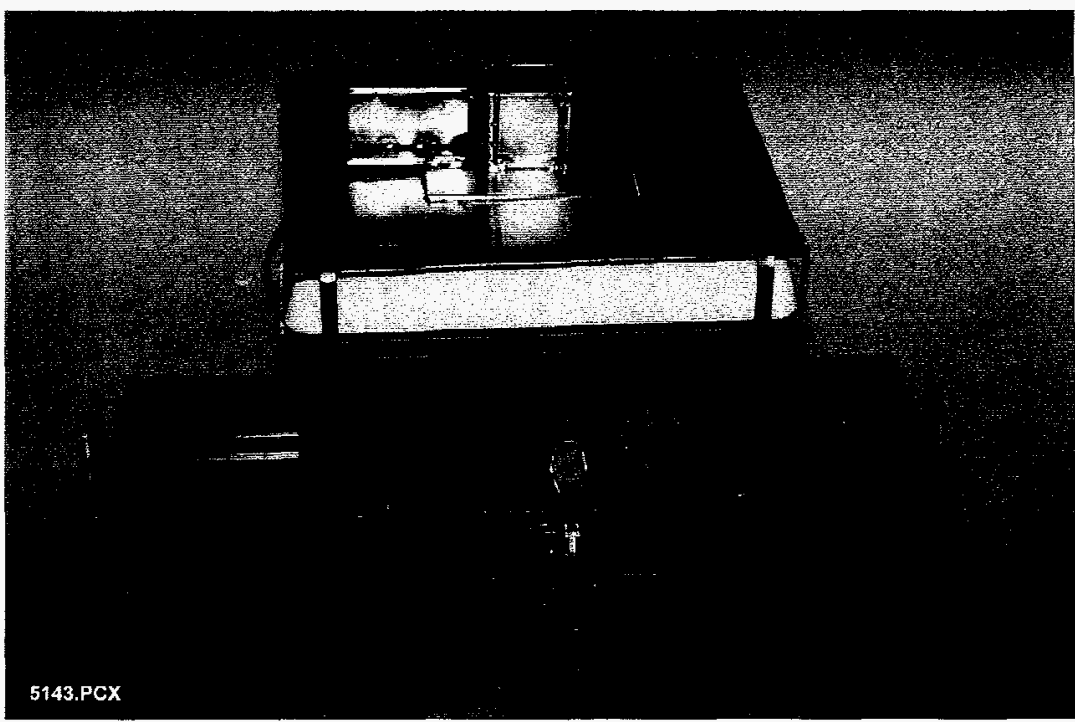

Figure 16. Sliding Base with Magnetic Stirmotor, Center Positioner, and Single RBG Bottle Holder

The same model magnetic stirmotor is used in each of the analytical cells, which allowed development of uniform accessories for the stirmotor. A thin metal plate was made to fit over the top of the stirmotor with a square hole cutout directly above the magnet's center of rotation. The hole is the same size as the base of the single RBG bottle and single scintillation vial holders. The positioning plate allows the bottle to be placed in the optimal position for magnetic stirring action every time. The $12 \times 4 \mathrm{~mm}$ stirbar rotates smoothly in the bottom of the RBG bottle as long as the RBG bottle is centered over the magnetic stirmotor, which is essential for reproducible aliquoting (see figure 16).

\section{G. Round Bottomed Glass (RBG) Bottle Holders}

The rounded outer bottom surfaces of RBG bottles makes handling them in the analytical cells rather difficult because they cannot stand by themselves. For this reason, stainless steel holders have been fabricated for various uses (see figures 16 and 17).

The most commonly needed RBG bottle holder is for single bottles only. It has a raised square frame in the

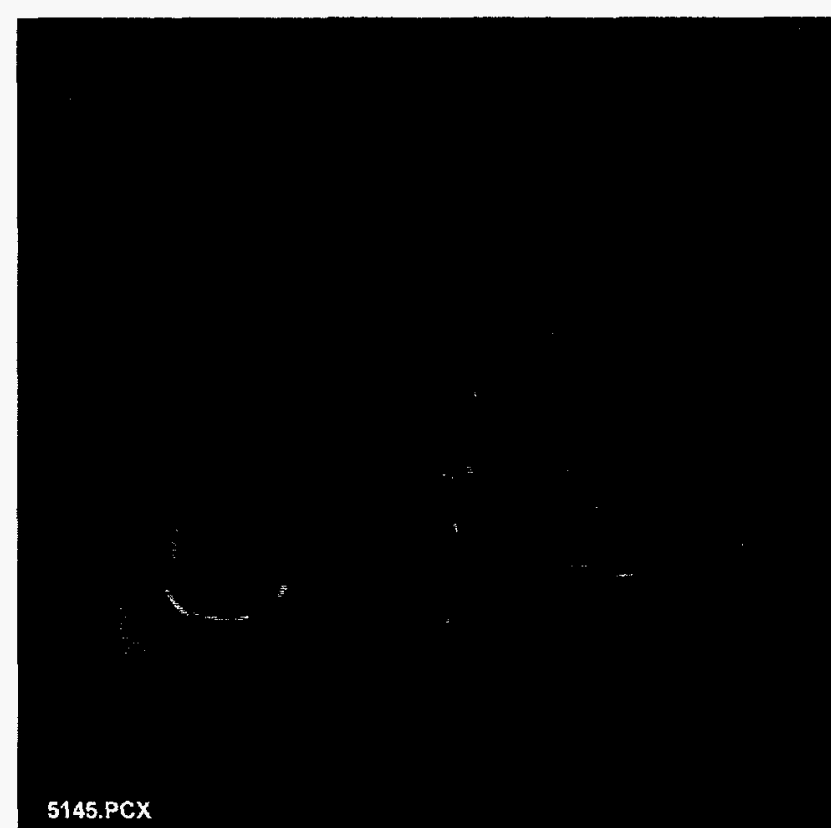

Figure 17. Single Scintillation Vial Holder and RBG Bottle Holders center and a large square base of uniform size. (The base fits into the center of the stirplate positioner.) The single bottle holder is used primarily for aliquoting slurry.

If whole bottle aliquots are to be used, a holder for a single bottle and cap is useful for drying. The full bottle is weighed, the slurry is removed, the bottle is rinsed, and the clean bottle and cap are dried. This holder helps keep the appropriate cap and bottle together for subsequent final weighing. Another holder, which is used in whole bottle aliquoting, holds two bottles and caps for drying. 
A holder for 10 bottles is called a transfer rack and is used to transfer sets of samples from one cell to another via the transfer cart. This transfer rack is light enough to be handled using the light-duty RMs.

A holder for 24 bottles is called a storage rack and is used for storage of samples in the analytical cells. The storage racks are stackable and are too heavy to be routinely moved using the RMs.

\section{H. Scintillation Vial Holders}

An upright holder for a single scintillation vial has been fabricated for use in chloride and fluoride analysis, as well as for dilutions. The prototype was made of $1 / 8^{\prime \prime}$ stainless steel tubing at the ACMUs for use in fluoride analysis. It is similar to the single RBG bottle holder, except that it has a circular raised section to hold the round nominal $20-\mathrm{mL}$ scintillation vial. It has a square base the same size as that of the single RBG bottle holder. The base is used for centering on the magnetic stirmotor. The base gives the vial stability while ion-selective electrodes are being used (see figure 17).

A tilted vial holder has been manufactured to aid in the removal of ground glass from a scintillation vial for in-cell digestion. The holder has been found useful in other procedures as well.

A rack that holds multiple scintillation vials has been developed for use in making cell transfers. Before a diluted sample is removed from the analytical cells, a small quantity of the sample is placed in a clean scintillation vial. The vial's exterior surfaces are cleaned in an ultrasonic bath using this rack. Cleaning the vials helps reduce contamination that could otherwise hamper handling the samples after they are removed from the cells.

\section{Vortex Mixer with Large Sample Head Set}

Before aliquots are taken from RBG sample bottles, $4 \times 12 \mathrm{~mm}$ teflon coated magnetic stirbars are added to the bottles. The contents of the bottles are mixed for at least 15 minutes on the vortex mixer with a large foam sample head set. One of the foam heads as-received holds four RBG bottles snugly. The other foam heads may be modified to fit the RBG bottles. The mixers have flexible bails (arched handles) added for repositioning within the cells.

\subsection{Remote Density Determination}

Density is the mass per unit volume of a substance determined at the temperature of measurement, e.g., $1.38 \mathrm{~g} /$ $\mathrm{mL}$ at $29.7^{\circ} \mathrm{C}$. The density values of slurry samples are needed for HLW qualification and for process control.

\subsubsection{Digital Density Meter}

The densities of aqueous samples with few suspended solids are easily determined using a digital density meter that measures the change in the resonant frequency of a hollow mechanical oscillator cell after being filled with a sample. The volume of the oscillator cell remains constant; any change in resonant frequency is due to a change in the sample density. 
The first approach to remote density measurement of slurry samples was to use the digital density meter. Experiments were performed at the ACMUs using a corrosion resistant density cell for chemical resistance. Waste simulant was easily injected into the cell and density measurements were made. The values were reproducible, but the procedure included numerous water rinses, dilute acid rinses, and more water rinses after each sample was analyzed. Another challenge was the settling of suspended zeolite particles inside the oscillator cell. The zeolite particles sometimes adhered to its inner surface causing difficulty in cleaning the oscillator cell.

Attempts were made to inject feed slurry simulant containing larger particles into the oscillator cell. The inlet line became plugged and was difficult to clean. The conclusion was made that the density meter would not be reliable enough for remote WGF density measurement. It was decided to investigate a gravimetric method.

\subsubsection{Gravimetric Techniques}

A gravimetric density measurement requires a container with a calibrated volume that can be filled with the sample, i.e., a pycnometer or a volumetric pipette or flask. Because of the highly colored and opaque nature of the slurry samples, it is not possible to accurately read a meniscus or volume indication, which rules out the use of a volumetric flask or graduated cylinder.

An aluminum "grease pycnometer" was purchased and tested with simulants. It was extremely awkward to handle with the remote manipulators and proved to be unsuitable for density measurement of the less viscous slurry samples. It was impossible to clean them completely using the remote manipulators due to a surface layer of oxidation that formed rapidly due to the acidic nature of the SF simulant.

A pseudo serendipitous solution to the problem of density measurement was found during development work at the ACMUs. It was noticed that the nominal $20 \mathrm{~mL}$ polyethylene scintillation vials have caps with conical inserts. The insert could be used to push out excess liquid from the vial, allowing the vial to be completely filled with the sample: a pycnometer! The vials are plentiful, inexpensive, and easy to handle with remote manipulators. Density Quality Control (QC) standards and waste and feed slurry simulants were used to develop and validate this technique.

A clean dry vial (with the cap) is labeled and weighed. The vial is filled with water that has reached temperature equilibration with the work area. The cap is placed on the vial and the conical insert forces out the excess water and air. The cap is tightened, resulting in the entire volume of the vial being full of water. The outside surface of the vial is dried thoroughly and the vial is weighed. The density of the water at the known temperature (from a table) and the weight of water are used to calculate the volume of the vial. The vial is emptied and a small volume of the sample is placed inside the vial. The vial is capped and shaken to "rinse" with the sample. The sample is poured out and the vial is filled with a fresh sample. The vial is capped, expelling excess sample and air. The outer surface of the vial is rinsed well with water and air-dried. The sample-filled vial (with the cap) is weighed and the previously determined volume is used to calculate the density.

\subsubsection{Density Rinsing Station}

Unfortunately, gravimetric density measurement of slurry using scintillation vial pycnometers can be a messy technique. In an effort to contain the slurry's chemical and radioactive contamination during this procedure, a device was created called the density rinsing station (see figure 18). It consists of a stainless steel containment vessel, lid, and rack. The lid has a rubber gasket, enabling it to be sealed to the vessel using remote manipulator-friendly clamps. The rack holds a single RBG bottle and a scintillation vial. The rack and the vessel are fitted with remote manipulator grips for easy lifting. 
Density analysis is performed with the rack mounted over the vessel. The RBG bottle of the sample is placed in the square holder in the rack and the calibrated vial is placed in the round holder. Slurry is poured from the RBG bottle into the vial and the vessel catches any spilled slurry. After the vial is filled (2-3 RBG bottles full of the sample per vial) it is capped and rinsed in the rack. The water rinsate is collected in the vessel.

After analysis is completed, the rack is removed and excess water is poured from the vessel through a fine screen in one corner, leaving the thick slurry inside. The lid is clamped on and the vessel is sealed for transport via the transfer cart to the flush pot in AC4. There, the lid is removed and the vessel is rinsed into the flush pot. Once clean, the vial is returned to the cell where density analysis is performed. This keeps the analytical cells clean and keeps slurry from going down the cell drains (see figure 19).

\subsection{Remote Sample Digestion}

Slurry and glass samples are digested using a 1:1 mixture of concentrated hydrofluoric acid and concentrated nitric acid in a sealed (pressure-relief-vented) teflon vessel. The sample is heated, cooled, treated with hydrogen peroxide, and diluted to weight with water. This "pre-boric" digestate is analyzed by ICP for the majority of metals. An aliquot of the diluted digestate is heated with boric acid to decomplex thorium, barium, cerium, and neodymium fluorides. The "post-boric" solution is diluted to weight and analyzed by ICP specifically for the elements listed above. This procedure is chemically identical to the benchtop digestion procedure.

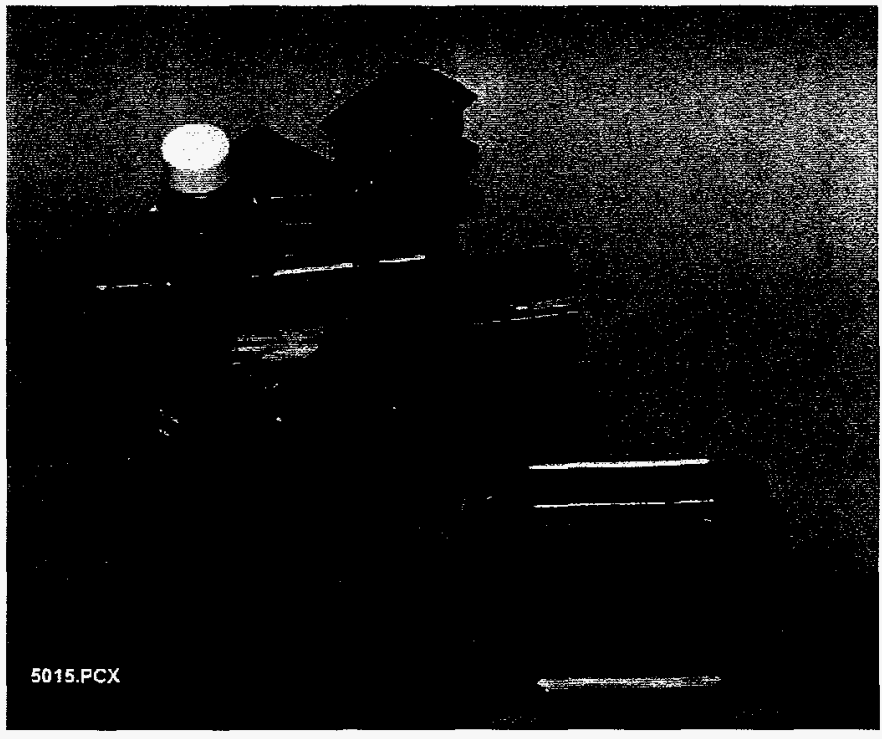

Figure 18. Density Rinsing Station, Open

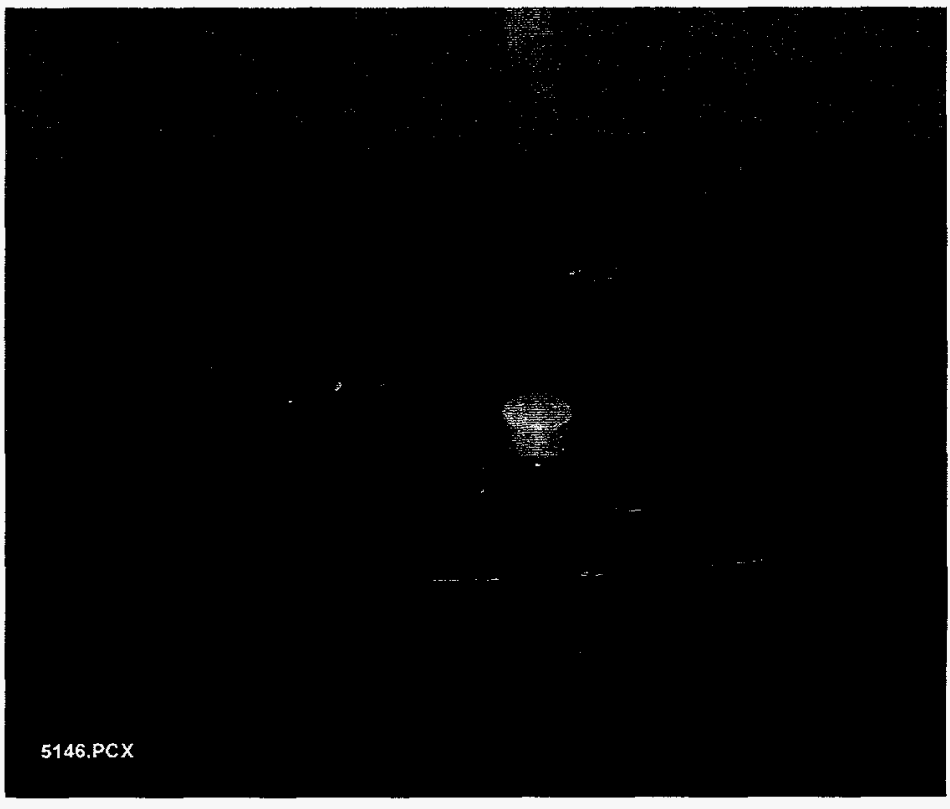

Figure 19. Density Rinsing Station, Closed

\subsubsection{Remote Microwave Ovens}

Sample digestion using concentrated acids and microwave heating in teflon vessels is a well-established technique. Successful dissolutions of simulants had been proven using microwave digestion, without loss of analytes or contamination. The technique is fast and reproducible, making it a natural choice for use in a remote radioactive environment. 


\section{A. Initial Remote Microwave System}

Remote digestion development work at the ACMUs was performed using an initial remote microwave digestion system to heat the samples. The microwave digestion system consisted of a compact in-cell oven with a turntable and separate exhaust blower, 30 -foot electrical cables, and an ex-cell controller. The initial remote microwave system performed very well at the ACMUs. Jnfortunately, when the time came for purchase of equipment for the hot cells, it had become unavailable for purchase, and another remote microwave system manufacturer was sought.

\section{B. Final Remote Microwave Digestion System}

WVNS purchased a remote microwave digestion system (MDS), which is only available by special order. The MDS consisted of a microwave oven unit, a controller, and three 30-foot electrical cables. Benchtop MDS systems were already in place at the Vitrification Cold Lab (VCL), where the nonradioactive GF samples would be digested and diluted for ICP analysis.

The remote system was manufactured with a remotely replaceable magnetron, turntable motor, and numerous other remotely replaceable internal parts. It was much larger than the initial remote MDS unit. The oven unit had been modified with a clear plastic cover, which was light enough to remove using RMs, because the original metal housing was too heavy. RM grips were added to several parts of the instrument to facilitate remote removal and replacement. Pneumatic cylinders and modified props were incorporated into the hinged oven unit to decrease the force needed to lift and prop the upper section for access to the turntable motor and other electronic parts. The oven unit was extremely complex (electrically and mechanically) and several breakdowns were experienced during nonradioactive testing in the ACMUs. Two of three connectors were replaced and other wiring problems were corrected before placement in AC3.

The MDS unit was functional for less than a year in AC3. During that time the turntable motor was remotely replaced and sporadic unexplainable error messages and shutdowns occurred. A method was developed for in-cell wattage determination. It was found that the wattage output of the microwave oven varied from 450 to 650 watts every few days for unexplained reasons. Unsuccessful troubleshooting attempts were ongoing by A\&PC and service personnel. Finally the oven ceased to function altogether and an alternative was sought while repairs were being attempted.

\subsubsection{Thermal Oven}

An alternative heating device was needed and a thermal oven was considered.

A small thermal oven was used in laboratory experiments to heat sample digestions side-by-side with a microwave oven and the results were compared. The teflon digestion vessels were torqued as usual and heated at $100 \pm 5^{\circ} \mathrm{C}$ for one hour in each step where a microwave oven would have been used. Dilutions, boric acid addition, and ICP analysis were performed as usual. The data showed that for nonradioactive waste, feed, and glass simulants, the two types of digestions were equivalent and the thermal heating method was validated.

Attempts to repair the remote MDS system were abandoned when electrical arcing was observed after remote replacement of the magnetron. A gravity convection type oven was placed in AC3 to heat the digestions. A specially made metal floor rack was placed in the oven to hold the vessels above a large ceramic heat sink which helps to stabilize the oven temperature. The heat sink was a WVNS innovation added in response to long equilibration times after each opening of the oven door. Metal racks with RM grips were fabricated to hold six 
teflon digestion vessels at a time. Digestions are currently performed using this equipment. The thermal oven has many advantages over the microwave: it is simple, inexpensive, stable, compact, reliable, and durable.

\subsubsection{Digestion Vessels}

Even though WVDP no longer uses remote microwave ovens, the microwave digestion vessels are optimal for use in thermal ovens.

Microwave digestions are generally performed in sealed teflon vessels that contain some type of pressure relief device to vent at a specific pressure. Teflon is microwave-transparent and inert to acids, which makes it a perfect material for microwave digestions because the vessel is unaffected by the microwaves; only the contents are heated. Silicon is an analyte of major importance in all HLW sample types and hydrofluoric acid (HF) is necessary to dissolve silicon; it does not affect the teflon but does dissolve glass. The chemically inert teflon does not contribute to contamination of samples.

\section{A. High-pressure Vessels}

Digestion vessels were investigated that were made for high-pressure applications using teflon pressure-relief membranes and outer sleeves made of a resin for structural strength (a total of five pieces per vessel assembly). The teflon membranes could not be handled with the RM and the resin sleeves were difficult to use.

\section{B. Low-pressure Vessels}

The basic, low-pressure solid teflon vessel was usable with the RMs. The vessel consists of a teflon body, a teflon pressure-relief disk, and a teflon cap (no sleeve, no membrane). This vessel is set to vent at approximately $120 \mathrm{psig}$. Technicians working at the ACs considered the pressure-relief disk troublesome to handle without contaminating it. Another type of vessel was considered.

A different type of teflon vessel was ordered and found to be superior to the previous model for in-cell handling. The vessel has a pressure-relief valve installed in the cap instead of using a disk. Only two pieces (the cap and the vessel) are handled routinely and the valve only needs to be taken apart if venting occurs. At $100 \pm 5^{\circ} \mathrm{C}$ (in the thermal oven), venting of these vessels has not been observed. The valve is set to vent at approximately $100 \mathrm{psig}$. A\&PC personnel tighten the vent valve to the appropriate setting and mark the valve and vessel to indicate the correct alignment. Each cap and vessel comes as a unique pair that has been proven to seal properly, so both are marked with the same identification letter. The matched cap and vessel are kept together this way. Marks are made on the teflon surface first by using a hand-held engraver and then filling in the roughened areas with an indelible high-temperature marking pen (see figure 20).

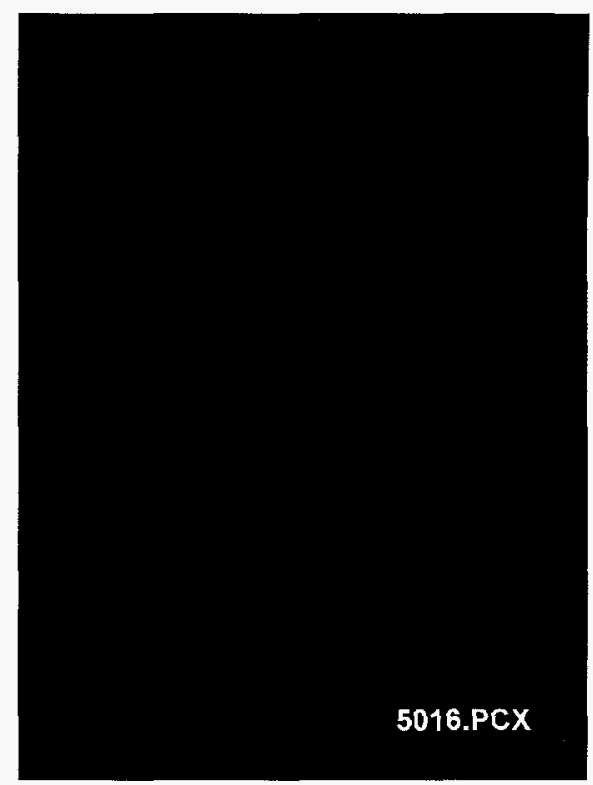

Figure 20. Digestion Vessel with Pressure-relief Valve in Cap 


\subsubsection{Remote Capper/Decapper and Spring}

Both the low-pressure digestion vessels have caps that need to be torqued down for proper sealing and to ensure the pressure-relief device function. This is accomplished using a remote capper/decapper that is commercially available from CEM Corp. (see figure 21).

During development of the remote digestion method at the ACMUs, a digestion vessel was completely decapped using the remote electric torque capper/decapper. The cap was retained by the notched ring and the vessel dropped all the way down inside the capper/decapper to the work surface. It was very difficult to lift the capper/decapper using the RMs to retrieve the vessel and impossible to retrieve the vessel from the top. A support was needed inside the capper/decapper to hold the vessel off the work surface, so that the vessel could always be retrieved from above (see figure 21).

A solid platform, which was supplied by the manufacturer, was tested. This was difficult to use because it required the operator to start the capping process using the RMs before placing the vessel inside the capper. The insert was a fixed height; a variable height was thought to be much more useful.

A prototype spring was made from $1 / 8$ " stainless steel tubing, which would fit inside the capper and hold the top edge of the vessel slightly above the notched ring. The cap could be held on the vessel and pressed down slightly, depressing the spring and allowing the cap to turn onto the vessel using the electric capper for the entire process. When decapping, the vessel could be completely decapped electrically, decreasing RM use for starting the capping process and finishing the decapping process. With engineering assistance, a sophisticated spring has been fabricated of stainless steel (see figure 22).

\subsubsection{Dispensette}

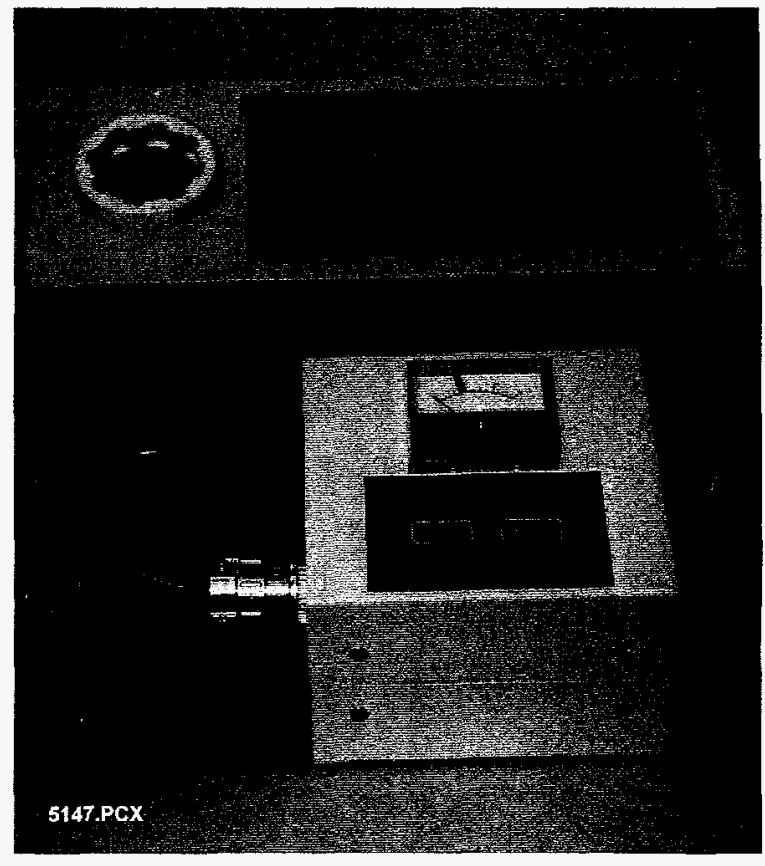

Figure 21. Remote Capper/Decapper

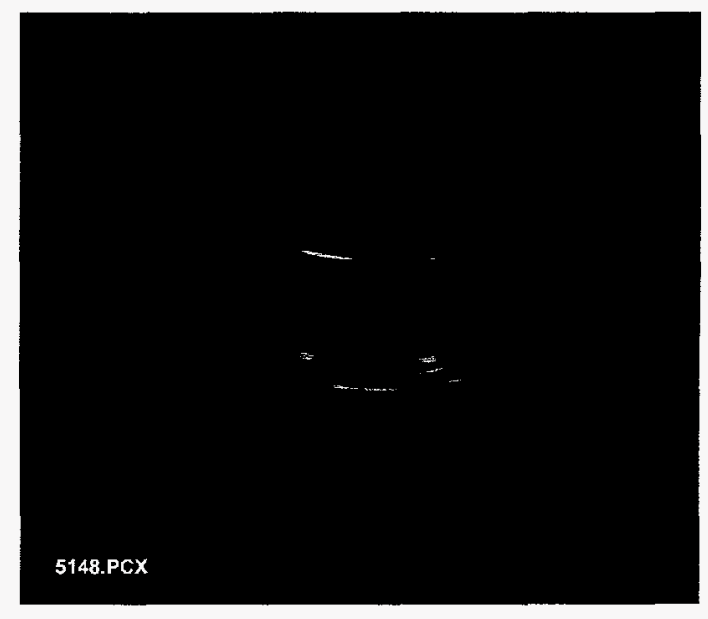

Figure 22. Remote Capper/Decapper Spring

Large volumes of water are needed to dilute the digested samples and to rinse the digestion vessels. To supply the quantities needed, a dispensette capable of delivering 10 to $100 \mathrm{~mL}$ of liquid was attached to a 1-gallon reservoir outside the cell. Teflon tubing enters the Analytical Cell through a penetration, using a check valve to prevent any backflow. A conical spray nozzle is attached at the in-cell end of the tubing to aid in rinsing vessels (see figure 23). 


\subsubsection{Conical Spray Nozzle}

In $\mathrm{AC} 3$, where remote digestions are performed, a conical stainless steel spray nozzle is attached to the end of the water line from the dispensette. The nozzle improves the vessel-rinsing capacity of the water expelled using the dispensette by producing a conical spray pattern instead of an unstructured stream. The nozzle was commercially available, having been manufactured for use in an ultrasonic unit. It allows the rinse water to spray the inner walls of the digestion vessel, resulting in a complete rinse using minimal water. The nozzle is connected to the $1 / 4$ " diameter teflon tubing by using stainless steel fittings (see figure 24).

\subsection{7 "C-shaped" Bottle Holders}

A "C-shaped" bottle holder was developed for use in iron ratio analysis. It is a sheet of stainless steel folded into a square "C" shape. Two sizes of bottle holders were developed, each with a top cutout that conforms to the bottle size. The $125 \mathrm{~mL}$ size holder is used in digestions and fusions to steady the dilution bottles and

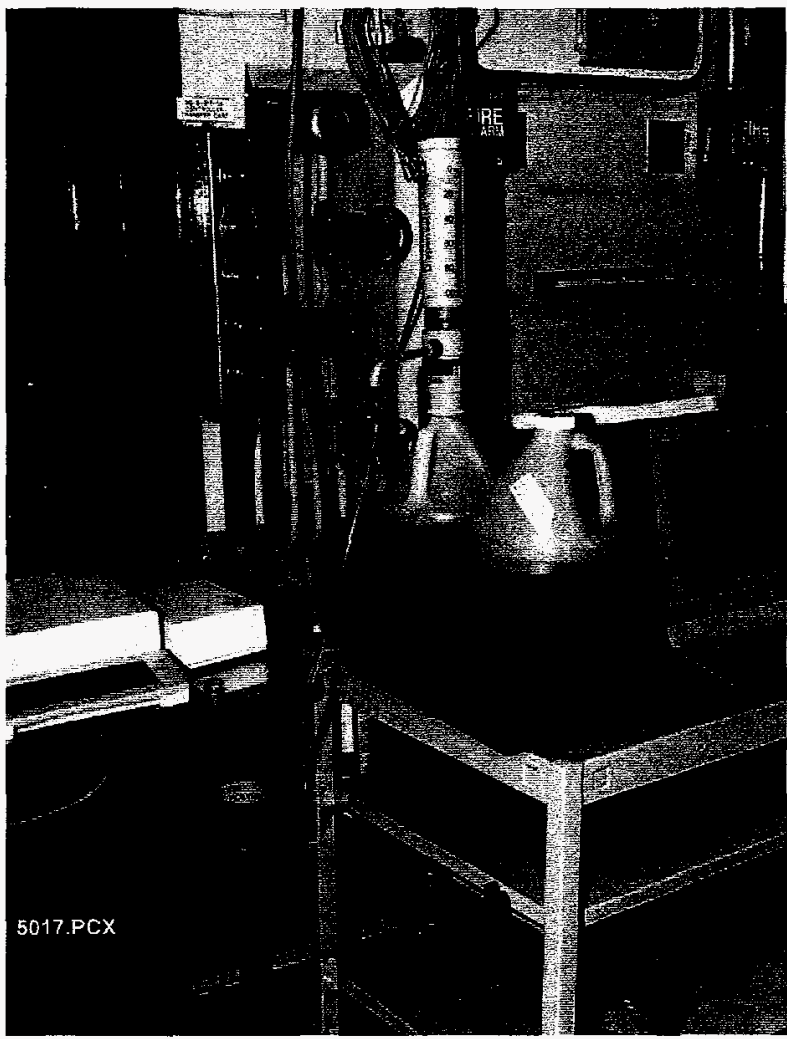

Figure 23. Dispensette Outside Analytical Cell to indicate approximately $100 \mathrm{~mL}$ volume. The $60 \mathrm{~mL}$ size is used in fluoride and chloride analyses and in remote iron ratio determination (see figure 25 ).

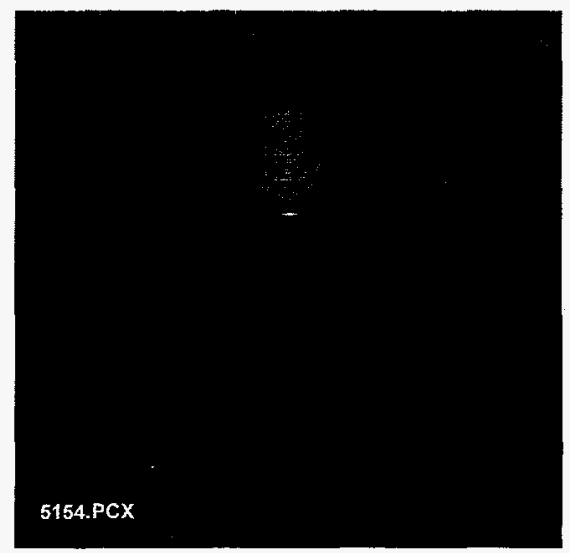

Figure 25. C-shaped Bottle Holder with $60 \mathrm{~mL}$ Bottle

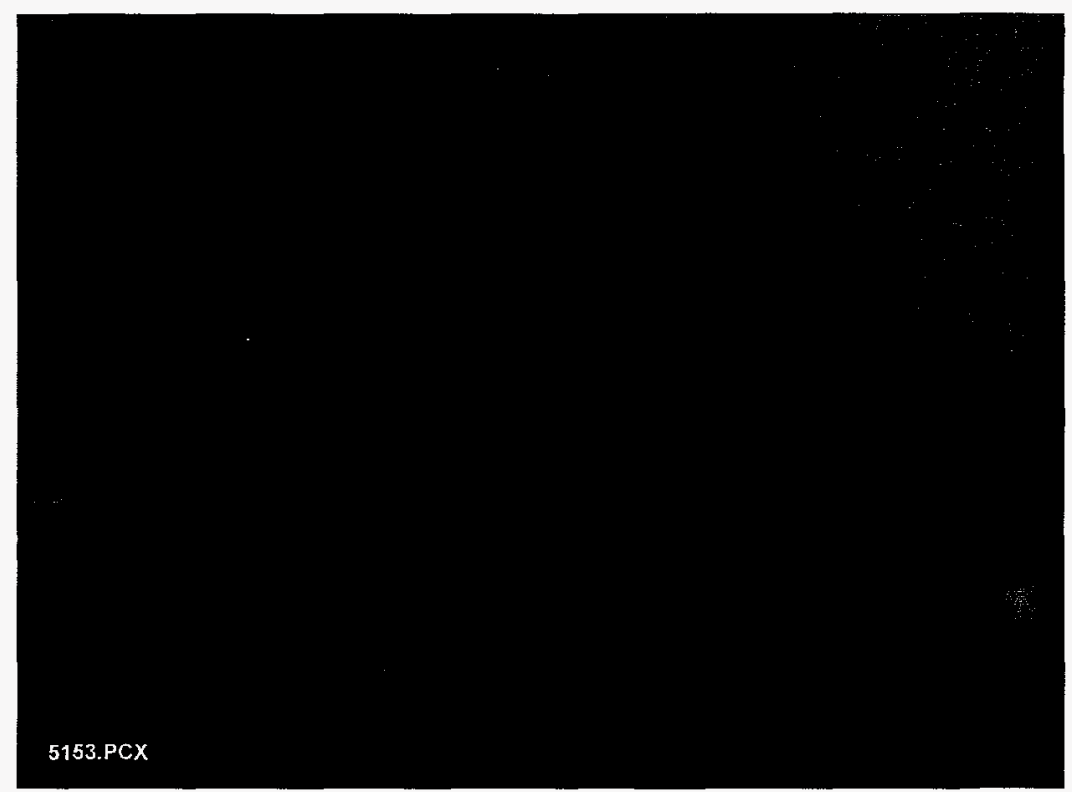

Figure 24. Conical Spray Nozzle at End of Water Line in Analytical Cell 
$\mathrm{KOH}$ fusions are performed on radioactive slurry samples to obtain titanium data by ICP analysis; titanium is not completely dissolved by the acid digestion procedure. The samples are fused in a furnace with $0.5 \mathrm{~g} \mathrm{KOH}$ at $500 \pm 50^{\circ} \mathrm{C}$ for 15 minutes, cooled, leached with $0.01 \mathrm{M}$ oxalic acid and concentrated nitric acid $\left(\mathrm{HNO}_{3}\right)$, and diluted to weight. Fusions are performed in the SSC using the drying oven and the furnaces.

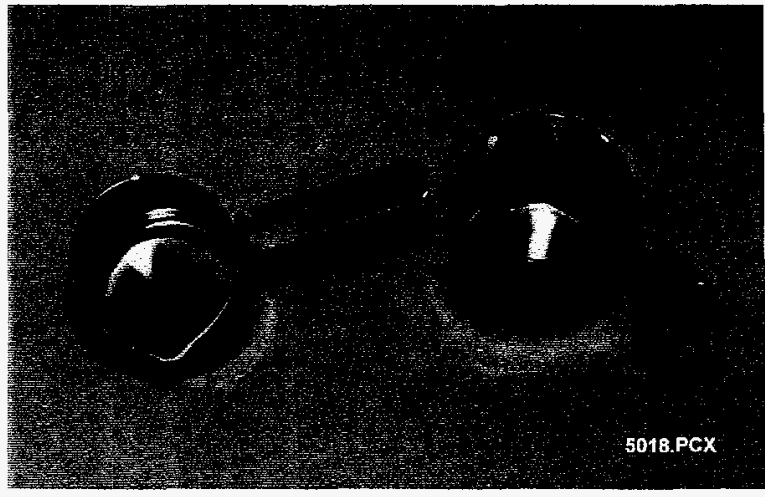

Figure 26. Zirconium Crucibles with Handles and Spouts; Original and Modified

\subsubsection{Zirconium Crucibles with Handles and Spouts}

Crucibles designed for routine laboratory use and handling with tongs are smooth and tapered. These crucibles are very difficult to manipulate with RMs. Zirconium crucibles with handles and spouts ( $55 \mathrm{~mL}$ capacity) were tested in the ACMUs. They were slippery and difficult to label (as received), but were preferable to the smooth-walled variety.

The crucibles with handles and spouts are currently modified at WVNS for better control. The handle is twisted $90^{\circ}$ and doubled back on itself, leaving a slight gap to allow for a wider grip. Numbers are stamped into the handle and front wall of the crucible (see figure 26). The crucibles are cleaned with dilute nitric acid and passivated in the furnace before use. Zirconium is preferable to nickel for this application because it does not react violently with dilute nitric acid as nickel does.

\subsubsection{Dispensettes}

Large quantities of water and oxalic acid are required for $\mathrm{KOH}$ fusions. Two dispensettes have been set up at the SSC to supply the needed reagents. Each dispensette is connected to a 1-gallon jug and dispenses liquid through teflon tubing and check valves into the SSC through the penetration, in a similar fashion to those at $\mathrm{AC} 3$ for digestions.

\subsubsection{Crucible Cart}

A small metal cart was fabricated to facilitate the use of equipment at both ends of the SSC that has three windows and three pairs of RMs. Zirconium crucibles containing sample and solution are passed from the aliquoting station at one window to the drying oven at the other, and later to the furnace. A rack which holds four crucibles is used for heating the samples in the oven and the furnace. The crucible rack mounts on the cart and crucibles containing aliquots of the sample are placed in the rack. The cart is then gently wheeled across the cell to the drying oven. This eliminates the need to hand a single crucible from the right RM at SSC window \#2 to the left RM at window \#3, or to put the crucible down

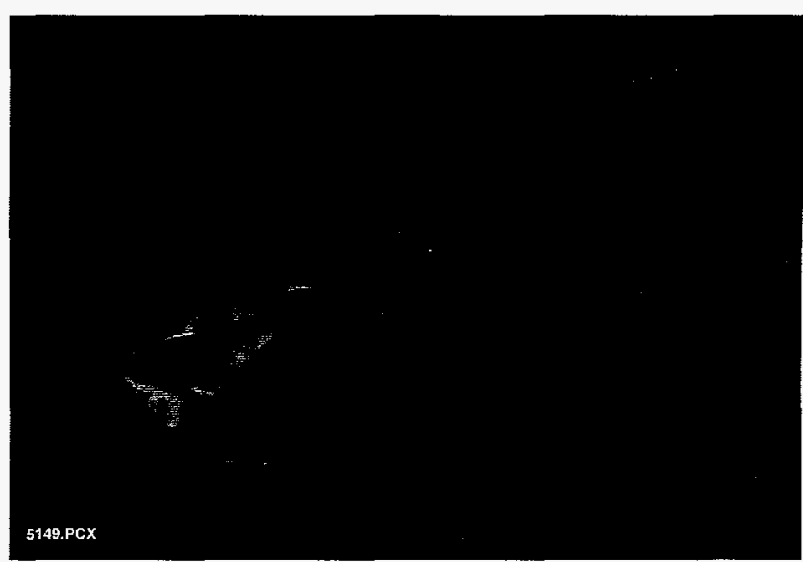

Figure 27. Crucible Rack with Detachable Angled Handle and move to the next window (see figures 27, 28, and 29). 


\subsubsection{Crucible Rack for KOH Fusions}

Stainless steel crucible racks were made to hold four of the $55 \mathrm{~mL}$ zirconium crucibles. The rack may be used with the same straight detachable RM handle as the Inconel crucible racks that are used for vitrification. An angled handle was fabricated to allow the technician visual access to the rack while it is being placed into the furnace (see figure 27).

\subsection{Remote Fluoride Analysis by ISE}

Fluoride analysis in feed slurry is used as an indicator of potential corrosivity in conjunction with $\mathrm{pH}$ and chloride concentration. The analysis could not be performed by simple dilution and IC because of very low expected fluoride concentrations and extremely high known nitrate concentrations. An ISE with a powerful decomplexing buffer and a known addition technique has proven to be a successful way to determine the fluoride content of feed slurry.

\subsubsection{Total Ionic Strength Adjusting Buffer IV (TISAB IV)}

Total ionic strength adjusting buffer, formula IV (TISAB IV) is used to decomplex the fluoride ions from major interferents, especially aluminum, silicon and iron, all of which are present in high concentrations. Approximately 30 minutes is needed after sample dilution with TISAB IV to allow decomplexing to progress. Without TISAB IV the fluorides in HLW slurry are not free to be measured by the electrode.

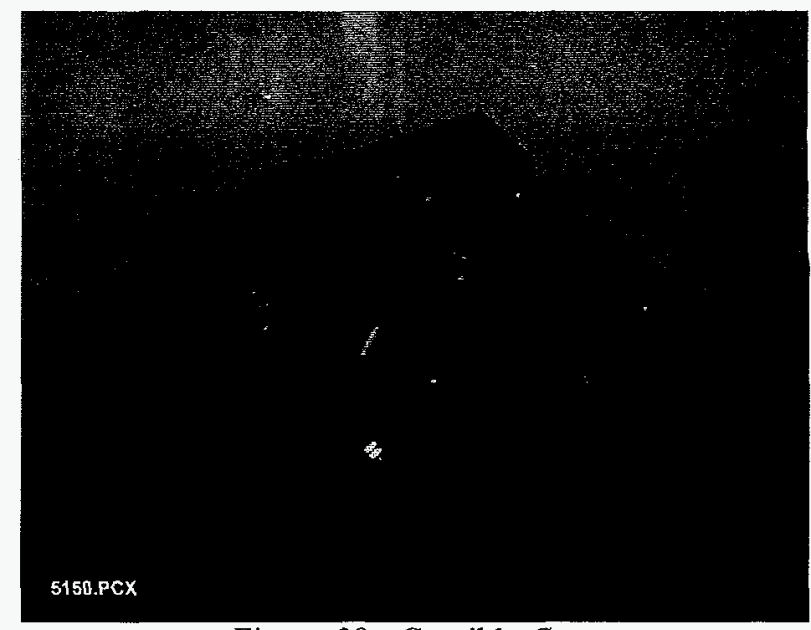

Figure 28. Crucible Cart

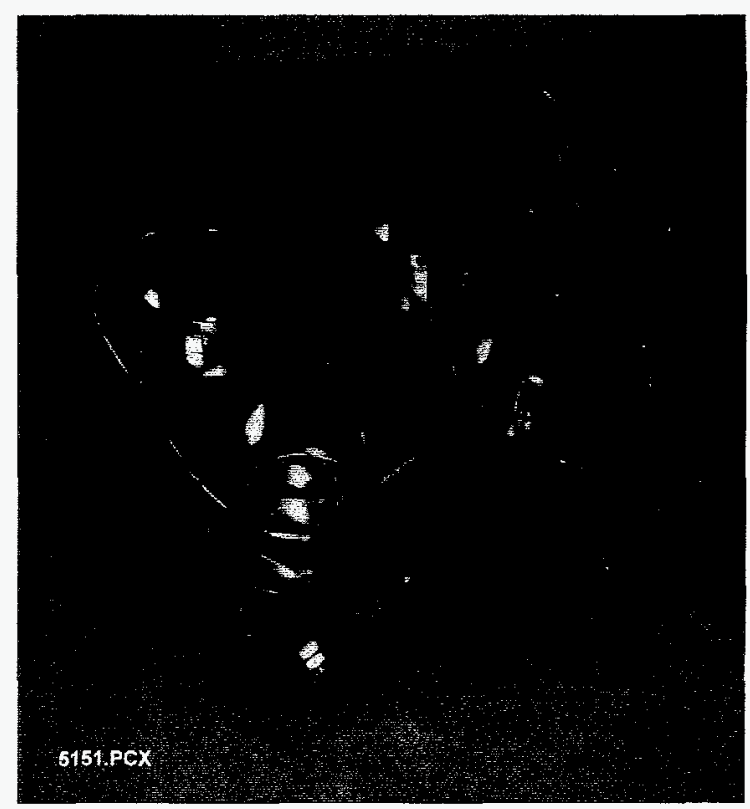

Figure 29. Crucible Cart with Rack and Crucibles

\subsubsection{Known Addition Double Increment Calibration}

A known addition double increment technique is used for calibration and analysis. The sample is diluted approximately 150-200 times with TISAB IV buffer which has previously been diluted 1:1 with water $(1+1$ TISAB IV). Using the programmable meter, the stable $\mathrm{mV}$ reading is obtained for the "sample," "sample + I1" (the first incremental addition of the calibration standard), and "sample + I2" (the second incremental addition of the calibration standard). One hundred $\mu \mathrm{L}$ and $1000 \mu \mathrm{L}$ of the $0.1 \mathrm{M}$ fluoride standard $(1900 \mu \mathrm{g} / \mathrm{g})$ are added as I1 and I2, respectively. Ideally, I1 should approximately double the concentration of fluoride in the diluted sample and $\mathrm{I} 2$ should be ten times I1. The meter calculates the semilogarithmic calibration line and the fluoride concentration in the original dilution using a complicated algorithm. An electrode slope in $\mathrm{mV} /$ decade is displayed and used as an indication of the validity of each analysis. The technique has been validated using nonradioactive simulants spiked with sodium fluoride in the range of 30 to $2,000 \mu \mathrm{g} / \mathrm{g}$ fluoride. 


\subsubsection{Dilluter/Dispenser}

The increments of calibration standard, I1 and I2, are added using a diluter/dispenser. This consists of an in-cell pump unit with a gastight syringe and two tubes connected to the syringe. Precise volumes of liquid can be dispensed from a reservoir via a programmable controller. A foot pedal allows the program to be activated without use of the hands, which are needed for holding tke sample and electrode in place.

\section{A. First Generation Diluter/Dispenser}

ACMU development work was performed using the initial diluter/dispenser, which was the predecessor to the final diluter/dispenser. The diluter/dispensers are modular as received, so the only modifications needed were a 30-foot extension cable for the controller and an extension cable for the foot pedal. There was no difficulty involved in remote use of the initial diluter/dispenser at the ACMUs.

\section{B. Diluter/Dispenser with Line Signal Enhancer}

When the updated version of the diluter/dispenser was purchased and tested, it was found that the 30-foot extension cable no longer worked. Upon further investigation, it was found that the 4.0 milliampere (mA) signal from the dispenser unit (where the 120 Volts alternating current (Vac) was connected, in-cell) to the controller/ display had been reduced to about $3.75 \mathrm{~mA}$. Technical support personnel were consulted and did not have any suggestions to allow use of a $30-$ foot extension cable.

WVNS electrical personnel experimented with a boost in the line voltage and succeeded in powering up the controller/display of the $510 \mathrm{~B}$ with a 30 -foot extension cable. A standard " $\mathrm{D}$ " battery is mounted in a simple electrical box and used as a line signal enhancer.

\section{Foot Pedal and Extension Cord}

A detachable 30-foot extension cable for the foot pedal has been fabricated. If problems with the foot pedal are encountered, the controller can be actuated using the keypad by hand. The importance of a backup technique is amplified with remote analyses.

\section{Sensing Electrode and Cable}

The fluoride electrodes are commercially available without modification. BNC-type connectors and commercially available 25 -foot extension cables are used to connect the electrode in-cell to the meter ex-cell. When the electrode needs to be replaced in-cell, it is disconnected from the extension and a new electrode is connected.

\subsection{Remote Chloride Analysis by ISE}

Chloride analysis in feed slurry serves as an indicator of potential corrosivity in conjunction with $\mathrm{pH}$ and fluoride. The analysis could not be performed by diluting the slurry and performing IC because of very low expected chloride concentrations and extremely high known nitrate concentrations. Use of an ISE with an appropriate ionic-strength-adjusting solution and a known addition technique has proven to be a successful way to determine the chloride content of feed and waste slurry. 
The manufacturer's recommended ionic strength adjusters (ISAs) were unsuccessful in trials using simulated slurries spiked with sodium chloride. Several WVNS candidate ISAs were tried at the ACMUs. Various concentrations of nitric acid, oxalic acid, disodium ethylenediaminetetraacetate (EDTA), citric acid, citric/oxalic acid mixture, sodium phosphate buffer, and other concentration ranges of phosphoric acid $\left(\mathrm{H}_{3} \mathrm{PO}_{4}\right)$ were evaluated before $0.125 \mathrm{~N}$ phosphoric acid was proven effective. To negate the effects of manganese II $\left(\mathrm{Mn}^{+2}\right)$ ion and hydroxide $\left(\mathrm{OH}^{-}\right)$ion, which are the major interferents for this analysis, $0.125 \mathrm{~N} \mathrm{H}_{3} \mathrm{PO}_{4}$ is used. The $\mathrm{pH}$ must be in the range 2 to 9 , which the acid also assures.

A known addition double increment technique is used for calibration and analysis. The sample is diluted approximately 10 to 150 times with $0.125 \mathrm{~N} \mathrm{H}_{3} \mathrm{PO}_{4}$. Using the programmable meter, the stable $\mathrm{mV}$ reading is obtained for the "sample," "sample + I1" (first incremental addition of calibration standard), and "sample + I2" (second incremental addition of calibration standard). One hundred $\mu \mathrm{L}$ and $1,000 \mu \mathrm{L}$ increments of the $0.1 \mathrm{M}$ chloride standard $(3550 \mu \mathrm{g} / \mathrm{g})$ are added as I1 and I2, respectively. The meter calculates the calibration line and the chloride concentration in the original dilution, as well as the electrode slope. A calibration is thus performed with each and every analysis.

The technique has been validated using nonradioactive simulants spiked with sodium chloride in the range of 50 to $8000 \mu \mathrm{g} / \mathrm{g}$ chloride. The increments of standard are added using a the final diluter/dispenser with the WVNS line signal enhancer. The chloride electrode uses a BNC-type connector and a 25-foot commercially available extension cable. When the electrode needs to be replaced in-cell, it is disconnected from the extension and the new electrode is connected.

\subsubsection{Apparatus and Tools}

Apparatus and tools are the same as those described for fluoride analysis.

\subsection{Remote $\mathrm{pH}$}

Analysis of waste and feed slurry in-cell for $\mathrm{pH}$ requires a rugged, nonclogging electrode. It must be capable of performing accurately in the high $\mathrm{pH}$ ranges and at high temperatures, which are demanding requirements. Several combination electrodes were tested using simulants at the ACMUs.

Electrode testing involved calibrating the electrode, checking a QC standard, analyzing a slurry simulant sample, rinsing, reanalyzing slurry, etc. for 10 analyses, then checking the QC standard again. A second test involved soaking the electrode in the simulant for one hour, rinsing in $1+1 \mathrm{HNO}_{3}$ followed by a water rinse, and analyzing the QC standard again. These were "worst case" trials of accuracy and durability.

The best electrode based on this testing proved to be the an epoxy-bodied, gel-filled, double reference junction flat surface electrode. The sensing element is flat, which affords durability; there is no protruding glass bulb to easily knock off. The double reference junction allows high flow rates, consisting of a fitted glass ring around the sensing element. The epoxy body is sturdy and the gel filling never needs to be replaced. A 25-foot extension cable with a BNC connector is used in the cell.

An alternative electrode that requires liquid refilling is also acceptable but has a glass (breakable) body, clogs easily, and uses a glass bulb sensing element that protrudes and is easily broken. 


\subsection{Remote Total Solids}

The percentage of total solids (\%TS, a classic method) is determined by the ratio of the dry weight over the initial (wet) weight. Total solids analysis is performed by weighing an aliquot of the sample, drying it, and weighing it again. In the laboratory this analysis is performed using a microwave system that consists of a sensitive balance inside a microwave oven. A glass fiber pad is tared, the sample is added to the pad and weighed, and the sample pad is dried in the microwave oven while being weighed. The dry weight is determined based on various parameters, including the rate of weight loss or \% power vs. time.

A remote version of the microwave solids analyzer was purchased and tested in the ACMUs. It was built so that its components would be replaceable using RMs. Handling the absorbent glass fiber pads proved difficult with RMs and various special tools and forceps were tested to increase functionality.

Ultimately the remote microwave \%TS system has proven to be unreliable; similar problems were encountered with this system as with the microwave oven, and the thermal oven has been employed instead. The sample is weighed into a clean, dry, preweighed glass beaker; dried in the thermal oven; and weighed to constant weight.

\subsection{Vitrification: Iron Ratio and ICP Analyses}

Preparation for an iron ratio $\left(\mathrm{Fe}^{2+} / \mathrm{Fe}^{3+}\right)$ analysis using slurry samples involves vitrification of the slurry in furnaces located in the SSC. As noted in 4.2.1, if slurry aliquots prove to be inhomogeneous, whole RBG bottles of slurry may be vitrified, ground, aliquoted, digested, diluted, and used for ICP analysis.

\subsubsection{Method Development}

Vitrification method development activities were conducted in the ACMUs located in the Vitrification Test Facility (VTF) using a small furnace. Nonradioactive feed slurry simulant was dried in an oven then vitrified at $1100^{\circ} \mathrm{C}$ in an open platinum crucible. The techniques have since been refined, as described below.

\subsubsection{Preparation for the Iron Ratio Determination}

Knowledge of the iron ratio is helpful in process control during vitrification because the ratio indicates the oxidation-reduction (redox) status of the glass. If the melt is too reducing or too oxidizing the melter may be damaged. The iron ratio determination is usually performed using feed slurry that is vitrified in-cell. The resulting glass is ground and dissolved for the iron ratio analysis.

\section{A. Methodology}

Oxygen from the air and from nitrates and nitrites in the slurry oxidizes $\mathrm{Fe}^{2+}$ into $\mathrm{Fe}^{3+}$ during vitrification. Sugar is added during the feed preparation cycle to scavenge the excess oxygen as the batch melts and becomes glass. In the laboratory, the atmosphere above the slurry sample must be controlled to simulate the reactions that occur inside the melter. Excess oxygen from the air would produce a false (low) iron ratio result. A completely oxygen-free environment during vitrification would produce a false (high) iron ratio result. Method development focused on vitrification in sealed containers to simulate the melter environment.

After months of development, homogeneous glass samples were consistently obtained. A sample size of about $30 \mathrm{~mL}$ is vitrified at a temperature of $1150^{\circ} \mathrm{C}$ for 45 minutes in a custom made pear-shaped quartz crucible 
with a standard tapered joint sealed with a quartz stopper (see figures 30 and 31). The special crucible provides a vitrification vessel that simulates the melter environment.

The contents of 2 to 3 RBG bottles are shaken and transferred to the pear-shaped crucibles. The sample is then dried at a maximum temperature that would not cause splattering for a set time period. Because the result is a ratio, it is not necessary to quantify the amount of slurry used to make the glass.

The stoppered crucibles are placed in a preheated furnace. In the first 1 to 2 minutes of vitrification off-gassing occurs. The stopper must be able to allow the gas to escape and then seal the crucible. The stopper was custom made to a specific mass that would allow it to be pushed upwards by the off-gas pressure without being totally displaced from the crucible. Due to the weight of the stopper, it settles back into position to seal the crucible after the off-gassing.

Vitrified samples are then removed from the furnace and allowed to cool. During this period the samples and quartz crucibles crack and shatter. For this reason and because of the shape of the crucibles, vitrification is performed in a secondary $100-\mathrm{mL}$ or larger standard high-form quartz or porcelain crucible. Shattering of the quartz, pear-shaped crucible occurs only where the quartz contacts the sample.

Cooled samples are crushed into small pieces and

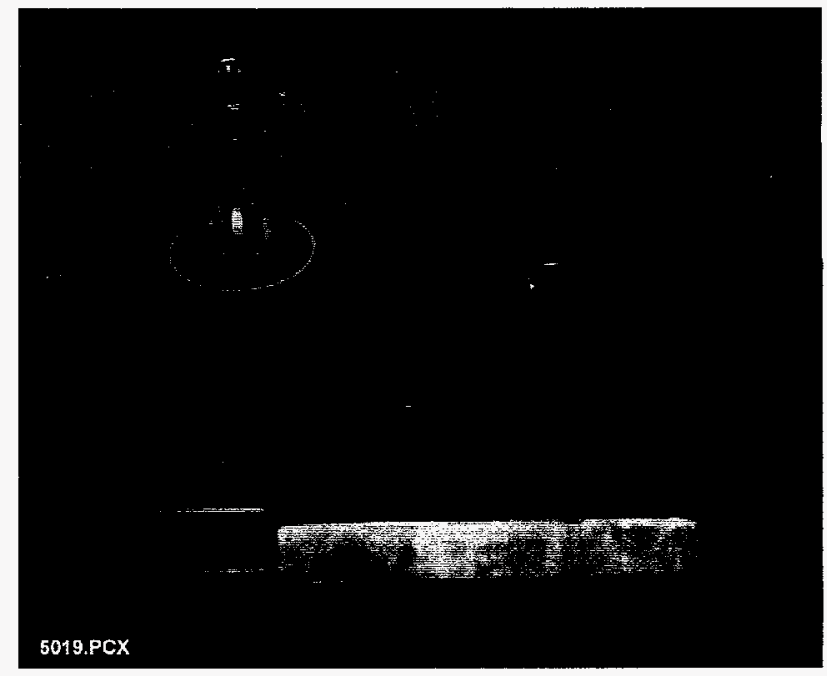

Figure 30. Extension Tool and Inconel ${ }^{T M}$ Crucible Rack

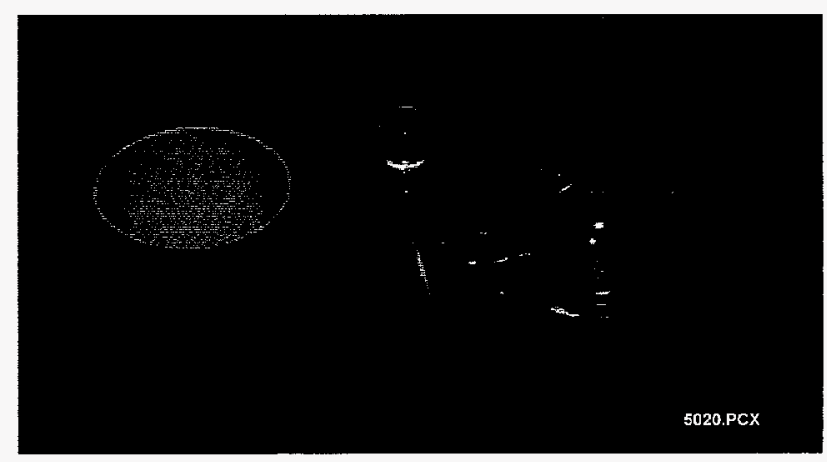

Figure 31. Pear-shaped Quartz Crucible with Secondary $100 \mathrm{~mL}$ Crucible separated from the quartz as much as possible. Small pieces of the sample are then ground to a powder in a mixer/mill. The powdered sample is transferred from the SSC to the appropriate cell for dissolution and iron ratio analysis.

\subsubsection{Preparation for ICP Analysis}

In case wet slurry aliquots were proven inhomogeneous, a method to verify the elemental composition of entire RBG bottles of the sample was needed as a backup to the preferred method of removing a small aliquot from each of the RBG bottles. Two to three RBG samples of WGF or SF are vitrified quantitatively, ground and digested for ICP analysis. The results are converted using a "vitrification factor" (ratio of weight of slurry to weight of glass) from $\mu \mathrm{g} / \mathrm{g}$ of glass to $\mu \mathrm{g} / \mathrm{g}$ of slurry. Vitrification involves a much longer turnaround time for results, as discussed in section 4.2 on aliquoting.

\section{A. Methodology}

ICP analysis does not depend on oxidation states. Therefore, vitrification for ICP analysis does not require a sealed vessel. Sample contamination from the vitrification vessel is the major concern. Performing vitrification 
in gold-platinum (Pt-5\% Au) crucibles prevents contamination with elements such as silicon (a major analyte present in quartz).

Reinforced standard high-form $100 \mathrm{~mL}$ crucibles with lids (to minimize splattering) provide sturdy crucibles that can be used many times. The $5 \%$ gold in the platinum improves wettability to ease the separation of the vitrified sample from the crucible. Sample separation still proves to be trying and the reinforced crucibles handle the punishment of separation better than the standard crucible.

Samples are dried in the Pt-5\% Au crucibles at a temperature below that which would cause splattering. Vitrification at $1150^{\circ} \mathrm{C}$ for 45 minutes for a sample size of about $30 \mathrm{~mL}$ is sufficient to produce a homogeneous glass sample.

After removal from the crucible, the vitrified sample is crushed into pieces small enough to fit inside a grinding vial. The sample is ground in a mixer/mill and transferred from the SSC for dissolution.

The Pt-5\% Au crucibles are cleaned for reuse in a mixture of hydrofluoric and nitric acids (the nitric acid was added due to site waste constraints) with or without the use of an ultrasonic bath.

\subsubsection{Tools and Equipment}

Special tools and equipment were developed for use with the furnaces. Some equipment needs to withstand repeated exposures to the $1150^{\circ} \mathrm{C}$ vitrification conditions.

\section{A. Racks}

Inconel ${ }^{\mathrm{TM}}$ crucible racks were made to hold four samples at a time in the furnace. The racks were made with a rear slot to accommodate an extension tool to help protect the RM tong assembly from the heat of the furnace (see figure 30). The Inconel ${ }^{\mathrm{TM}}$ withstands $1150^{\circ} \mathrm{C}$ temperatures.

\section{B. Crusher}

Vitrified samples are separated from quartz and reduced in size by crushing. A stainless steel tray with a RM grip, lift bail, and large pour spout is used as the crushing container. A $2.5 \mathrm{lb}$ smasher with a spiked disc on one end and a cylindrical knurled grip on the other was fabricated to crush the glass samples (see figure 32). Glass samples are then ground to a powder in a mixer/mill.

\section{Mixer/Mill for Grinding}

A mixer/mill with tungsten carbide vials and balls was the choice for grinding samples after investigating several different grinders. The mixer/mill could be operated with the RMs as received from the vendor with no major modifications. The mixer/mill uses two vials in opposing positions that are rotated in a figure eight pattern. The grinding vials are wrapped with heat shrink tubing to enhance gripping with RM fingers (see figures 33 and 34).

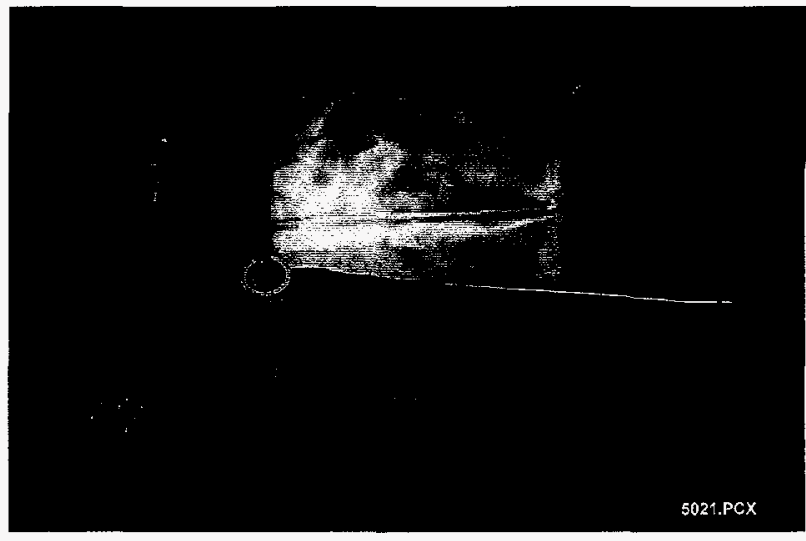

Figure 32. Sample Crusher with Tray 
A stainless steel cart with stainless steel casters provides the grinder with mobility. The cart is fitted with lifting bails and a lever brake similar to the cart made for the furnaces (see section 10.6). A lever tool engages the brake on the cart, which keeps the mixer/ mill from "wallking" during operation.

\section{Drying Oven}

A gravity-convection oven was placed in the SSC for drying samples. The oven temperature is monitored using a type $\mathrm{K}$ thermocouple in-cell and thermocouple wire inserted through an SSC penetration with a thermocouple readout ex-cell.

\section{E. Vortex Mixer}

A vortex mixer was placed in the SSC for mixing RBG bottle samples. The mixer was not modified for use.

\section{F. Funnels with Screens}

For collecting ground glass remotely, a powder funnel was fitted with a circular piece of stainless steel screen about halfway between the stem and the rim. The screen is pressed so that the sharp edges bite into the plastic funnel. The funnel is placed in a collection bottle and the contents of the grinding vial are poured into the funnel. The screen catches the grinding ball and allows the ground sample to pass through. The grinding ball is then poured back into the vial for cleaning.

Plastic funnels with stems that are narrower than the grinding ball may also be used without screens but some "jiggling" must be done to allow the ground sample to pass through the stem, which is blocked by the grinding ball.

\subsubsection{Iron Ratio Analysis}

It has been shown that the control of the oxidation-reduction (redox) potential in glass processing for high-level nuclear waste vitrification affects glass processing and may extend the melter's useful life. The ratio of ferrous ions $\left(\mathrm{Fe}^{2-}\right)$ to ferric ions $\left(\mathrm{Fe}^{3+}\right)$ is one indication of the overall redox conditions in the glass melt and is readily determined in the laboratory. 


\section{A. Background}

A simple colorimetric method for ferrous-ferric $\left(\mathrm{Fe}^{2+} / \mathrm{Fe}^{3+}\right)$ ratio determination for monitoring the redox conditions in vitrification was developed for the commercial glass industry. This method involves the dissolution of glass in an $\mathrm{HF} / \mathrm{H}_{2} \mathrm{SO}_{4}$ (sulfuric acid) mixture. Reagents are added to the dissolved glass and the $\mathrm{pH}$ is adjusted with $\mathrm{HCl}$ or $\mathrm{NH}_{3}$ to a $\mathrm{pH}$ of 3.3 to 3.5. Reduction of the ferric ion is accomplished by the addition of hydroquinone followed by a 30 -minute reaction period. The resulting orange-red solution is analyzed spectrometrically at $510 \mathrm{~nm}\left(\mathrm{Fe}^{2+}\right)$.

A WVDP adaptation of this method was attempted at the ACMUs and was not readily performed. It was difficult and time consuming to perform the $\mathrm{pH}$ adjustment step in-cell with dropwise addition of acid or base, particularly for large batches of samples that included blank and quality control samples.

A review of the literature, in search of a more adaptable method that would produce acceptable results, suggested that Standard Method 3500-Fe D, Phenanthroline Method, would be a useful starting point. This is because of the minimum number of reagents required for complete analysis and the acceptable sensitivity of the method in the range desired. The addition of excess buffer to establish an acceptable solution $\mathrm{pH}$ instead of acid/base addition for $\mathrm{pH}$ adjustment is readily accomplished in-cell. The method calls for the use of an ammonium acetate/acetic acid buffer, which has a $\mathrm{pH}$ of approximately 4.0 standard units (S.U.).

\section{B. Method}

A finely ground glass sample weighing 50 to $80 \mathrm{mg}$ is placed in a $125-\mathrm{mL}$ plastic container. One $\mathrm{mL}$ of conc. $\mathrm{HF}$ is added and allowed to react. One $\mathrm{mL}$ of conc. sulfuric acid $\left(\mathrm{H}_{2} \mathrm{SO}_{4}\right)$ is then added and allowed to react. Approximately $100 \mathrm{~mL}$ of water is added. Approximately $2 \mathrm{~mL}$ of this dissolution is transferred to a $60-\mathrm{mL}$ analysis bottle that contains $15 \mathrm{~mL}$ of reagent water, $10 \mathrm{~mL}$ of ammonium acetate-acetic acid buffer, and $5 \mathrm{~mL}$ of $0.1 \% 1,10$-phenanthroline solution. The solution is diluted to $50 \mathrm{~mL}$ with water.

After 10 minutes the $\mathrm{Fe}^{2+}$ has reacted with the 1,10-phenanthroline solution to form a colored complex and each solution is analyzed spectrophotometrically at $510 \mathrm{~nm}$ for $\mathrm{Fe}^{2+}$. The spectrophotometer used is equipped with fiber optics and a dip probe for remote, in-cell analysis.

To reduce all the $\mathrm{Fe}^{3+}$ (to $\mathrm{Fe}^{2+}$ for analysis), approximately 0.1 to 0.2 grams of solid hydroxylamine hydrochloride $\left(\mathrm{NH}_{2} \mathrm{OH} \cdot \mathrm{HCl}\right)$ is added to each solution and allowed to react for 30 minutes at ambient temperature. Alternatively the solution is gently heated to boiling in a microwave oven followed by a 15-minute cooling period. Each solution is again analyzed spectrophotometrically at $510 \mathrm{~nm}$ for total $\mathrm{Fe}\left(\right.$ as $\mathrm{Fe}^{2+}$ ). Ferric ions $\left(\mathrm{Fe}^{3+}\right)$ are determined by the difference between total iron and $\mathrm{Fe}^{2+}$ and, as a result, the $\mathrm{Fe}^{2+} / \mathrm{Fe}^{3+}$ ratio is computed.

\section{Cell Findings}

During method development, the fiber optic dip probe was found to be much easier to use and maintain in-cell than a flow-cell. A "C"-shaped stainless steel fixture is used as a sight guide in-cell for the $50 \mathrm{~mL}$ dilution prior to analysis; this fixture is sized to fit $60 \mathrm{~mL}$ poly bottles (see figure 25 ).

During method development, all reagents were dispensed in-cell. To speed the overall TAT it was decided to prepare dissolution and analysis bottles ex-cell. This practice also limits the quantities of acids available for potential spills. The only reagents that are added in-cell are water and hydroxylamine hydrochloride.

Pre-weighed hydroxylamine hydrochloride is introduced in scintillation vials for each analysis. 


\subsection{Remote Dilutions}

Dilutions of feed and waste slurry are made for removal from the cells and subsequent TOC and IC analysis. The slurry aliquots are taken using the same type of remote aliquoting apparatus and technique as those used for digestion and fusion aliquots. In some cases the dilutions are expelled through syringe filters prior to removal from the analytical cells. This is helpful because it reduces the effective radiological dose of the sample when a lower dilution factor is required, increasing the ultimate detectable level of the analyte of interest. Filtration also removes interferences caused by particulates injected into the TOC analyzer. Because the anions and organic carbon (sugar) are water-soluble, filtering the dilution does not adversely affect results. 


\subsection{CELL WINDOWS}

The inside area of each analytical hot cell is viewed through a liquid-filled shield window that protects personnel performing remote manipulations from the radioactivity of items within the cell. The two types of windows used at the WVDP are $\mathrm{ZnBr}_{2}$ and oil-immersion/leaded glass.

\subsection{Lead Shielded Window Modification at AC5}

In 1984 a major refurbishment effort was undertaken to decontaminate and refurbish the analytical cells. This activity focused on the removal of accumulated wastes from the cells, decontamination and painting of the cell interior, installation of 15 new RMs at the eight work stations, and refurbishment of six zinc bromide windows. This effort was undertaken to provide the A\&PC Department with a facility to analyze samples of high-level waste and to support STS process requirements.

The zinc bromide window in AC5 had become clouded, causing a reduction in clarity of view. Due to this deterioration it was determined that the AC5 window should be replaced to insure against total failure during the vitrification campaign. Zinc bromide solutions can be very corrosive. To alleviate the negative aspects of using zinc bromide, the decision was made to convert the window to oil immersion/leaded glass.

First, all radioactive materials were removed from the cell, then the cell was decontaminated to reduce background dose levels. The zinc bromide was drained and the window components were disassembled. The interior cavity and components of the window were sandblasted to remove the old epoxy coating then resealed with multiple layers of epoxy coating.

The window was reassembled and filled with mineral oil instead of zinc bromide. Zinc bromide has good optical characteristics and, due to its high density, zinc bromide has good radiation shielding performance. Mineral oil has good optical characteristics but does not provide significant shielding. In order to obtain the necessary shielding, leaded glass was attached to the outside surface of the window.

Due to differences in refractive indices between zinc bromide and oil there would be a reduction in the amount of effective in-cell viewing area. In order to evaluate the potential impact of the additional thickness of leaded glass on the window and the reduced viewing area, these changes were mocked up at the ACMUs. This activity was performed by attaching a plexiglass box to the ACMU window to simulate the extra thickness of leaded glass and by taping off the in-cell coverglass to reduce the viewing area. Mockup testing indicated no unforeseen problems and the decision was made to go ahead with the modification of the window from zinc bromide-filled to mineral oil-filled.

\subsection{Installation of the New Oil Shield Window at the SSC}

In addition to the zinc bromide shield windows at the analytical cells, there are two oil-immersion/leaded glass windows at the SSC. The SSC is 6 feet wide and 25 feet long, with three work stations. Each station is composed of a shielded viewing window and two RMs.

During the original construction of the SSC, a shield plug made of concrete had been placed in an opening designed for a (future) shield window. In order to make effective use of the SSC, the decision was made to remove the shield plug and install a shield window and two remote manipulators. A new oil immersion/ leaded glass shield window with two RMs was installed to allow use of the previously inaccessible area of the SSC. 


\subsection{REMOTE MANIPULATORS}

The A\&PC Department includes several functional laboratories and the analytical hot cells. The cells consist of seven different compartments. These cells are labeled Cells 1-5 (AC 1-5), Sample Cell 2 (SC2), and the Sample Storage Cell (SSC). A\&PC also has two ACMUs that are identical in size and functional operations to ACs 1-5. All of these cells have been described in greater detail in other sections of this report and all have RMs manipulators that are used to carry out remote analytical operations.

Remote work with radioactive samples at the hot cells requires the ability to manipulate objects inside the cells using controls outside the cells. The RMs allow a person to control the fingers (jaws) inside the cells using the hand grips outside the cell, while looking through the shield window. The RMs are used to facilitate analytical procedures for analyzing high-level radioactive samples, operate instruments and equipment, move and decontaminate equipment and supplies, package waste in different types of containers, and many other in-cell operations. These remote operations are considered light-duty functions for the RMs.

\subsection{Types of Remote Manipulators}

The type used by $\mathrm{A} \& \mathrm{PC}$ is a variable ratio $\mathrm{Z}$ remote manipulator (see figure 35). Additional types of remote manipulators are available.

Some of the key specifications for the remote manipulator are its handling and vertical lift capacities. Maximum handling capacity is $18 \mathrm{lbs}$ and maximum vertical lift capacity with a load hook is $50 \mathrm{lbs}$, per manufacturer's recommendations.

ACs 1-5 each have two ports available for RMs, while SC2 has only one port (see figure 36). The SSC is a much larger cell and contains three windows. Above each window of the SSC

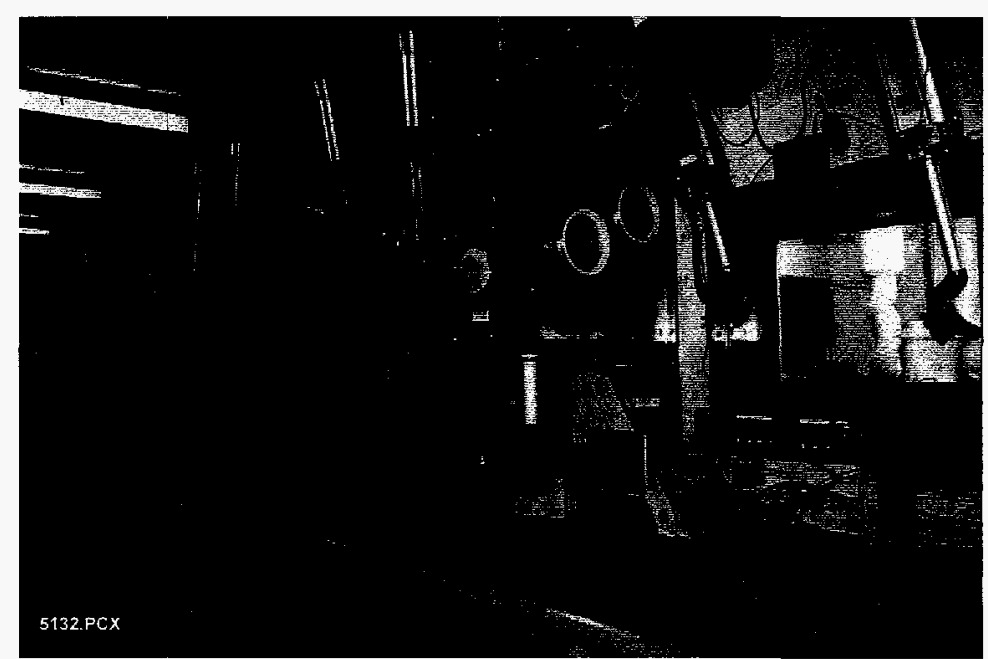

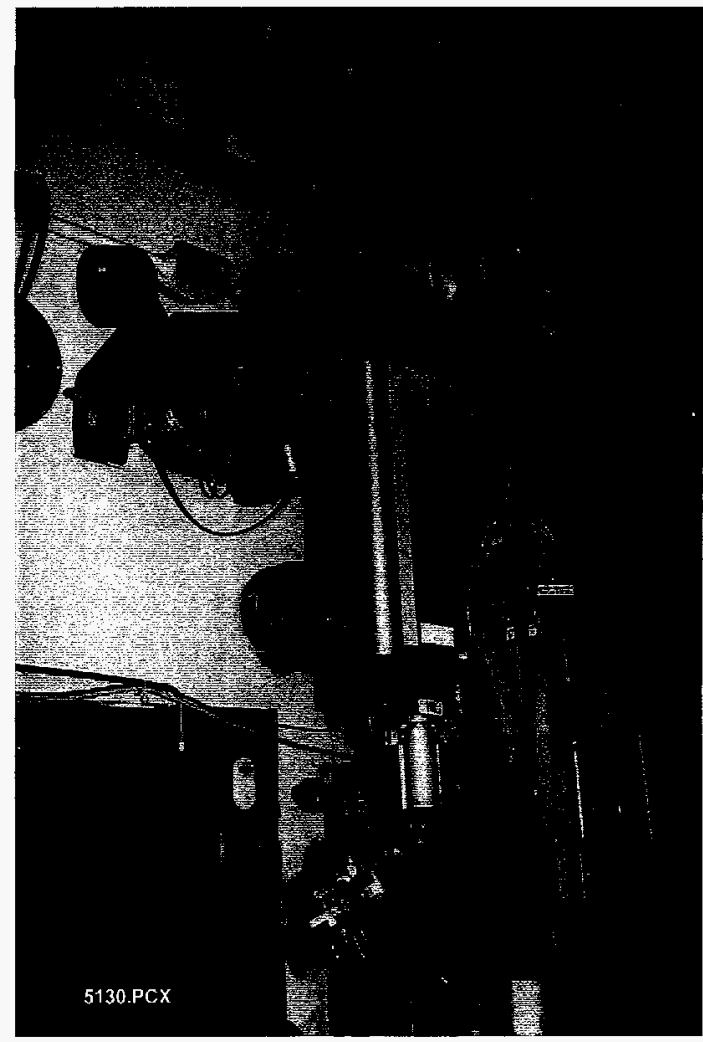

Figure 35. Remote Manipulator (RM) Used at A\&PC Hot Cells and ACMUs

Figure 36. SC-2 and AC1-5: Eleven Remote Manipulators (RMs) in Working Positions 
are two ports available for RM (see figure 37). The ACMU is nearly identical to cells 1-5 and has two ports available for remote manipulators (see figure 10). At present, the total number of working RMs stations in A\&PC is 19.

\subsection{Remote Manipulator Re- moval Rail}

In order to disassemble and repair in-cell components of a remote manipulator, it is necessary to remove the RM from the cell. In the past this required the use of a large transfer cart to remove the RM from the cell port. A support was adjusted to the proper height to secure the RM as it was removed. It was awkward to use the cart due to its large size and the limited amount of space in the operating aisle. To properly position the cart to support the RM during removal, the gantry in front of the cells had to be disassembled.

It was decided to install RM removal rails at each RM port to alleviate these problems (see figure 38 ). The RMs are currently removed in the following manner:

The area surrounding the ex-cell RM port is covered with plastic sheeting to contain any potential contamination. The RM tong assembly is removed from the RM, and the in-cell end of the RM is fully extended into a horizontal position. A come-along is attached to the RM and its removal rails. The RM is withdrawn from the port into a sleeved containment bag. The RM rail and come-along maintain the correct positioning. The RM is lowered onto a cart for transportation to the remote manipulator Repair Shop.

At the Repair Shop the RM is decontaminated prior to performing repair work. The installation of the RM rails has resulted in decreased turnaround time in RM replacement.

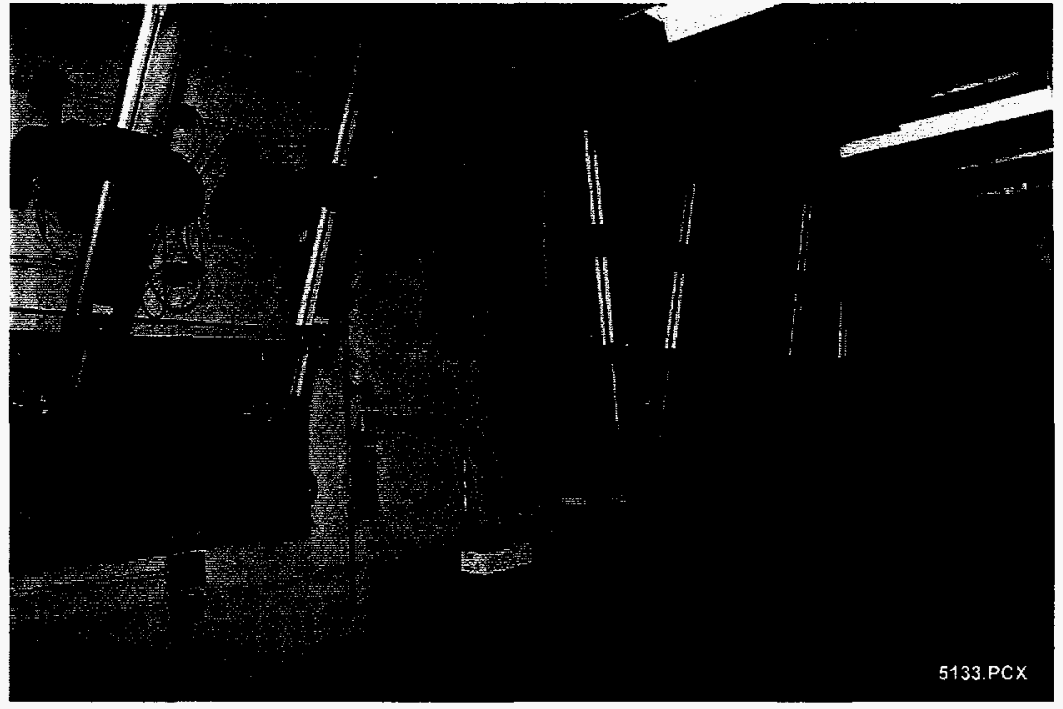

Figure 37. View of SSC with Six RMs in Working Positions 


\subsection{Remote Manipulator Jaws (Fingers)}

All of the working cells are equipped with various types of jaws (also known as fingers). The stainless steel and rubber padded jaws are most commonly used in the cells. Removable pads allow the operator to vary the pad type depending upon the type of material being handled. For example, it is very difficult to grip glass objects using stainless steel-padded jaws. However, using neoprene-padded jaws, one is able to securely grip glass objects. The opposite is true when handling larger metal objects; the stainless steel jaws are more suitable.

In certain cases it is necessary to reach areas in the cell that could not normally be reached by the RM. In order to extend the remote manipulator reach distance, standard jaw assemblies were customized to extend the reach by 10 inches (see figure 39). In addition, the jaw removal tool was also modified for use with the extended reach jaws (fingers).

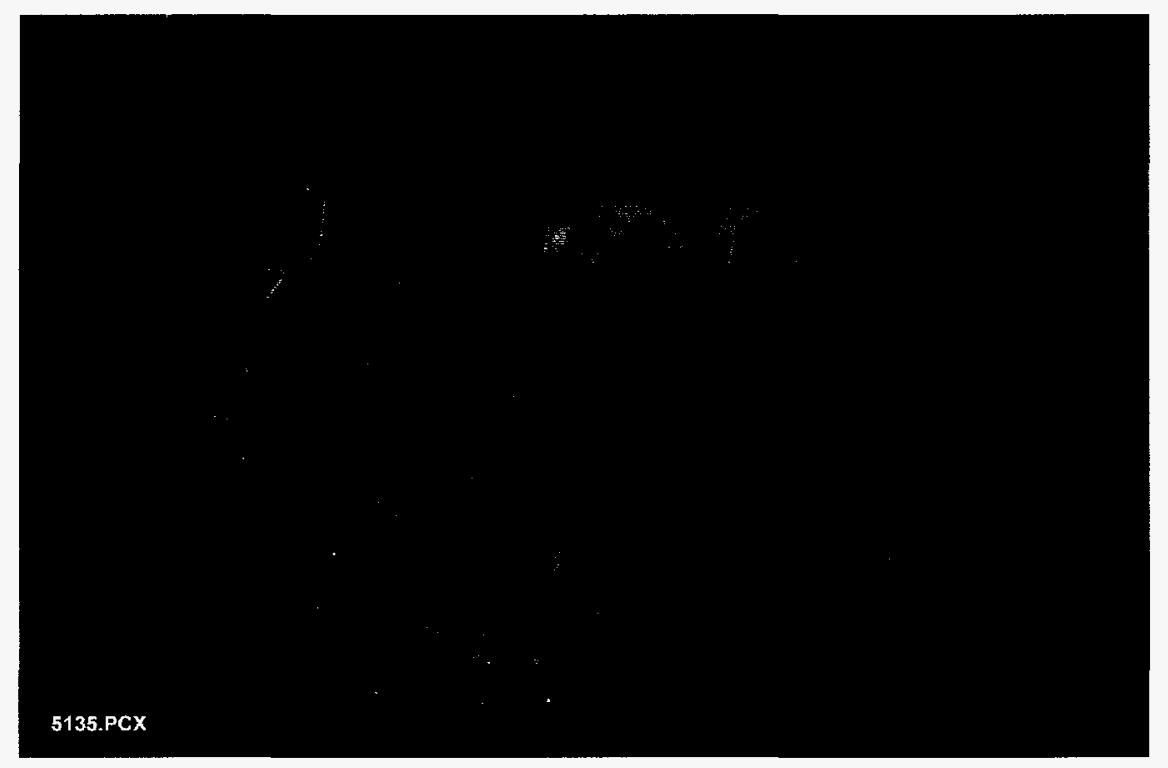

Figure 39. Ten-inch Fingers (Jaws) 


\subsection{ANALYTICAL CELL DECONTAMINATION}

The analytical cells required decontamination prior to setting up the vitrification support equipment. Through the years of IRTS operations support and process development activities, a large amount of discarded equipment and general cell waste material had accumulated in the cells.

Each of the five analytical cells and Sampling Cell 2 has an access door at the rear to allow personnel access to the cell. This feature proved invaluable in the removal of waste items and the decontamination of the cells.

\subsection{Cell Decontamination Techniques}

The general approach to decontaminating the cells involved removing the waste from a particular cell and decontaminating the waste in an ultrasonic bath to reduce the dose rate. The waste was packaged into 53-gallon drum liners for removal from the cell. The waste-filled drums are transferred to the on-site Interim Storage Facility.

The cell workpan and walls were washed down with soap and water using the RMs. Next, the cell work pans and walls were power washed to further decontaminate the cells. This process was repeated for each cell.

The floor drains and drain tubes in each cell were visually inspected for debris. Three of the drain tubes were clogged with vial bottles and other types of debris. In each case the clogged tubing was replaced with new tubing.

Manned entries were made into each of the ACs to remove debris that had collected on the floor of the cell. Six-foot-long, hand-held extended reach tools were used to reach underneath the workpan to remove debris while the operator stood at the rear cell door. After the cell floors were cleaned, the cell walls and floor were decontaminated by power washing with water and detergent. 


\subsection{ANALYTICAL CELL MODIFICATIONS}

Several modifications were made to the hot cells and surrounding area in preparation for A\&PC support of the vitrification process.

\subsection{Fire Extinguishers}

Each cell has a dry chemical fire extinguisher system that is composed of two 8-lb dry chemical cylinders piped in through a cell penetration (see figure 40). A temperature sensor is located in each cell. If the temperature in the cell exceeds approximately $190 \mathrm{~F}$, the alarm panel is activated. Upon visual confirmation that a fire hazard is present in the cell, a manual pull station is activated to release the dry chemical into the cell. The manual system replaces an automatic deployment system that occasionally malfunctioned.

\subsection{Transfer Cart Refurbishment}

The primary means of transferring materials between the analytical cells is by the intercell transfer cart (see figure 41). The cart wheels are positioned on rails made of angle iron. The rails are supported approximately 12 inches above the floor of the cell. Below the rails is a 10 -inch Hastelloy ${ }^{\mathrm{TM}}$ ventilation duct that runs the length of the analytical cells. The transfer cart moves along the rails underneath the cell workpan from SC2, through the five ACS to the SSC, a total length of 48 feet.

In front of each cell is a control panel for the cart with four buttons, labeled "Call," "Release," "Jog Forward," and "Jog Reverse." To move the cart from one cell to another, the "Release" button is pressed at the resident cell, which illuminates the release indicator light on

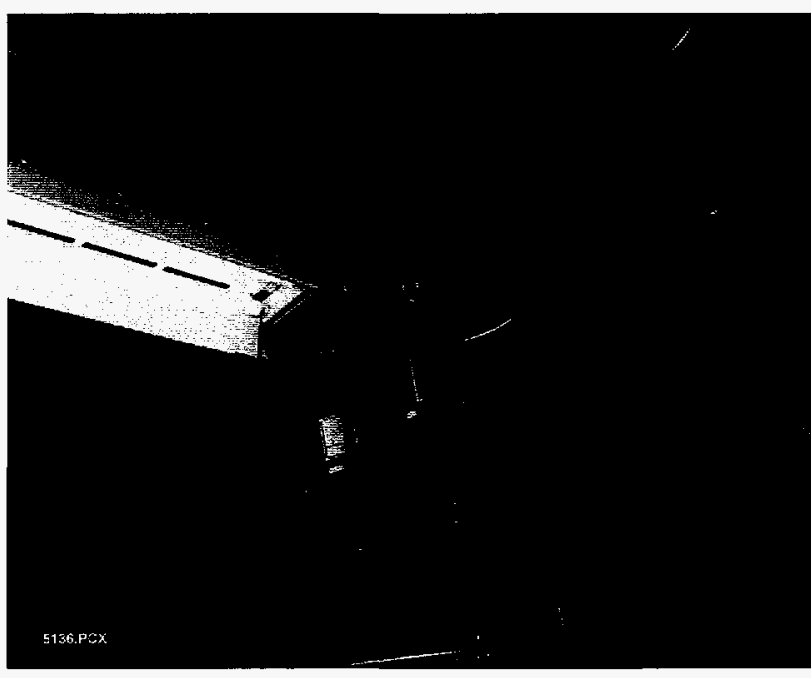

Figure 40. Dry Chemical Fire Extinguisher

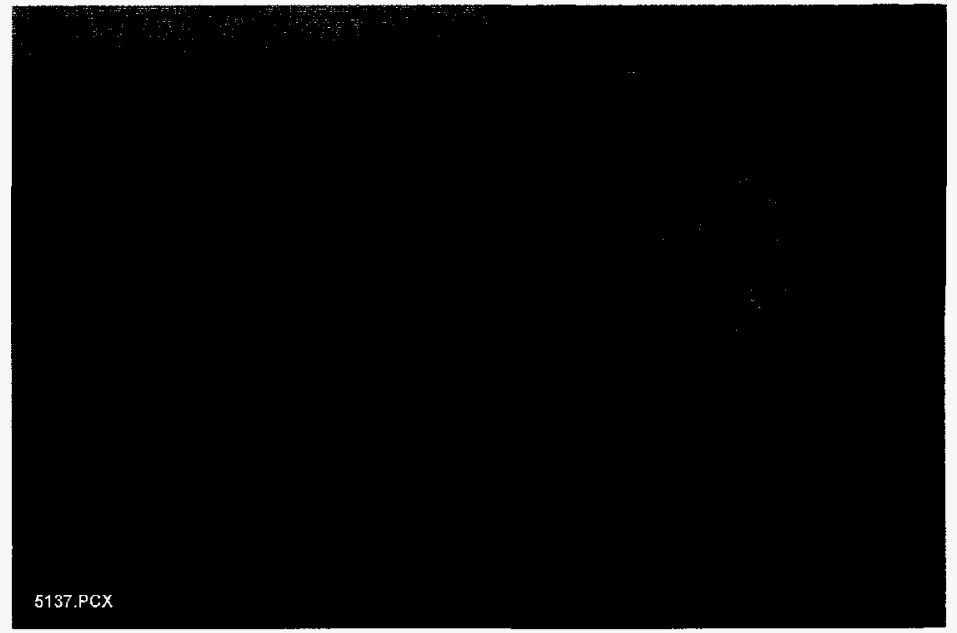

Figure 41. Transfer Cart each control panel. The "Call" button is pressed on the panel at the cell to which the cart is to be sent. The other buttons on the control panel are self-explanatory.

The transfer cart is necessary for cell operations. Samples are transported from the SSC (where they are received via the SGN system) to the other cells for preparation, analysis, and removal from the cells via the transfer drawers.

It was decided that the transfer cart should be refurbished to insure continuous operation during vitrification. A manned entry was performed to replace the cable shieve, axles, and wheels as preventive maintenance. 
A major problem in the past had been the transfer cart wheels derailing and becoming jammed against the rail supports. The buildup of plastic bottles and other debris on the rails eventually caused the wheels to ride up over the debris and off the rail. Due to limited visibility in the handling operation, many of the bottles on the rails had been accidently dropped while being taken in and out of the transfer cart tray.

A funnel-shaped device was attached to the outside surface of the tray to increase the likelihood that a bottle, dropped while being removed from the tray, would land back in the tray and not on the rail. The transfer cart tray is located approximately 8 inches below the cell workpan surface. Access to the transfer cart tray is gained by a sliding lid in the right side workpan. The access door opening dimensions are approximately $14 "$ $x$ 13". The transfer cart tray dimensions are 10" x 13". The funnel device was made from a brush bristle that was stiff enough to direct the falling bottle into the tray, but flexible enough not to cause any interference problems with the bottom of the workpan or piping supports as the transfer cart was moved from cell to cell on the rails (see figure 42).

\subsection{Workpan Modification}

Each of the five analytical cell working surfaces is composed of two stainless steel workpan sections, which are approximately 3 ' $\mathrm{W}$ by 6' $\mathrm{L}$ with a center drain trough approximately $3^{\prime \prime} \mathrm{W}$ by $6^{\prime} \mathrm{L}$. The right side workpan has a 14" $\mathrm{x} 13$ " opening with a sliding cover to allow access to the transfer cart tray. If the transfer cart derails on the right side of the workpan, it is possible to use a RM to reach the cart and often reposition the cart back on the rail through the transfer cart access door.

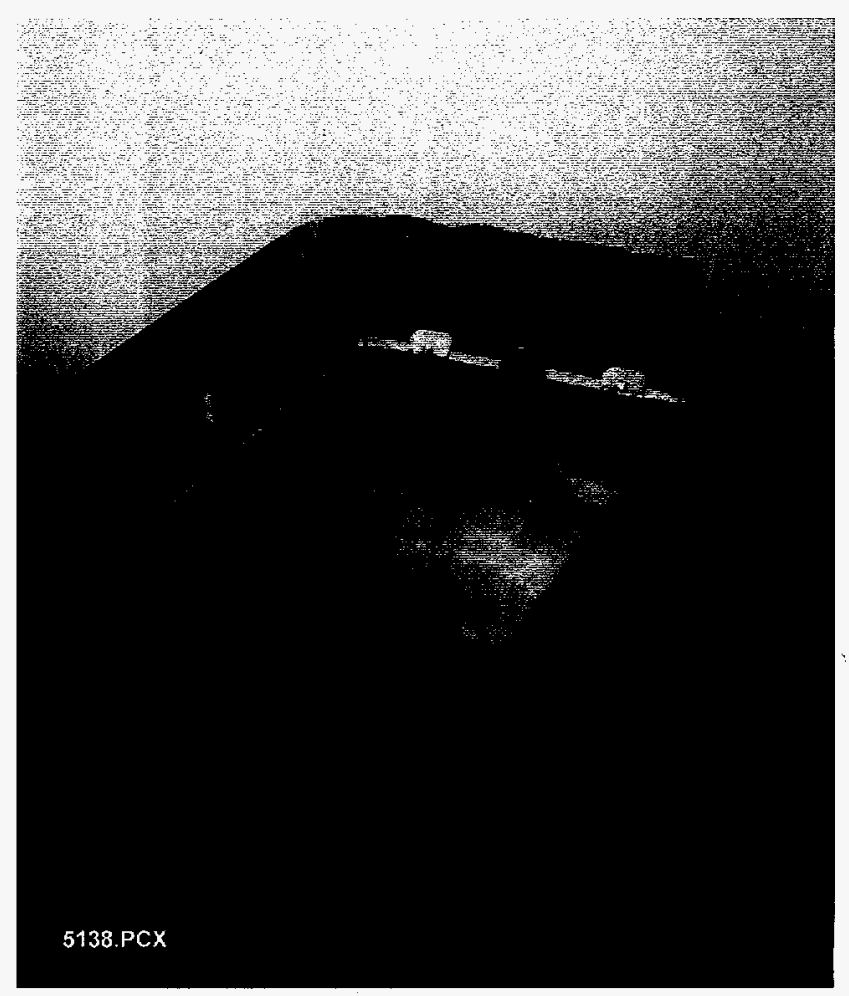

Figure 42. Transfer Tray

The left side workpan section, however, has no access opening and weighs approximately $90 \mathrm{lbs}$. It cannot be removed using RMs. In the past, if the transfer cart derailed on the left side of the cell, a personnel entry had to be performed. Personnel had to crawl underneath the workpan and replace the cart onto the rails. Due to the anticipated high dose samples that would be present in the cells and the potential high contamination levels, a personnel entry is not desirable. Access to the left side of the work pan was mandatory to recover from transfer cart derailments.

A new left side workpan was designed that included an opening to allow the RM to gain access to the space underneath the workpan. The design features a hinged lid to cover a 31 " wide by 11 " deep opening. The hinge feature allows the cover to be securely positioned over the opening while providing unencumbered access. Two handles were provided to allow the RMs to grab and swing open the hinged cover. The cover has a half-inch berm on two sides to help prevent bottles from falling off the elevated cover. The hinged cover in the closed position was also designed to support equipment, thereby maximizing cell work space (see figure 43).

The removal of the existing workpans was complicated by the rear door access to the cells that limited access space to one person. Space was extremely limited because the workpan has a width of 33 inches and the door width is only 36 inches. It was necessary to tilt the workpan to allow it to be removed from the cell. 
Due to the bulky size and weight of the workpan, special tools were developed to allow one person to enter the rear of the cell to lift the workpan and slide it out of the cell into a containment bag. The first tool was designed to be placed in the center trough and hook onto the lip of the workpan that overhung the trough. As the handle of the tool was pushed down, the workpan was lifted approximately 12 inches off of its support framework.

Rollers made from a ball transfer-mounted on a $2 " \mathrm{x}$ 4 " wooden support were placed between the bottom of the workpan and the support framework. The rollers allowed the workpan to be turned and posi-

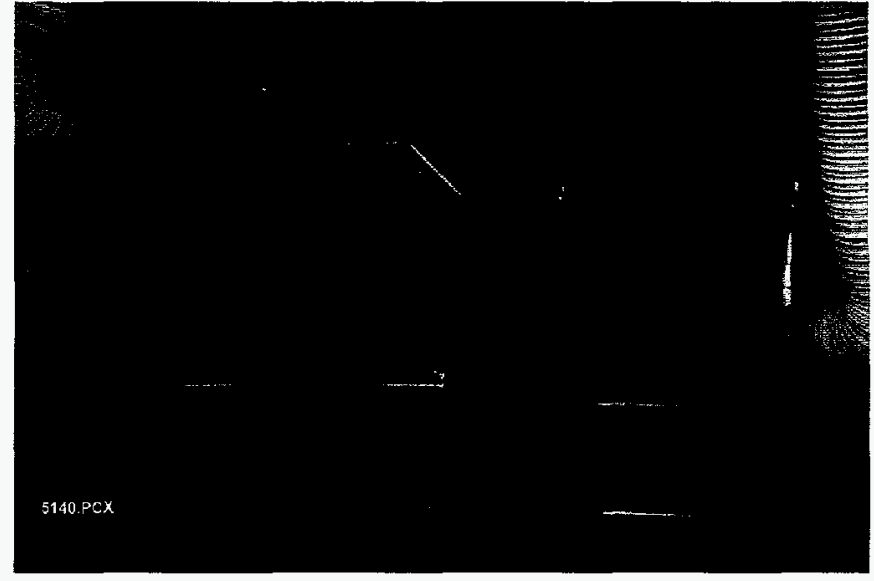

Figure 43. Hinged Work Pan tioned without lifting. The workpan was slid out of the rear of the cell into a plastic containment bag. The new workpan was placed in the cell by reversing the process. New workpans were successfully installed in all five ACs. The ACMU and a plywood mockup of the cell were used to refine the workpan removal and installation techniques (see figures 44 and 45).

\subsection{Drain Pipe Covers}

The left side workpan has a $6 " \mathrm{n} 7$ " notch to allow two drain pipes, which are not presently in use, to be located above the workpan. The 1" raised lip on the workpan was not sufficient to prevent sample bottles from accidently falling onto the floor of the cell. Stainless steel covers were fabricated to cover the pipes to prevent materials from dropping through this opening and to provide usable storage space. The covers are lightweight and can be easily handled using the RMs.

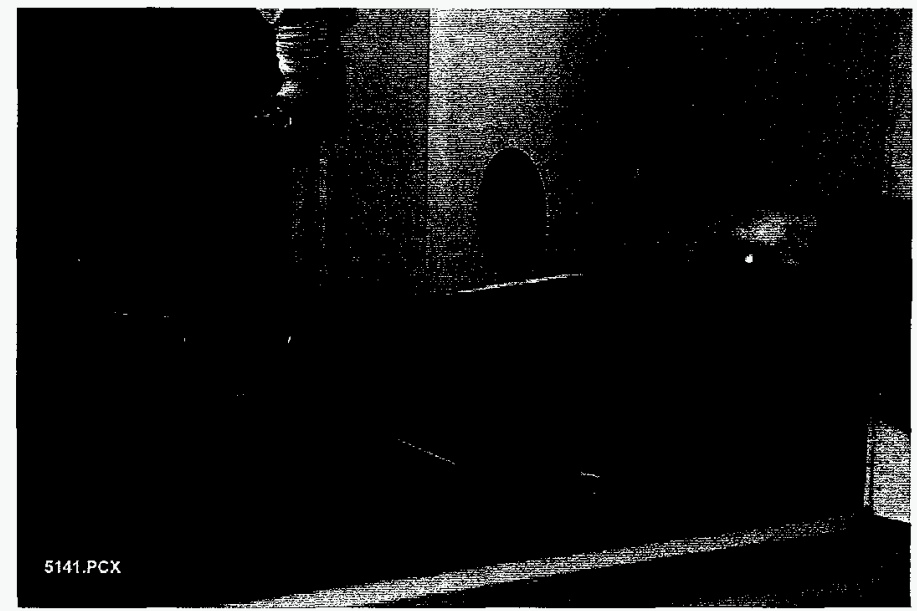

Figure 44. Work Pan Lifting Tool

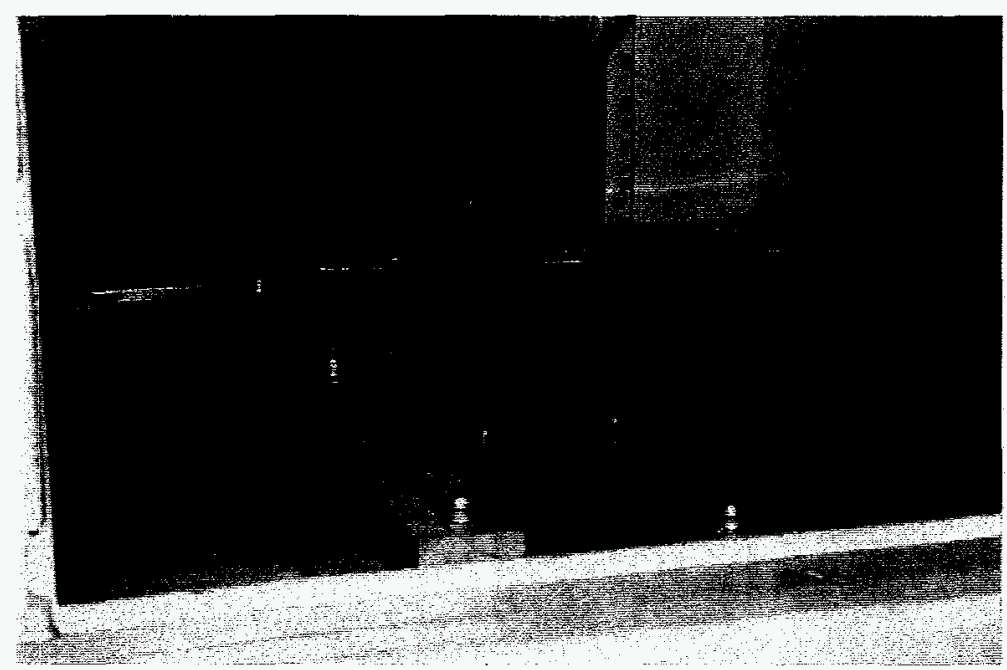

Figure 45. Work Pan Rollers 


\subsection{WASTE HANDLING}

Waste handling is a critical, often overlooked aspect of operating a facility such as the A\&PC analytical hot cells. All items put into the cells; including equipment, instrumentation, sampling devices, samples, and plasticware; must eventually be removed. Before any new item is placed in the cells or any new operational procedure is begun, the byproducts are evaluated from a waste handling perspective. The new application must be appraised in terms of the following questions to ensure the smooth flow of materials into and out of the analytical cells:

- What type of waste will be generated?

- How much of each waste will be generated?

- What is the expected dose rate of the waste?

- What are the expected contamination levels?

- Can the item be easily handled using RMs?

- Can the item be transferred between cells on the transfer cart?

- Is size reduction necessary or can the item be disassembled?

- How can the item be decontaminated?

- Is segregation of the waste needed?

- How is the waste going to be packaged for removal from the cells?

A similar evaluation is undertaken for all liquid and chemical waste streams generated in the hot cells. The key to effective waste handling is to identify and develop suitable removal pathways for specific waste forms.

There are five primary pathways for removal of liquid and solid waste materials from the analytical cells. Liquid waste is transferred from the cell to a collection tank through a floor drain that is located in each cell. Slurry waste is transferred to the same collection tank through a flush pot to transfer the slurry solids. The flush pot has been piped straight (no traps or horizontal sections) to the collection tank to minimize settling of solids in the plumbing.

Small items capable of fitting into a 7" diameter by 9 " long canister can be removed or placed into the cell by use of a $190 \mathrm{~mm}$ transfer canister. This is also the primary method of removing samples from the cells for analysis.

The bulk of all solid waste generated in the cells is removed periodically in a drum liner during a personnel entry through the back door of AC5. Large solid waste can be removed during personnel entries to the other ACs if necessary.

The last waste removal pathway is the use of a two-foot square hatch cover located in the ceiling of the SSC. The hatch would be used to remove large objects from the SSC that cannot be size-reduced and transferred to one of the ACs for removal through the rear door. Opening of the SSC hatch is an extremely rare occurrence. 


\subsection{Flush Pot for Slurry and Liquids}

One issue in the hot cells that was critical to future cell support for vitrification was disposal of the highly radioactive samples that would be received for analysis. Permission was obtained to send powdered glass and diluted slurry from the analytical cells back via intervening tanks to $8 \mathrm{D}-2$, the high-level waste tank, preventing collection of excessive waste during the vitrification campaign.

To facilitate disposal of waste slurry and ground glass to Tank 8D-2, a flush pot was designed with rinsing capabilities for the RBG sample bottles and other bottles. There are four nozzle positions to flush four RBG bottles at a time. The rinsing operation fills a 4-liter reservoir, the drain valve is opened, and the entire volume of rinse water and residual samples is flushed straight to the 7D-14 (laboratory waste) tank, bypassing a drain trap that would have allowed dropout of the slurry particles. The piping has been installed so that there are no horizontal sections that would allow settling of the solids. The water is allowed to run for one additional minute after opening the valve to

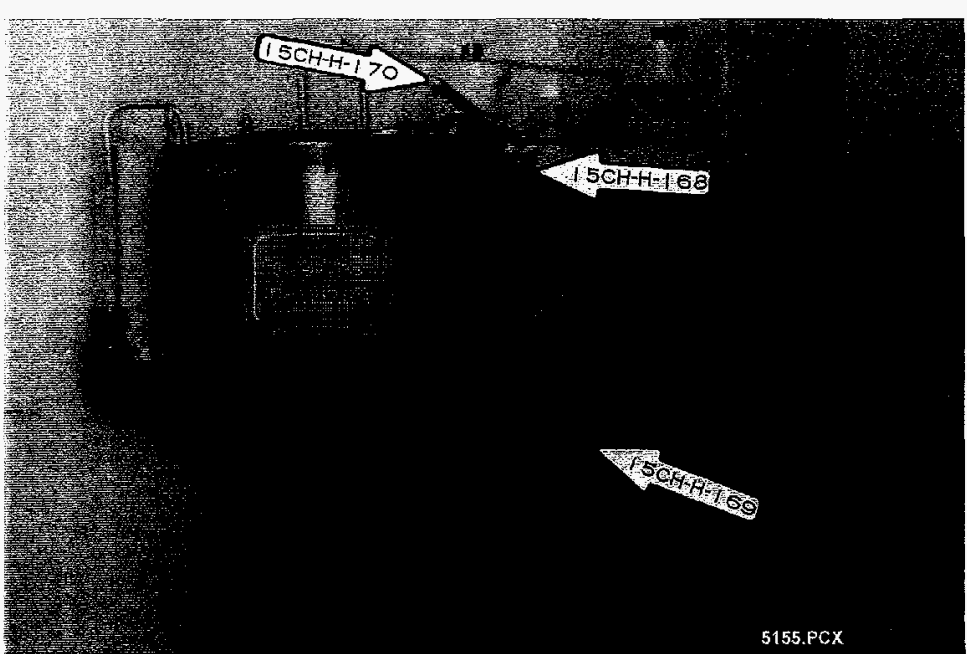

Figure 46. Flush Pot ensure that the solids do not coat or settle in the drain piping.

A remote installation of the hot cells prototype flush pot was evaluated in the ACMU to work out any problems with the on-off ball valve, the sight glass, the spray ring filler, and the pipe/tube dimensions. The final version of the flush pot was installed in AC4 via personnel entry in the Analytical Decontamination Aisle (ADA) (see figure 46).

\subsection{Decontamination of Waste}

Drum liners of solid waste that are removed from the cells must have a dose rate of less than $100 \mathrm{mR} / \mathrm{hr}$ in order to be accepted by the on-site Waste Storage Facility. Since many samples the lab will receive during vitrification would be $>40,000 \mathrm{mR} / \mathrm{hr}$, waste decontamination would be essential to meet the $100 \mathrm{mR} / \mathrm{hr}$ limit.

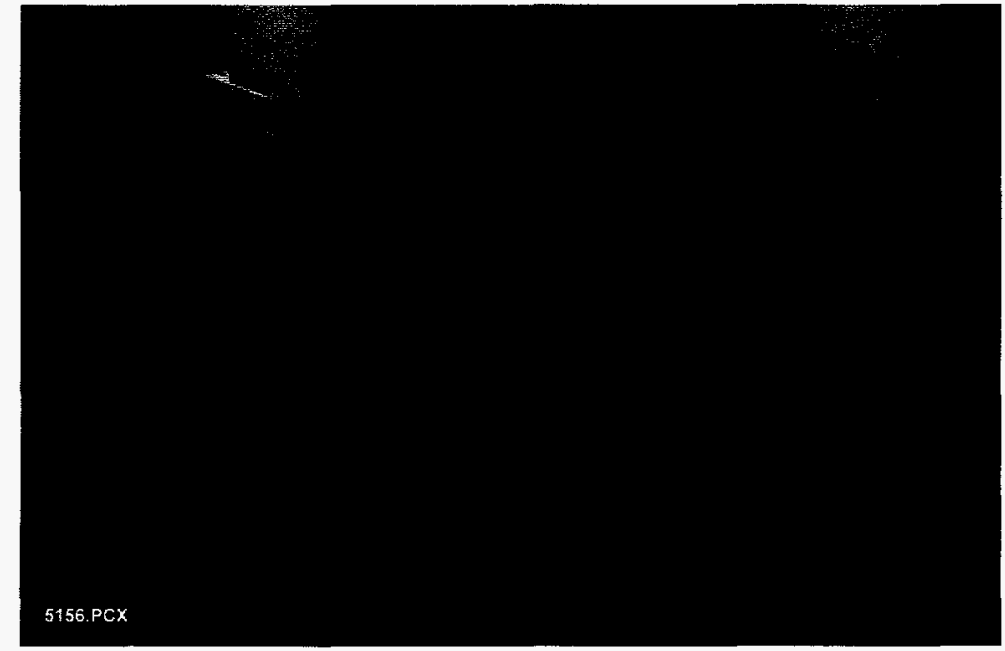

Figure 47. Ultrasonic Bath 
To facilitate decontamination of solid waste, a 5-gallon ultrasonic bath was modified for remote operation. The ultrasonic tank drain was rerouted from the rear of the unit to the side for easy access. A RM operable ball valve was installed to allow the removal of contaminated bath water (see figure 47). Stainless steel baskets are used to contain the waste material as it is being decontaminated in the bath.

The decontamination process involves four steps: First contaminated waste material is cleaned in the ultrasonic bath using water and detergent. The second part consists primarily of rinsing the materials with water to remove any residue. Third, the decontaminated waste is allowed to air dry. (All waste removed from the analytical cells must be dry.) The fourth step is the sorting of waste using a gamma Geiger-Müller (GM) detector (a dose rate probe) to determine the dose rate of each piece. Typically, if the dose rate of any decontaminated waste is higher than the cell background $(40 \mathrm{mR} / \mathrm{hr})$, the decontamination process is repeated for those pieces. Waste that has been sufficiently decontaminated is placed in the drum liner for disposal.

\subsection{Size Reduction}

During the decontamination and refurbishment of the analytical cells many metal and plastic items required size reduction to facilitate transfer in the cart to the ultrasonic bath for decontamination. The size reduction techniques involved the use of both a band saw and a reciprocating saw which had been modified for RM use. Adaptations of the saws include motor activation, blade speed, blade replacement, and remote manipulator grips to allow remote handling.

\subsection{Waste Packaging - 53-gallon Poly Liner}

After the waste has been decontaminated to acceptable dose levels, the waste is usually packaged into 53-gallon poly liners. Typical wastes include plastic bottles and other laboratory plasticware. A manned entry with supplied air into the ADA is required to open the rear door of the cell to replace the full poly liner with an empty one. During the manned entry the lid is secured to the liner and the liner is surveyed by Radiation Protection personnel to ensure that all radiological requirements are met (see figure 48).

Upon removing the liner from the ADA, the liner is placed into a drum. The contents of the drum are considered suspect transuranic (TRU) waste for storage classification purposes. During the support of HLW vitrification activities, the analytical cells generate one filled 53-gallon waste liner every seven to 10 days.

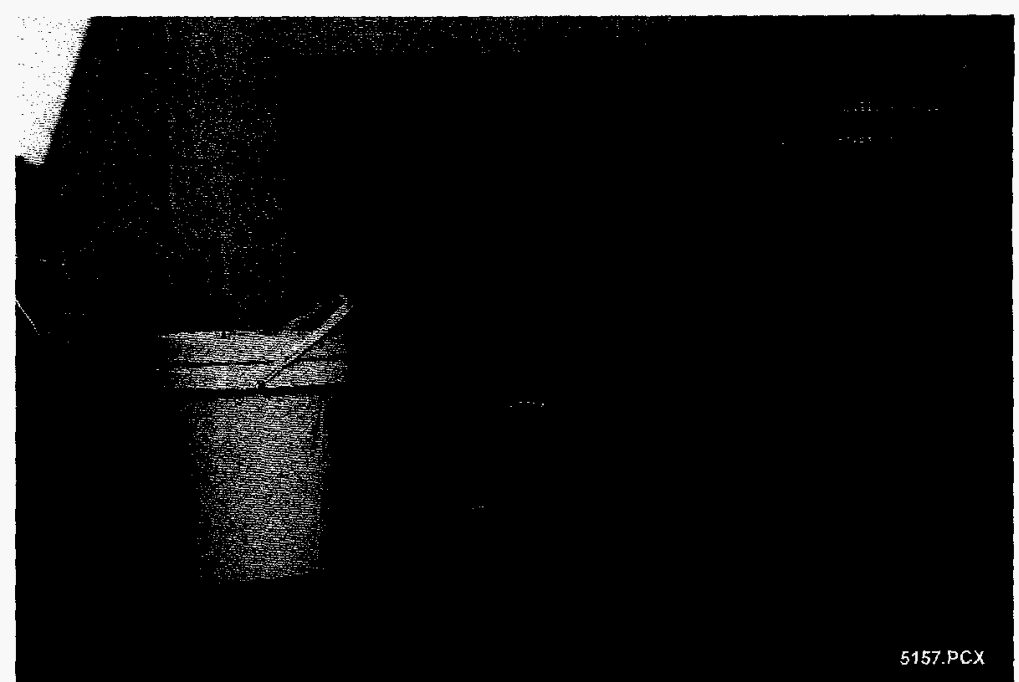

Figure 48. Cell Entry - Radiation Protection to Remove Drum Liner 


\subsection{Waste Packaging -- 5-gallon Pails}

Glass, metal, and other wastes with potentially sharp points that could puncture the poly liner and have a dose rate of less than $100 \mathrm{mR} / \mathrm{hr}$ are packaged into 5-gallon plastic pails. Each pail is assigned a unique number and its contents are recorded on a waste inventory sheet for tracking. When the pail is filled, its lid is fastened. The sealed pail is finally placed in the 53 -gallon poly liner for removal from the cell (see figure 49).

\subsection{Waste Packaging -- 2-gallon Cans}

Wastes that can be packaged into 2-gallon stainless steel cans have a dose rate of less than $1500 \mathrm{mR} / \mathrm{hr}$. The can is $9^{\prime \prime}$ in diameter and $10^{\prime \prime}$ tall, with a braided wire lifting bail (see figure 50). A lid is secured to the can after it is filled. A manned entry with supplied air is required to open the rear door of the cell to remove the stainless steel can. Two double-bagged waste cans are placed into a 55-gallon drum that contains 6 inches of concrete for shielding.

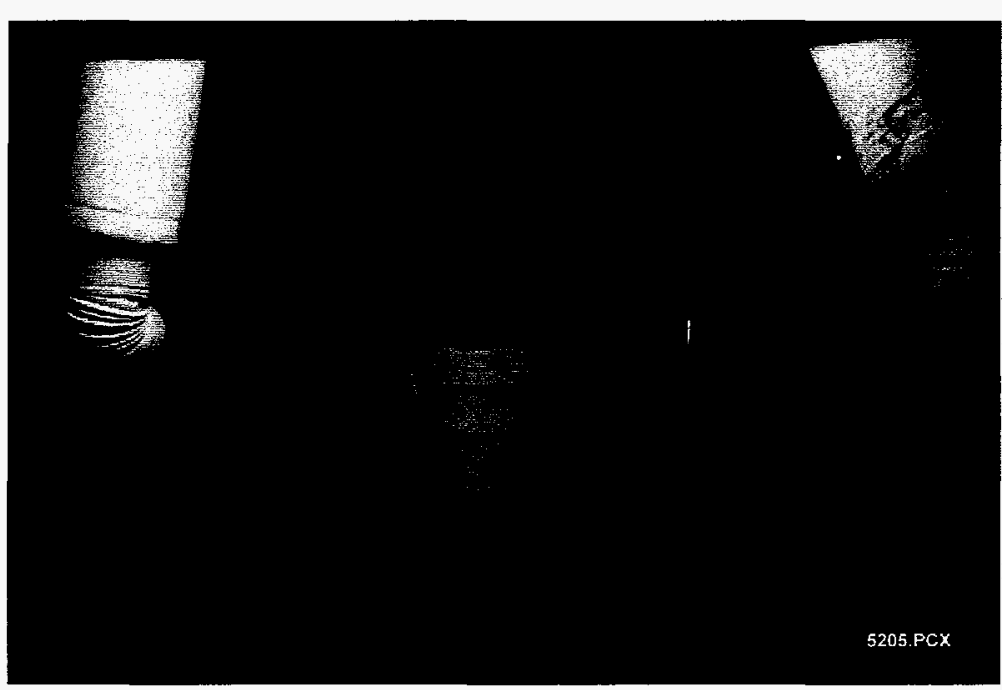

Figure 49. Five-gallon Plastic Pail

Each shield drum weighs approximately $1000 \mathrm{lbs}$. The drums are hoisted in through a roof hatch in the Off-gas Aisle (OGA) for staging. Typically, two filled waste cans are passed from the ADA to the OGA and placed in the shield drum. The closed drum is then hoisted back out through the hatch for transport to an appropriate storage area.

\subsection{Waste Packaging - Large Items}

Large items, such as in-cell instrumentation or laboratory equipment, that have a dose rate of less than $100 \mathrm{mR} / \mathrm{hr}$ can be bagged and taken out of the cell. A piece of equipment is decontaminated as much as is practical in-cell. A manned entry is required to remove the equipment from the cell and place it in a plastic bag or custom-made container (see figure 51). The bagged equipment is placed in a TRU waste box for storage.

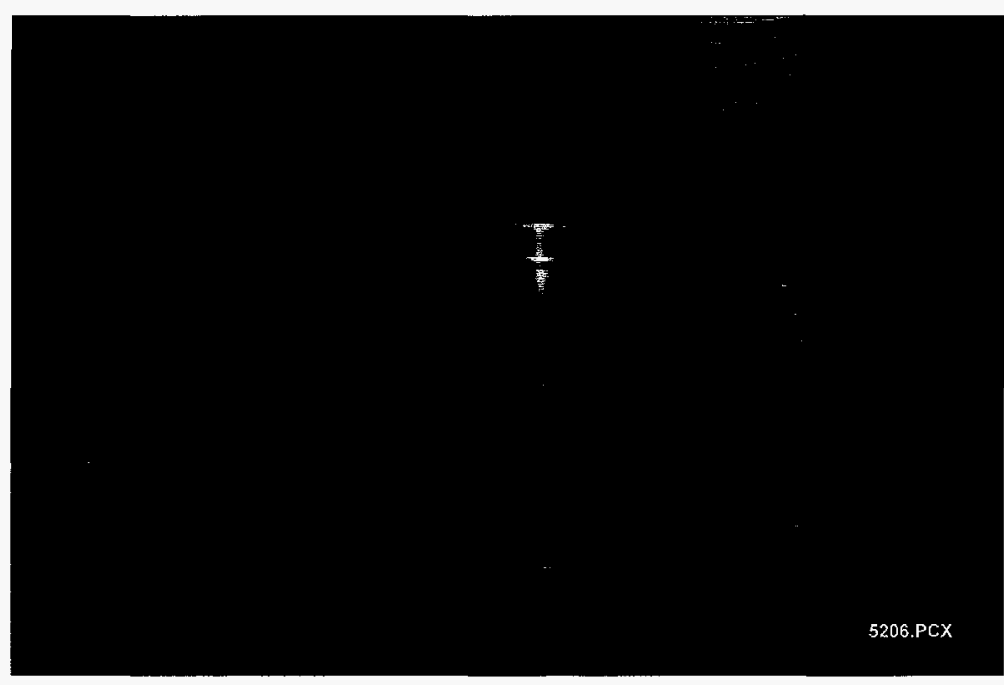

Figure 50. Two-gallon (Stainless Steel) Waste Can 


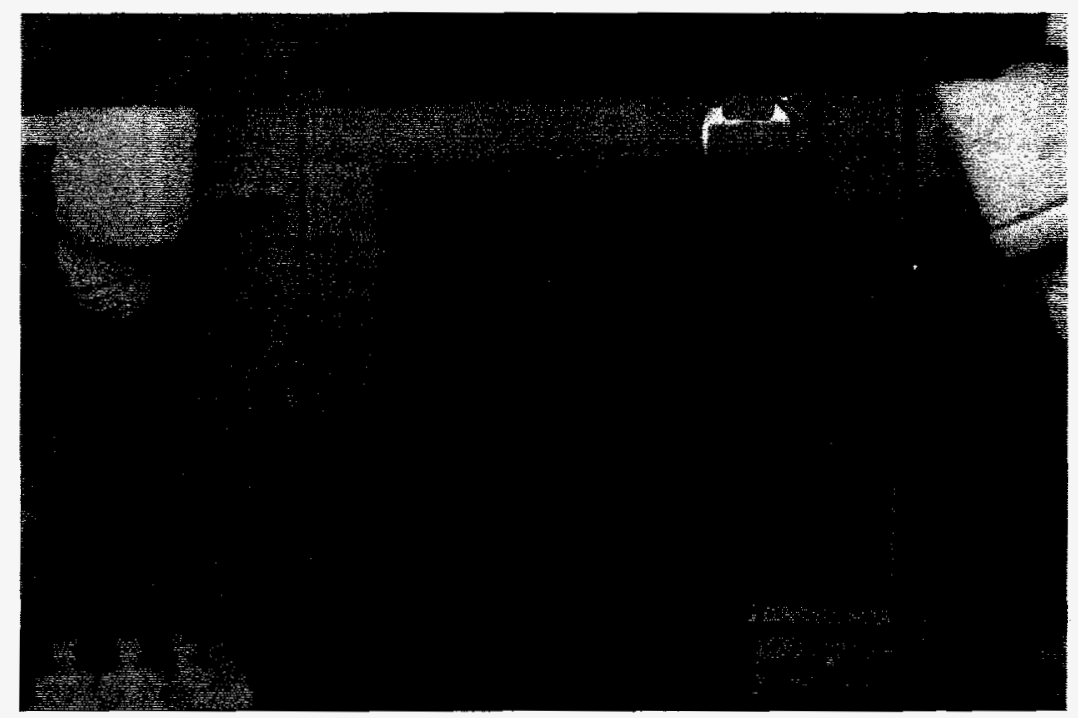

Figure 51. Example of Removal of a Large Item 


\subsection{SAMPLE STORAGE CELL (SSC)}

The SSC is a large cell adjacent to the five ACs. It is approximately $6^{\prime}$ deep by $25^{\prime} \mathrm{L}$ by $6^{\prime} \mathrm{H}$. The intercell transfer cart services the SSC and is used to transfer small items into and out of the cell. Large objects are not readily transferred into the SSC because it lacks the rear door access that is available in ACs 1-5. Large objects require access via the SSC hatch. The laboratory end of the SGN pneumatic sample transfer system is located in the SSC. There is also a "drop tube" for placing small bottles in-cell. Manned entries cannot be performed to transfer materials and equipment into or out of the SSC.

In the past, the SSC served as the main storage area for HLW samples and the staging area for the retrieval of HLW samples from the sampling and containment devices. As a result of these sampling operations and the limited movement of materials out of the SSC, a large quantity of HLW-contaminated materials was accumulated.

\subsection{SSC Decontamination}

The first operation to refurbish the SSC was the removal of accumulated cell waste. The bulk of waste was composed of yellow plastic sheeting, wipes, plastic and glassware, and high-level waste sampling devices. Waste items contaminated with high-level radioactive waste had been stored in the cells due to the inability to meet the requirements for removal.

A large quantity of waste contaminated with high-dose-rate material which had been stored in the SSC needed to be taken to the analytical cells for decontamination and packaging. Several large waste items required size reduction in the SSC for transport on the cart to the cell containing the ultrasonic bath.

A band saw and a vise stand were modified for in-cell use with RMs in the SSC for size reduction. A personnel entry was required to transfer the modified band saw assembly and a specially made flat bed cart into the hot cells. This entry required the operator to crawl underneath a 3' $\mathrm{H}$ workpan to gain access to the transfer cart rails. The operation was further complicated by piping and supports that limited access to the rails and limited the size of equipment to a maximum dimension of $12 "$. The flat bed cart and saw assembly were transferred into the cell and placed onto the transfer cart rails.

The saw and vise stand were reassembled once they were positioned onto the transfer cart. A six-foot handle was used by the cell entrant to push the transfer cart from AC5 into the SSC. A remotely operated hoist lifted the saw assembly from the cart and positioned it on the cell work surface. The cart was returned to AC5 and stored underneath the workpan for future use. The portable band saw was retrieved for disposal upon completion of size-reduction activities.

The speed of the band saw was controlled by an in-cell variable control transformer. A ball valve was located at the work station to activate the pneumatic vise to secure materials for cutting. A tension spring was connected from the band saw to the overhead hoist hook. By raising or lowering the hoist to adjust the tension in the spring, the saw could be easily raised or lowered using a RM. The saw had been modified to allow removal and installation of saw blades by RMs.

The saw was used to size-reduce the stainless steel HLW samplers and plastic primary containment devices into 18 " sections that could be handled by the RMs. The pieces were transported on the transfer cart to AC5 for decontamination and packaging. 
The floor drain located in the SSC had become obstructed, resulting in a backup of water. A modified vacuum cleaner with a knockout pot was used to remove the debris from the drain line by placing a tube down the floor drain pipe and sucking the debris out of the pipe. The drain debris was collected in the 4-gallon knockout pot, which had been made from two of the 2-gallon stainless steel cans. The vacuum cleaner was also used to collect shavings generated by the size-reduction activities associated with the band saw and other cell debris. Several knockout pots were used to collect and contain the floor debris. The knockout pots were removed from the cell and packaged into cement shield drums in a fashion similar to the packaging of the 2-gallon stainless steel cans.

Pieces of unused equipment were cut up using a modified electric hacksaw (reciprocating saw). The hacksaw was small enough to be moved from cell to cell using the transfer cart. Once the unused equipment had been size-reduced, it could be decontaminated in the ultrasonic bath and removed during a manned entry into the cell as described earlier.

\subsection{SSC Modifications}

To prepare the SSC for vitrification support, pathways were needed to provide utilities (air, water, electrical power, lighting), fire protection, and controller cabling from the ex-cell environment. Material transfer capabilities were also required.

Four penetrations in the SSC wall were created by core boring through the concrete walls to provide pathways for the utilities. The penetrations were fitted with stainless steel liner flanges. Various types of cabling and tubing carry the utilities through the penetrations. Electrical power is distributed throughout the cell using incell receptacle boxes.

Power cabling and thermocouple wiring were secured and routed along the inside surface of the cell wall at four different levels using WVNS cable support brackets. To secure the brackets, mounting studs needed to be added to the stainless steel sidewall. The threaded studs were welded onto the stainless steel wall using remotely operated welding equipment (see section 10.5.1).

Liquids are transferred into the cell through the use of a $100-\mathrm{mL}$ dispensette with a 1 -gallon jug as a reservoir. All liquid lines are equipped with check valves to prevent backflow of the materials out of the cell.

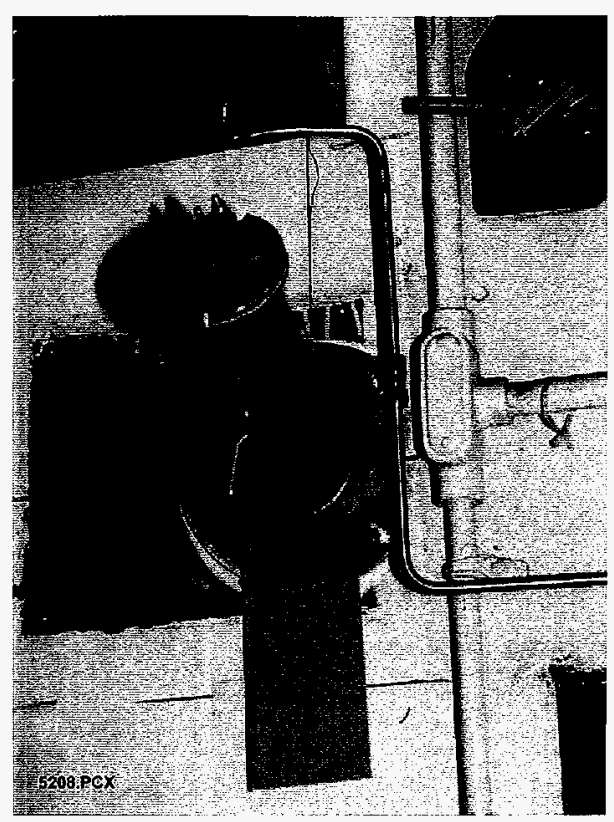

Figure 52. Transfer Tube, Ex-cell

One penetration was core-bored at a 30-degree angle and fitted with a stainless steel "drop tube." Small plastic bottles can be transferred into the cell using the transfer tube, the top of which is located ex-cell. The top of the drop tube is fitted with a pivoting lid that is opened to gain access to the transfer tube. A plastic bottle (up to $250 \mathrm{~mL}$ ) is placed into the top of the transfer tube and drawn down into the cell by gravity and negative pressure. The bottle comes to rest against a metal plate that covers the bottom end of the tube. The bottle is removed through an opening in the side of the tube using an $\mathrm{RM}$ (see figures 52 and 53). 


\subsection{Hatch Entry for Apparatus Support}

Large equipment; such as the remote furnaces, mixer/mill, and drying oven; was lowered into the SSC through a 2' $\times 2^{\prime}$ ceiling hatch. A tent was set up over the hatch cover tc provide contamination containment. Sufficient floor space was provided for the removal and storage of the hatch plug by relocating a stairway and some overhead components. A hoist was used to lift the $2000 \mathrm{lb}$ hatch cover.

The equipment was lowered by ropes ten feet down onto the cell work surface. The grapple was removed from the equipment in-cell using an RM.

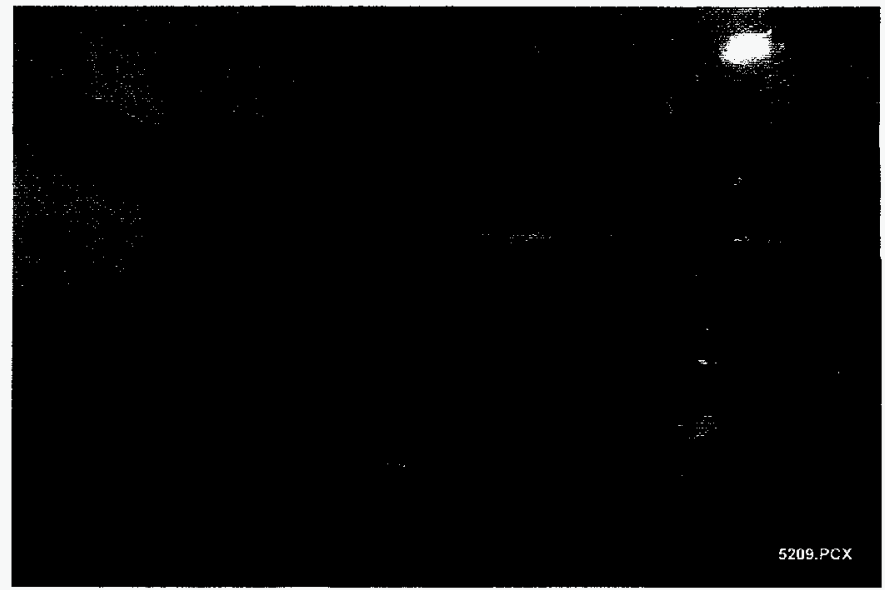

Figure 53. Transfer Tube, In-cell Equipment was lowered in specific sequence to facilitate organized arrangement of the equipment in the narrow space. Items located the farthest away from the hatch opening were placed in first.

Cables and power cords were connected to the equipment and energized. The extensive ductwork for the furnace exhaust system was remotely assembled. The exhaust ductwork is used to remove hot air from the furnace to prevent the buildup of excessive heat in the SSC.

\subsection{Pneumatic Lift}

Small wet aliquots are removed from RBG bottle samples in the SSC using a remote pipetter mounted on a pneumatic lift that raises and lowers the pipetter to the correct height during aliquoting (see figure 15). This system helps reduce tedious mechanical operations with the RMs. The lift is used with a magnetic stirrer and a positioning plate that locates samples in the correct position under the pipetter.

The lift is fabricated mainly of stainless steel with a base, pneumatic cylinder with shaft, and top stand fitted with a mounting post (where the pipetter is clamped). Electronic solenoids mounted at the base control the compressed air intake and exhaust. A receptacle box with a receptacle, also at the base, provides power to the solenoids. A jumper cord with connectors at both ends connects the lift to in-cell power. The solenoids are activated ex-cell via a joy stick that acts as an on/off switch. Compressed air (at about 16 psi) and pipetter control lines are supplied ex-cell via SSC penetrations.

\subsection{In-cell Receptacle Boxes}

Stainless steel boxes fitted with connectors and standard 2-pole, 3-wire ground receptacles supply $110 \mathrm{Vac}$ power to in-cell equipment. The boxes are welded to a self-supporting base that can be fastened to studs located on the SSC back wall (see figure 54).

The boxes are rectangular with three receptacles on top and three duplex 2-pole, 3-wire ground receptacles on the front face. One large receptacle located

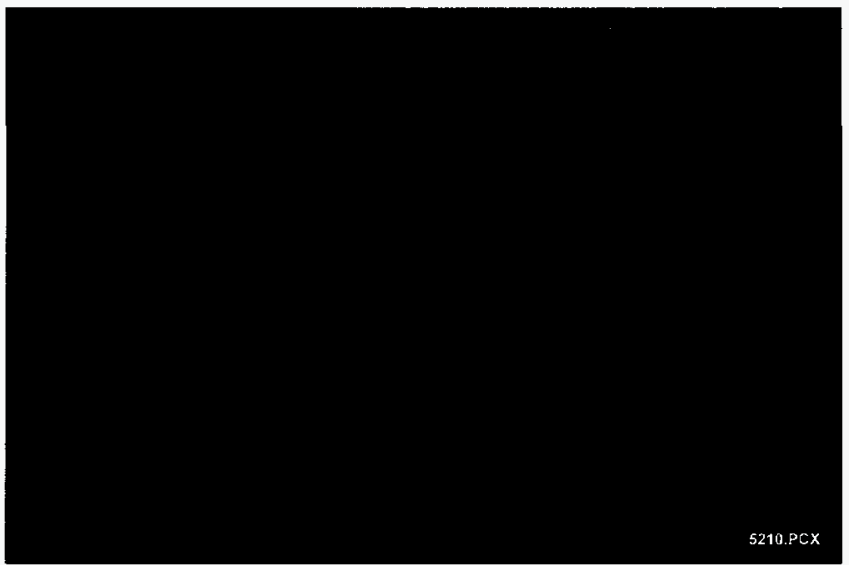

Figure 54. SSC Cord Brackets and Receptacle Box 
on one end receives a 14-pin connector. The 14-pin connector supplies power to the box from an ex-cell power source. Power to each receptacle is controlled by switches mounted ex-cell for easy access while working at the SSC. The boxes are elevated above the SSC floor for cell decontamination.

\subsubsection{In-cell Stud Welding}

Cord racks and receptacle boxes are fastened to the back wall of the SSC by $3 / 8$ " stainless steel studs and nuts. The studs were welded into place remotely using a modified stud welder. The welding process was developed and practiced at the VTF by Design Support Engineering and Maintenance personnel and qualified to meet American Welding Society standards.

The stud gun was fitted with RM grips and attached to a base. The base supported the gun upright so the RMs would not have to support the weight of the gun while welding. This provided a steady gun that could be repositioned with the RMs. The RM grips also provided a way to apply pressure symmetrically to the stud gun for good stud contact with the SSC wall.

A metal arm with a notched end fitted near the nozzle of the gun provided a means for a pair of studs to be welded with the correct spacing. Once one stud was in place the notched end of the arm would be placed against the stud, locating the gun at the correct distance for the next stud. Correct spacing was important because the cord racks were fabricated with two fastening arms with slots that were made to be slid over two studs, then fastened down with nuts (see figure 54). The nuts had washers welded to one side to prevent the nuts from jamming in the remote socket tool. The flared nuts also secured the racks and receptacle boxes better on the SSC wall.

Power to the stud gun was supplied ex-cell. Cords from the power source were placed through SSC penetrations. Connection of the cord to the stud gun with the RMs was made by marking connectors for proper alignment. A foot pedal was added to take the place of the gun trigger which acted as a switch to supply the current to the gun.

Upon completion of welding, cords were cut ex-cell and pulled into the cells for disposal. The gun was also disposed of in-cell.

\subsection{Furnaces}

Sample preparation during the vitrification campaign requires use of in-cell furnaces that must be RM-functional. The furnaces are needed for the vitrification, fusion, and calcination of slurry samples. Sample preparation requires temperatures ranging from $500^{\circ} \mathrm{C}$ to $1150^{\circ} \mathrm{C}$.

\subsubsection{Background}

Due mainly to space constraints, furnaces were placed at the west end of the SSC. The radioactive environment and limited access to the SSC required that the furnaces have special functionalities, such as a high maximum temperature to avoid burnout of heating elements and a means to remotely replace the elements. Also, due to limited access, any type of in-cell maintenance on the furnace would be difficult. Therefore, two furnaces would be used (one as a backup to the other) with maximum ex-cell functionality being key. The SSC's hatch dimensions, floor load limitations, and space required relatively lightweight furnaces with a small footprint. 
Two furnace models were found with the ability to change heating elements remotely. One model did not meet A\&PC's size and weight requirements, and the power supply and controls did not have the capability to be placed ex-cell. The remaining model was the high-temperature furnace (see figures 55, 56, and 57). The furnace has a maximum temperature of approximately $1600^{\circ} \mathrm{C}$ with dimensions of $14.625^{\prime \prime} \mathrm{L} x 16.625^{\prime \prime} \mathrm{W} \mathrm{x}$ $22.75^{\prime \prime} \mathrm{H}$. The heating elements have the capability to be changed remotely and the power supply and controller are remote from the furnace.

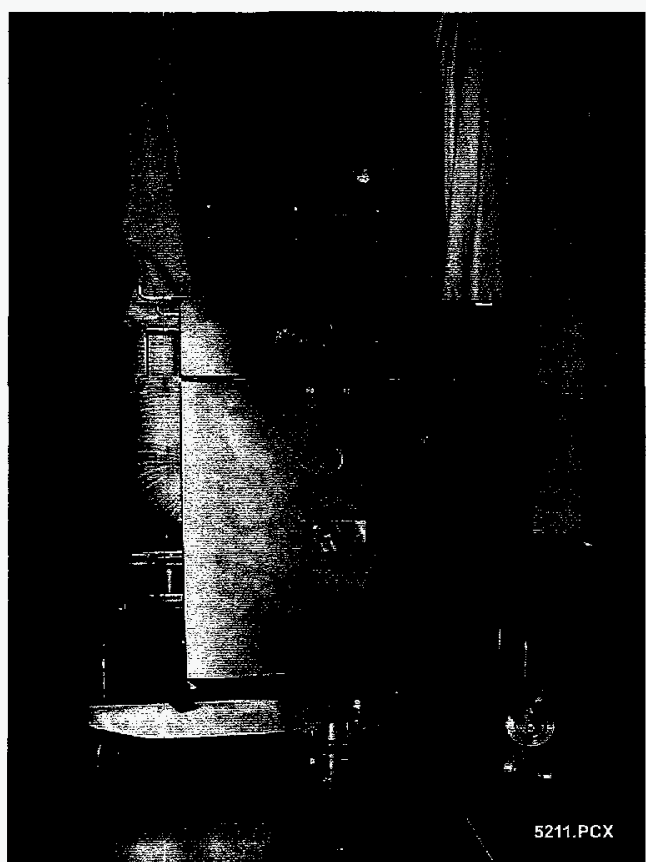

Figure 55. Furnace on Stainless Steel Cart, Front View

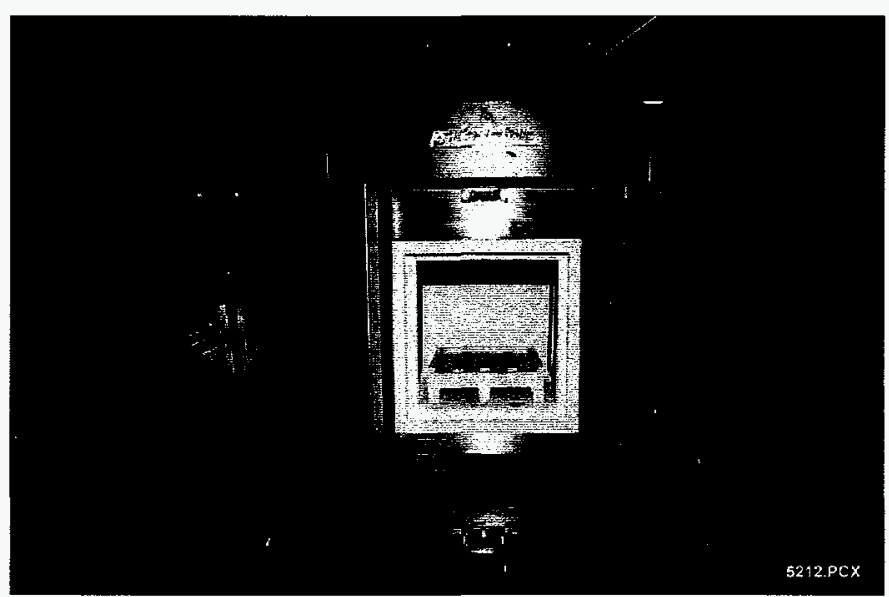

Figure 56. Furnace on Stainless Steel Cart, Front View, Door Open

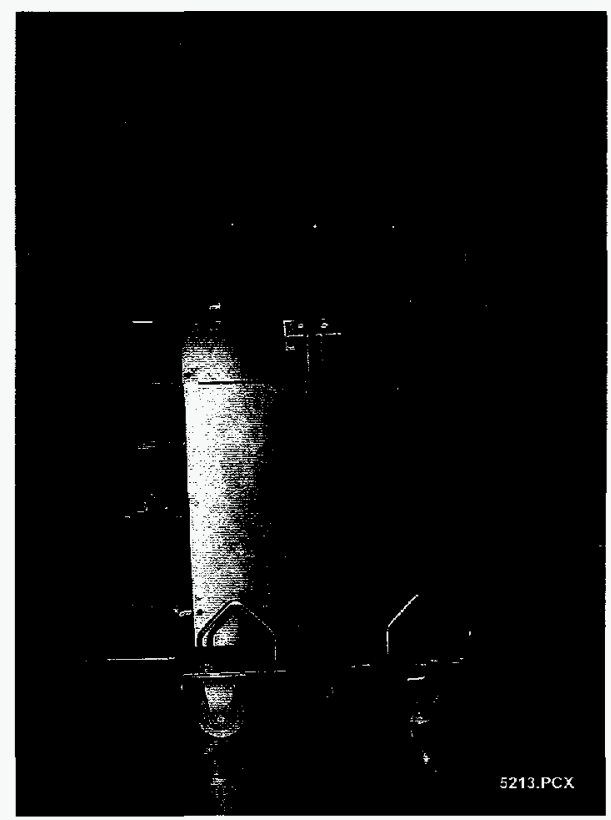

Figure 57. Furnace on Stainless Steel Cart, Side View 


\subsubsection{Description}

The furnace consists of a stainless steel outer shell and a carbon steel inner shell lined with loose alumina insulation. Two fans are located underneath the furnace for heat removal from the area between the inner and outer shells. The furnace is front loading (FL) with a door that swings open to the left or right.

A removable cover allows access to the heating elements and their electrical connections (see figure 58). Heating elements are removed and replaced through this opening. Figure 59 shows the molybdenum disilicide heating elements that are placed in slots atop the furnace and positioned on the sides in the furnace chamber. Electrical connections for the extension cables are located in back of the furnace to link the furnace to an external power supply and controller. The power supply draws 40 amps of current and provides up to 60 amps to the furnace at up to 40 volts. The power supply/controller unit is larger than the furnace $\left(22.5^{\prime \prime} \times 18^{\prime \prime} \times 29.5^{\prime \prime}\right.$ at $175 \mathrm{lbs}$.) and is placed ex-cell.

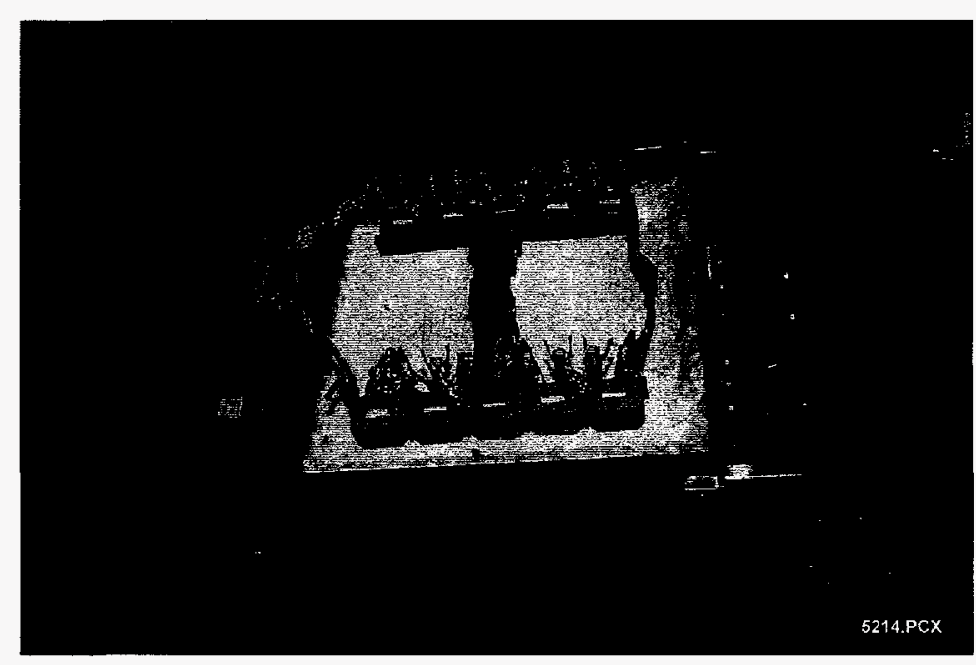

Figure 58. Electrical Connections Atop the Furnace

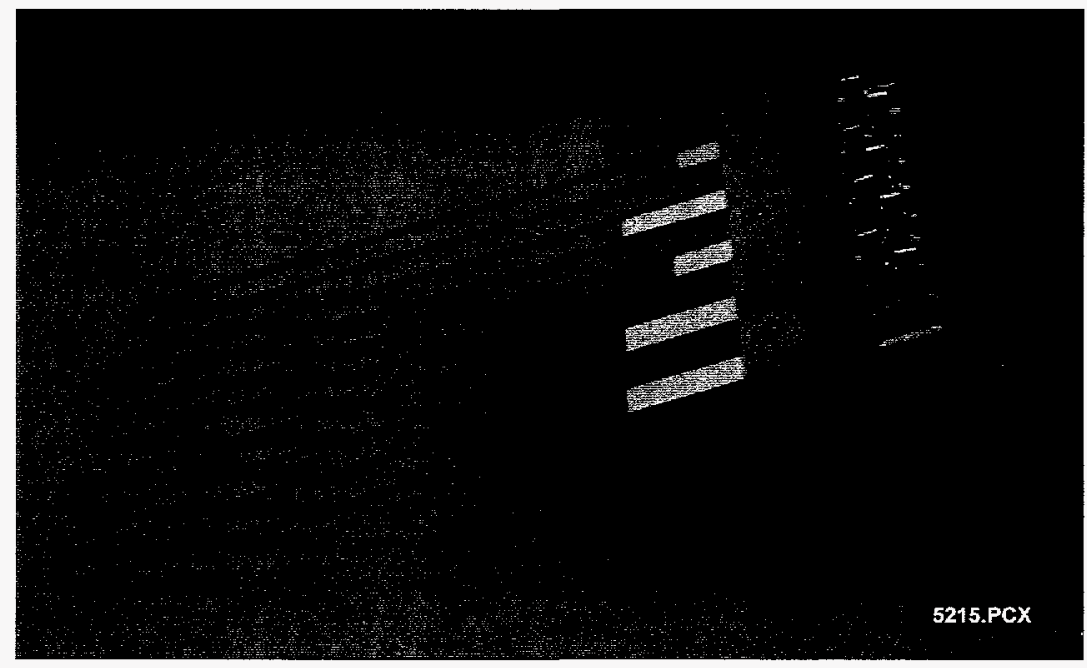

Figure 59. Molybdenum Disilicide Heating Elements with Lifting Apparatus

\subsubsection{Modifications/Equipment/Tools}

As it was received from the vendor, the furnace required modifications, equipment, and tools to meet the requirements of in-cell use and make it RM friendly. This hardware was made of stainless steel to resist corrosion and chemical attack. 


\section{A. Mechanical Modifications}

The very fragile individual heating elements were mounted on a lifting apparatus that was fitted with a knurled RM grip, which is a handle placed on tools and equipment to provide a place for RM fingers to grip firmly (see figure 60). This furnishes a rigid support by which heating elements can be removed from and replaced in the furnace. The lifting apparatus also allows electrical connections to be achieved remotely with minimal displacement of the 10 fragile heating elements. Five heating elements were mounted per lift, with many of the electrical connections made prior to cell entry. One broken heating element requires the replacement of the entire bank of five.

RM grips replaced the door handle and were placed on the furnace cover, which must be removed to replace heating elements.

Guides were placed on the door to aid in closing the door without damage to friable (easily crumbled) insulation.

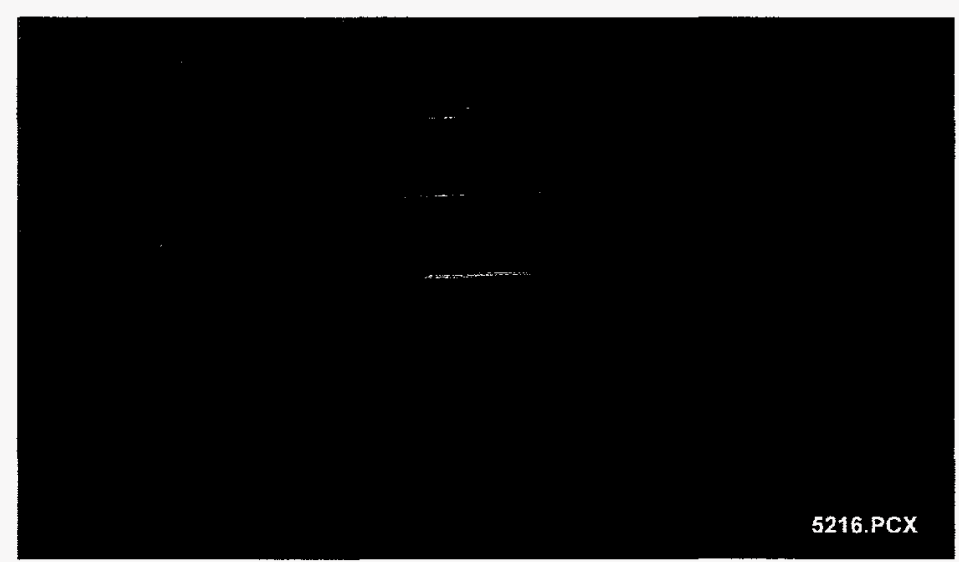

Figure 60. Heating Element Lifting Apparatus

Mullite reinforcement rods were inserted in the door insulation and in the insulation in the doorway of the furnace. Past experience has proven that the insulation in these areas can break and render the furnace non-operative.

Removable dense alumina slabs (much harder than the friable alumina insulation lining the furnace chamber) were placed on the floor to protect the insulation and provide for easy cleanups of spills.

Two ports were constructed on the rear of the furnace to hold the thermowells and thermocouples that provide temperature control and overtemperature protection. Sealing the thermocouples from the furnace's fans (even with the thermowells) proved difficult but worthwhile by providing more stable temperature readings.

\section{B. Electrical Modifications}

A receptacle box was fitted on the rear of the furnace. The box contains connections for the main power to the furnace and the power for the two fans (see figure 61).

RM grips were fabricated for the 50 -amp connectors that make the in-cell connection to the rear of the furnace possible (see figure 62).

Connectors were used for the fan connection to the rear of the furnace. The connectors proved to be difficult to align and grip with the remote manipulator fingers. The connectors were marked before placement in-cell to aid in alignment.

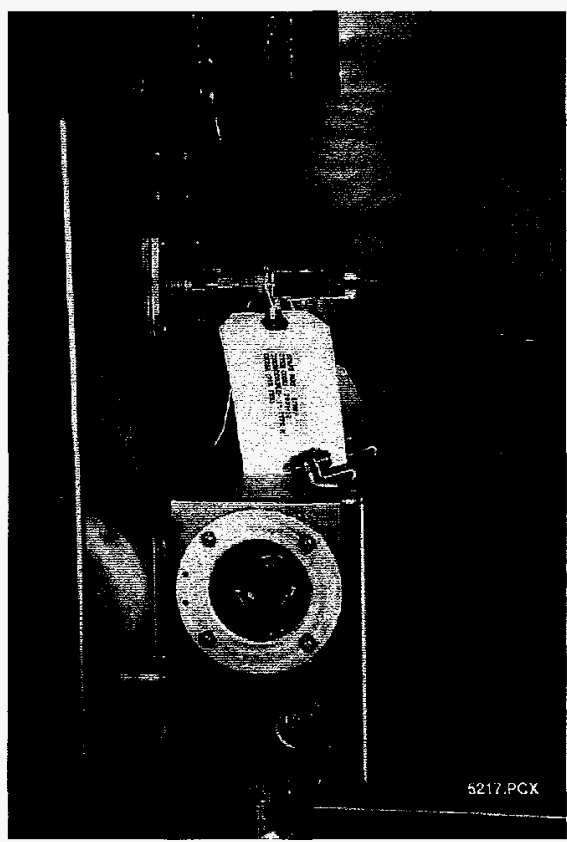

Figure 61. Thermocouples and Receptacle Box on Rear of Furnace 
Replacement of the braided straps, which provide power to the heating elements atop the furnace, is easily done with the RMs using special flange nuts and semi-threadless bolts.

Seven-inch type $\mathrm{R}$ ungrounded platinum sheathed thermocouples are used for temperature control and over temperature protection (see figures 61 and 63). Two thermocouples penetrate the rear of each furnace and extend approximately 3 " past the insulation inside the furnace. Thermocouple stability (drift and conflicting readings between the controller and overtemperature unit) was improved with the addition of ceramic tubes bonded to fittings that act as thermowells extending about 2" into the furnace (see figure 63). Thermocouples are calibrated and certified prior to use.
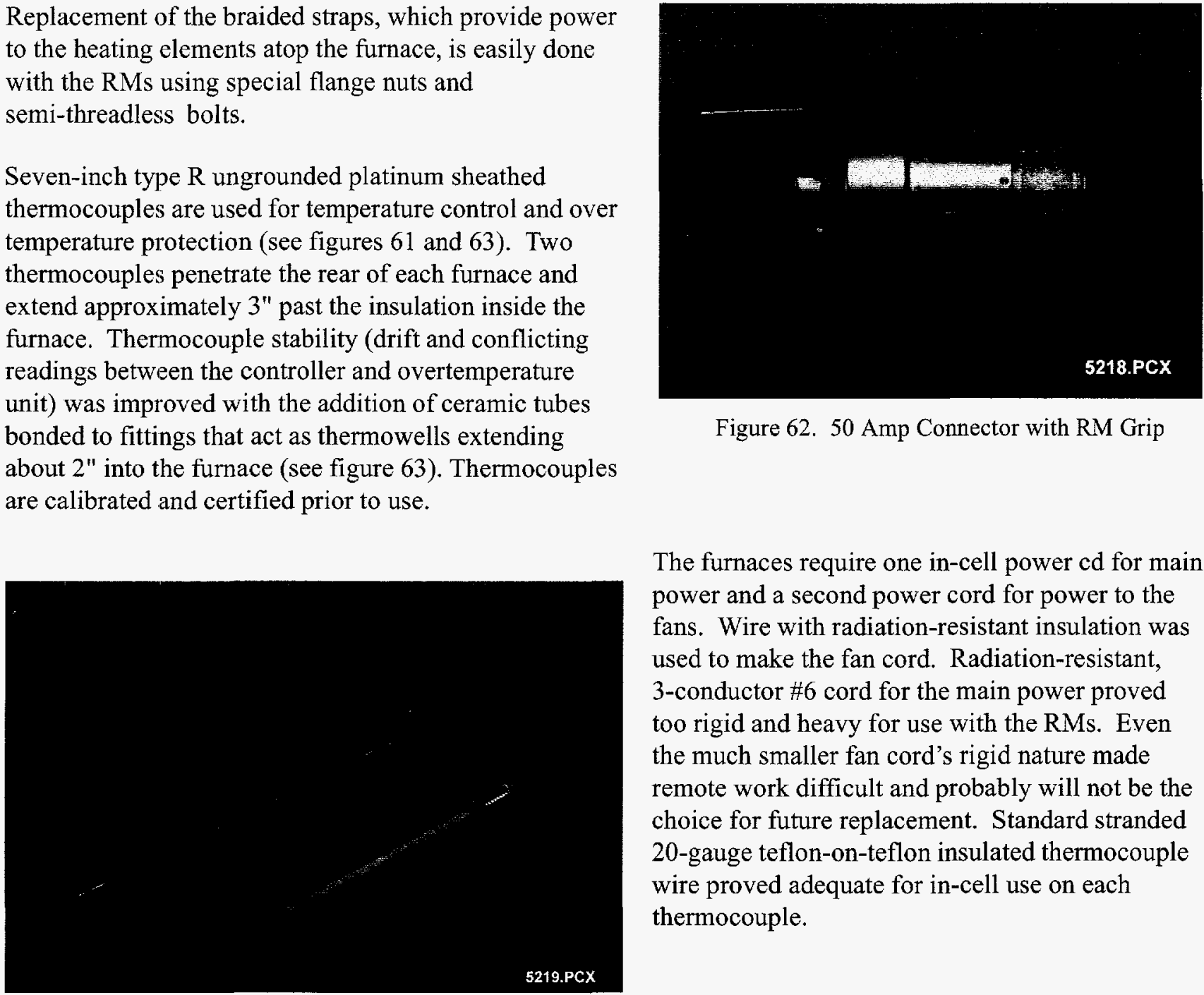

Figure 62. 50 Amp Connector with RM Grip

The furnaces require one in-cell power $\mathrm{cd}$ for main power and a second power cord for power to the fans. Wire with radiation-resistant insulation was used to make the fan cord. Radiation-resistant, 3-conductor \#6 cord for the main power proved too rigid and heavy for use with the RMs. Even the much smaller fan cord's rigid nature made remote work difficult and probably will not be the choice for future replacement. Standard stranded 20-gauge teflon-on-teflon insulated thermocouple wire proved adequate for in-cell use on each thermocouple.

Figure 63. Seven-inch Thermocouple and Thermowell

Experience has proven that flexible limp wire is best for handling with the RMs. Radiation-resistant cables, which are extremely thick and stiff, were not desired for use in the SSC. Instead, efforts focused on replacement of damaged cords in the SSC. Replacement was accomplished by boring large diameter penetrations in the SSC walls. The penetrations are covered with removable plates with holes drilled in them and grommets to fit various cord diameters. The grommets are fitted to the cables before the plates are attached.

A damaged cord is cut at the ex-cell end as close to the penetration as possible to eliminate in-cell waste and the penetration plate is removed. Using the RMs, the cord is then pulled in-cell, cut into small sections, and disposed. Because of the large size of the penetration, a cord can be pulled into the cell without affecting other cords in the penetration. A new cord with a grommet is pulled into the cell and the plate is replaced. 


\section{Equipment Modifications}

Limited mobility of each furnace was obtained by fabricating a stainless steel cart (see figures 55,56 , and 57). Lifting bails were provided at each corner to provide a means for lowering the furnaces into the SSC. The furnace cart could be locked into place with a lever brake positioned at the front of the cart. The brake raises the front wheels off the surface by a few millimeters. The front end of the furnace is then supported by the brake itself. For additional stability the rear casters were fabricated not to swivel. The cart was designed to keep the height of the furnace low. Replacement of the heating elements through the top of the furnace is less difficult at a lower height. The casters of the cart are stainless steel, which allows the SSC to be decontaminated without affecting the furnace cart.

Spills inside the furnaces are contained by a quartz tray. The tray was designed to allow spillage to flow underneath the sample racks so they would not adhere to the quartz tray. The quartz trays devitrify (crystallize) rapidly when cycled from ambient to very high temperatures $\left(1150^{\circ} \mathrm{C}\right)$. This causes deterioration of the tray, necessitating replacement.

The fans underneath the furnace force heated air upwards, out the top of the furnace. The air flow in the SSC, hoods placed on top of the furnaces, and sectional ductwork all improve heat removal from the SSC.

The electrical cords for the furnaces are held in steel brackets bolted to the SSC wall to keep them off the floor of the SSC (see figure 54). The brackets aid in the decontamination and relocation of the equipment in the SSC.

Items removed from the furnaces are placed on small, lightweight stainless steel cooling racks (see figure 64). The racks keep hot samples off the SSC floor which reduces their chances of contact with other materials in the SSC.

A shock absorbent foam, attached to sturdy cardboard pieces, provides a means for transferring delicate heating elements into the SSC (see figure 65). The cardboard with foam is formed into a wrap that snugly surrounds a bank of elements. Once in-cell, the protective wrap is disposed of immediately to avoid having flammable materials in the cells.
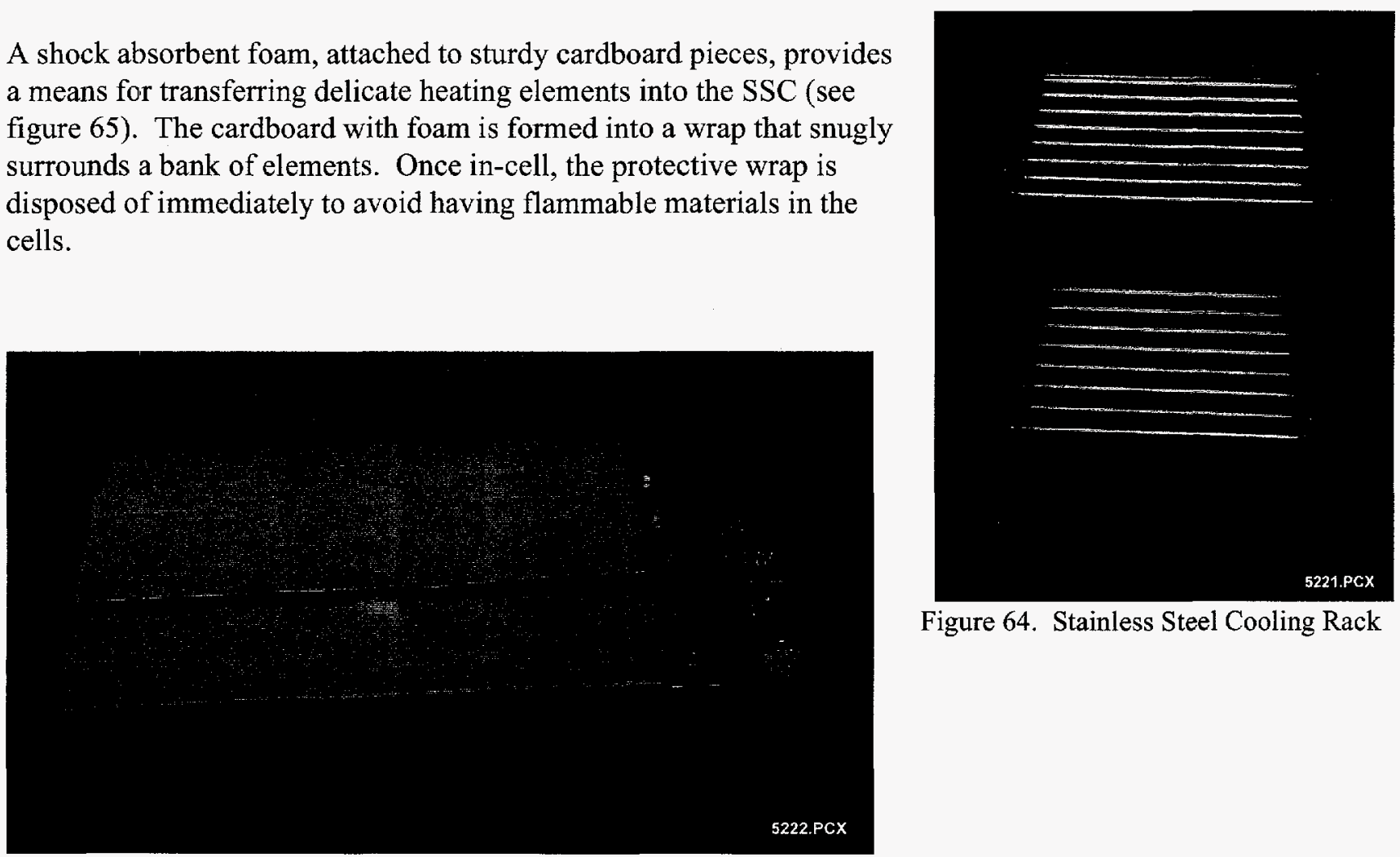

Figure 64. Stainless Steel Cooling Rack

Figure 65. Cardboard and Foam Wrapped Around Heating Elements 
Spare heating elements kept in the SSC are housed and protected in a rack fabricated of stainless steel. The rack holds two banks of elements ( 10 elements for two change outs) and was fabricated with a bail for movement around the SSC with the RMs.

\section{Tools}

The tools fabricated for use with the furnace are made of stainless steel and fitted with knurled RM grips. Tools should be lightweight without compromising strength or utility. Lightening holes cut throughout the material and decreased the thickness were techniques used to accomplish this.

Due to the heavy weight of the furnace, a tool to increase leverage is required for engaging the brake on the cart. A simple lever tool fitted with a remote manipulator grip provides enough leverage to engage the brake with one remote manipulator (see figure 66).

RM fingers were modified to make the pinch clamp electrical connections to the heating elements. A piece of metal rod welded to the fingers engages the indentation on the pinch clamp (see figure 67).

Sockets and open-end wrenches were modified with RM grips (see figure 68). These tools can be used with the RMs to loosen or tighten nuts on the furnace.

A forklift-type tool was made to move the quartz spill trays into and out of the furnaces (see figure 69). The weight of the quartz tray (approximately 7 lbs.) requires two RMs, so the tool was fabricated with two RM grips positioned so that the line of view is not totally blocked during use. The spill trays rest only 1 to 2 inches away from each bank of fragile: heating elements. A clear view is important to avoid contacting the heating element during insertion and removal of the spill trays.

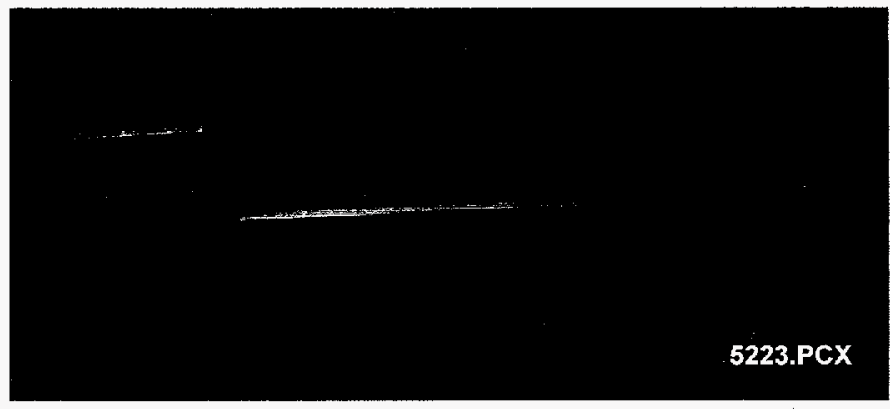

Figure 66. Furnace Cart Brake Tool

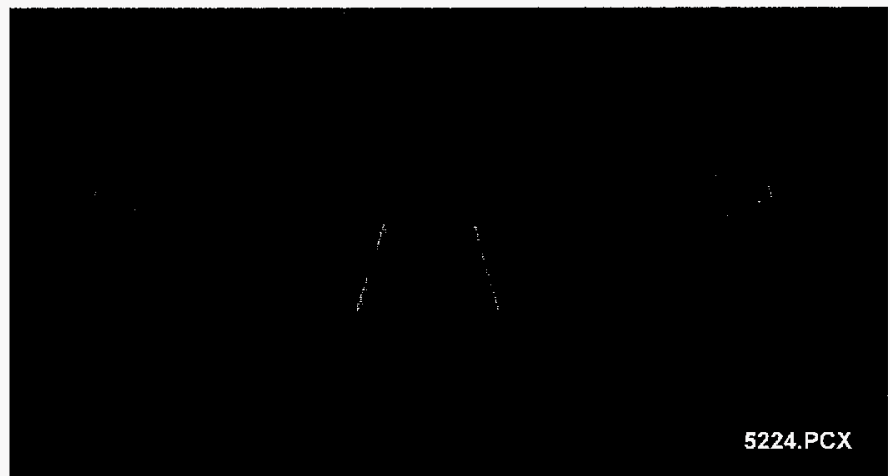

Figure 67. Modified RM Fingers for Furnace Pinch Clamps

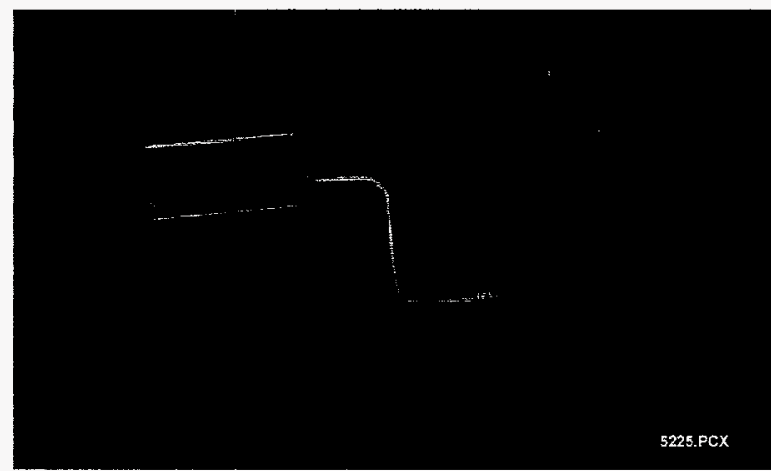

Retrieval of samples in custom-made racks requires an extension of the RM jaws. The high temperatures inside the furnaces limit placement of RM hands inside or near the furnace opening. A flat piece of stainless steel with one end to engage the sample racks and the other end fitted with an RM grip was fabricated for this purpose (see figure 30 ).

Figure 68. Socket Tool for RM Use 


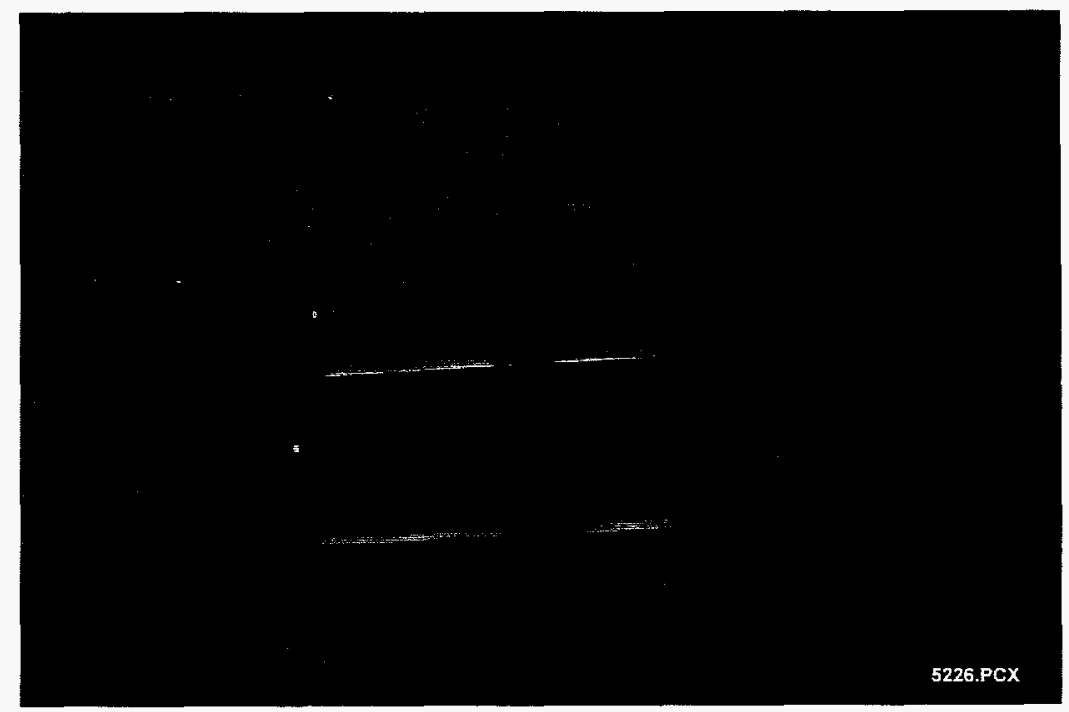

Figure 69. Spill Tray Removal Tool

\subsubsection{Maintenance}

Occasional glazing of the heating elements at $1500^{\circ} \mathrm{C}$ for at least four hours provides an oxide coating that protects against chemical attack. 


\subsection{IN-CELL REMOTE CAMERA}

A remotely operable video camera is positioned in the SSC near one end of the transfer cart rail system. It is extremely useful in viewing the rails to locate and remove obstructions, thus avoiding transfer cart derailments and the ensuing difficulties.

\subsection{Camera Mounting Support System}

Inside the analytical hot cells, a common passageway runs from the northern wall of the SSC to the southernmost wall of SC2. Within this passageway is the transfer cart system (TCS), consisting of two rails made of $90^{\circ} 1.5$-inch stainless steel angle iron. One rail is attached to the east wall of the passageway and the other is supported by a frame structure (see figure 70). The transfer cart is pulled back and forth on the rail system by an electric motor and cable mechanism. The TCS is used extensively to transport samples, supplies, and equipment from one cell to another. The system decreases the number of personnel entries into the backs of the ACs. Personnel entries are undesirable because of the risks of personnel radiation contamination and exposure.

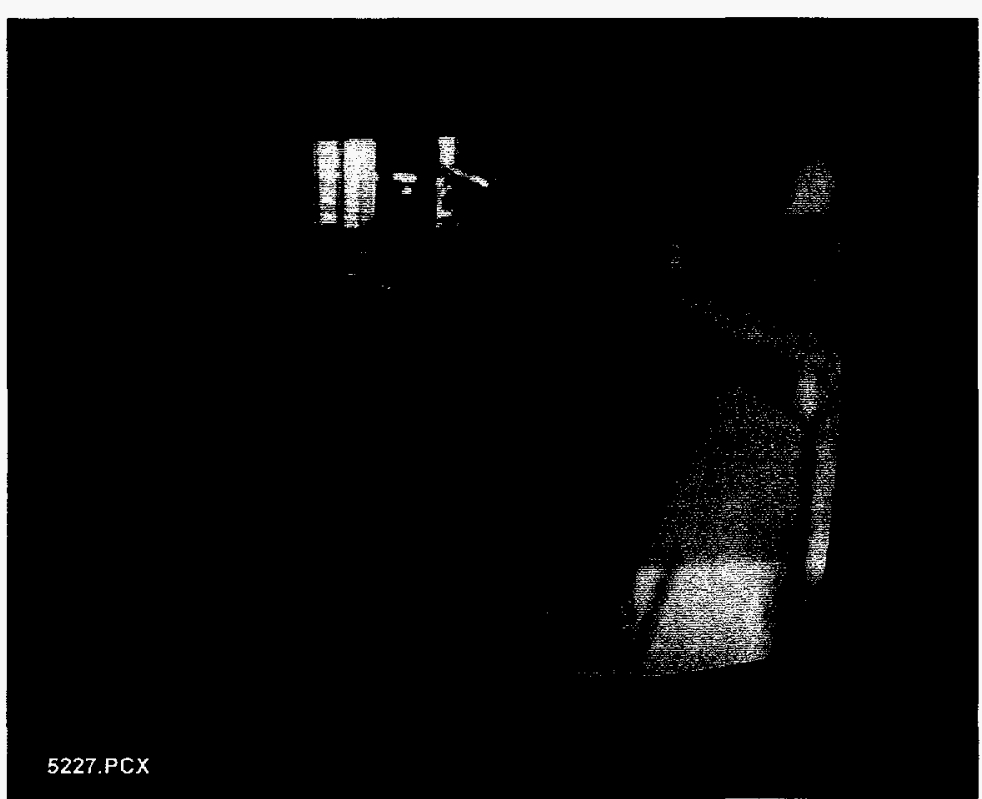

Figure 70. Camera View of Passageway from SSC through AC1-5

The TCS is vital in support of the vitrification process. The most common malfunction of the TCS is derailment of the cart, caused by debris trapped between the angle iron rail and the wall, particularly the east wall. There is approximately 1.5 inches between the vertical upright of the angle iron and the wall. Small plastic bottles sometimes fall into that space, obstructing the cart and eventually causing it to derail. It is extremely difficult to view the rails from above at the window area to inspect them for debris.

\subsection{Original Camera Systems}

The first in-cell camera system was not RM user friendly. It consisted of a charged coupled device (CCD) video camera with a 10X TVzoom lens (see figure 71). The only remote options available for the camera were the zoom and iris adjustments. A special hanging bracket was designed to support the camera above the tunnel of the passageway. In order to adjust the viewing angle of the camera (Up, Down, Left,

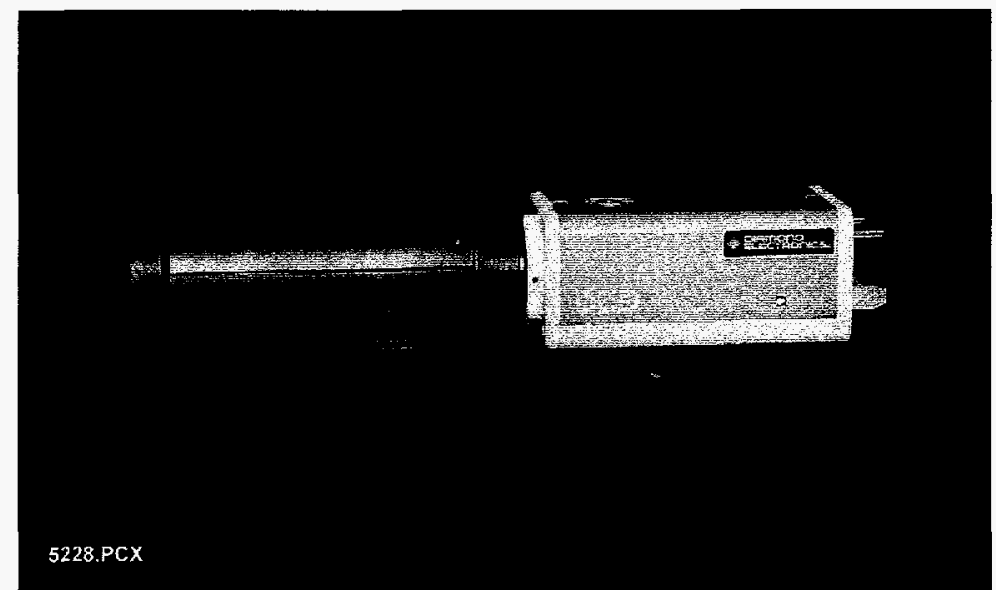

Figure 71. Charged Coupled Device Camera and 10X TV Zoom Lens 
Right), an operator would have to grab the camera with an RM and mechanically turn the camera to the desired position.

The camera was incapable of focusing on objects closer than six feet away. An infrared light source was attached to the mounting bracket to illuminate the point of interest in the passageway, which often proved to be a nuisance rather than an aid. One of the wires broke off the camera and was not able to be repaired remotely inside the SSC. It was decided at that time to replace the camera system with a system that offered more remote capabilities and better optical features.

\subsection{Improved Camera System}

A camera system that was being used in the Chemical Process Cell (CPC) during modifications was considered for use in the Analytical Cells. The system offered the versatility needed to perform the passageway survey remotely. The camera setup consists of a digital camera and an auto focus $8 \mathrm{X} \mathrm{TV}$

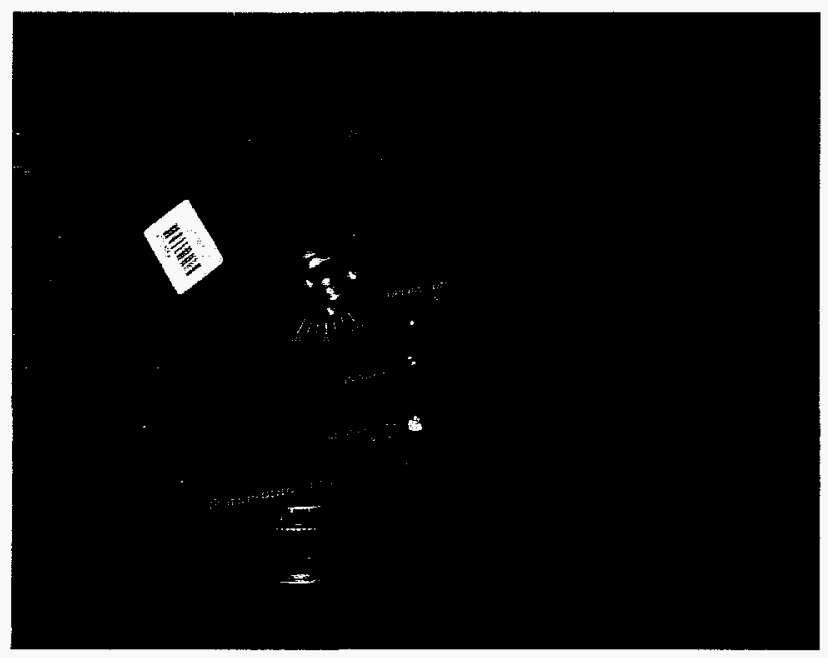

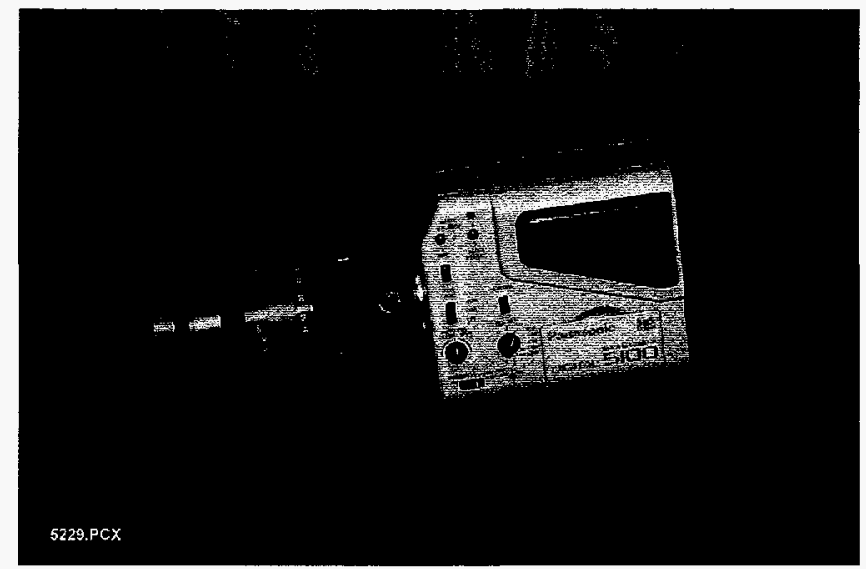

Figure 72. Camera with $8 X$ Zoom Lens

zoom lens (see figure 72). Attached to the camera and lens is a pan/tilt head, which provides the required mobility for operating the camera in the SSC (see figure 73).

Figure 73. Pan/Tilt

A camera remote controller enables all functions to be executed from outside the cell (see figure 74). Electrical cables are fed through a port hole in the cell to connect the in-cell camera/lens/ pan/tilt mechanism to the ex-cell controller.

A special support bracket houses the camera/lens/pan/tilt mechanism within full view of the entire cart passageway. A bracket was engineered to support the camera at the top edge of the tunnel in the SSC (see figure 75). The location of

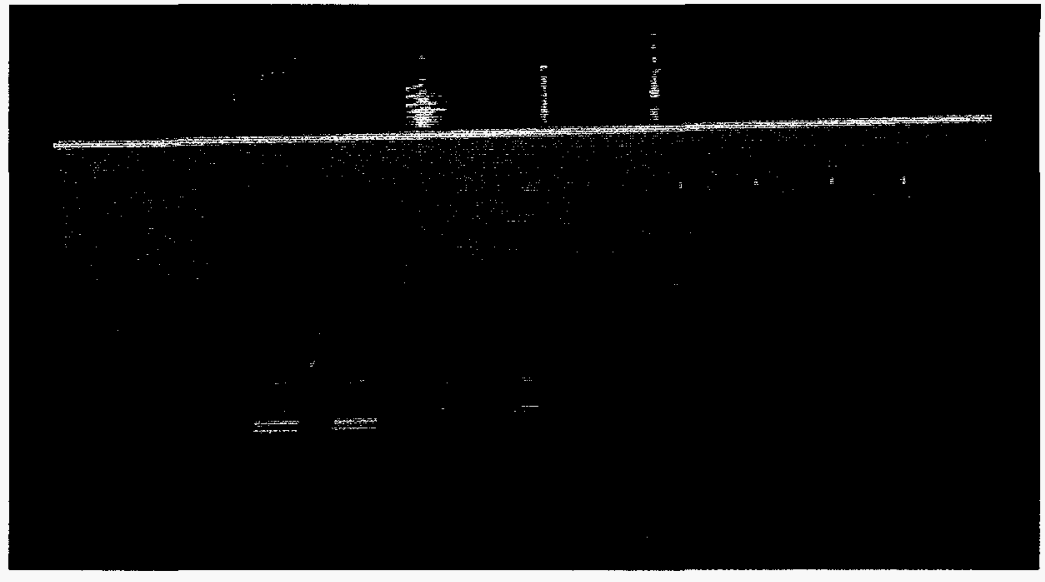

Figure 74. Camera Remote Controller Used with Camera System in SSC and SC2 
the camera in the SSC affords an optimum view of the tunnel and various equipment and locations inside the SSC. A second identical camera system is available as a spare.

The TCS rail system and any debris that may be lodged between the rail and the east wall can be seen clearly for the full length of the transfer cart passageway. A bracket has been built to be installed on top of the end of the rails in SC2. Since the transfer cart does not fully enter the SC2 there is room to install the bracket and the camera setup (see figure 76). Installation of a second camera system in $\mathrm{SC} 2$ had been under consideration but is not currently anticipated.

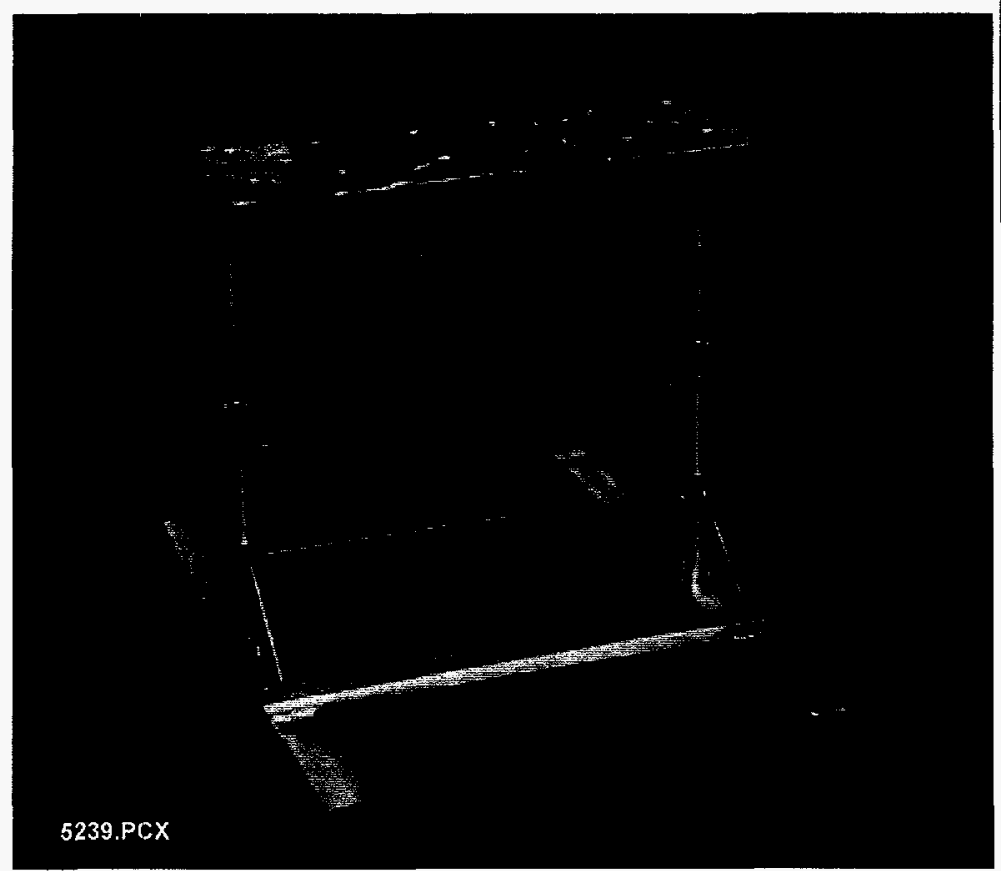

Figure 75. Present Camera Setup with Bracket Used IN SSC for Surveillance of Passageway

Figure 76. Bracket to Support Camera System in SC2 on Rails 


\subsection{CELL MAINTENANCE AND SUPPORT}

The analytical hot cells, including ACs 1-5, SC2, and SSC, are a vital interconnected system for A\&PC support of the vitrification process. As such, they require considerable maintenance and support for continuous smooth functioning.

\subsection{Housekeeping}

Samples are received in batches for in-cell analysis. Waste generated and collected in each cell during analysis is processed when the sample batch analysis is complete. Most of the solid waste generated in the cells consists of plastic bottles. The waste is decontaminated, dose-checked, and packaged into a suitable container, typically a 53-gallon poly liner. The stainless steel cell workpans are decontaminated using water and a squeegee. Samples are collected and stored in the cells, while the analytical data is reviewed by the process support engineers. Once the data has been accepted by the customers (SAEs, engineering, etc.) the samples are disposed of in Tank 7D-14 via the cell drains and the flush pot.

\subsection{Routine Manned Cell Entries}

Radiological waste support (RWS) personnel routinely perform manned entries into the $\mathrm{ADA}$ to remove waste packaged in 53-gallon poly liners from AC5. The rear door of the cell is opened to provide access to the cell (see figure 77). A full liner is ready for removal every 7 to 10 days. A typical manned entry involves three personnel from RWS and two Radiological Protection technicians.

\subsection{Weekly RM Preventive Maintenance}

The Maintenance Department provides a weekly preventive maintenance (PM) check of the RMs at the analytical hot cells. Finger/jaw status, tong assembly status, up-down and rotational movement of the RMs and cables, with fine-tuning if necessary, are checked during PM. Problems experienced with the remote manipulators in the cells are written in the Cell Logbook that Maintenance personnel review and respond to during the weekly $P M$.

\subsection{Administrative Control of Dose Rate}

The administrative dose limits for a sample being removed from the hot cells are $10 \mathrm{mR} / \mathrm{hr}$ at 2 inches (window closed) for gamma and $50 \mathrm{mR} / \mathrm{hr}$ at 2 inches (window open) for

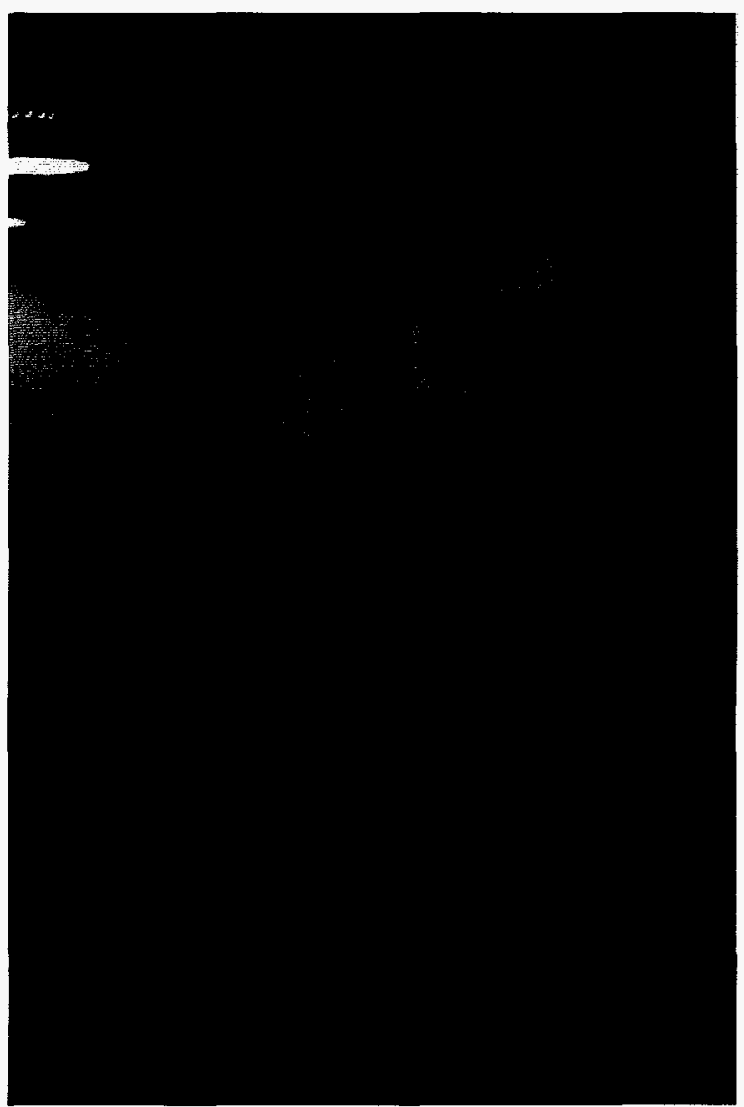

Figure 77. Analytical Decontamination Aisle (ADA) beta-gamma. Sample dose rates above these limits require a separate radiation work permit (RWP) signed off by the responsible supervisor/engineer, A\&PC shift supervisor, radiological control (RC) technician and RC supervisor. Radioactive dose limits are met by transferring a small volume of a prepared sample to a vial or by 
diluting the sample to reduce the dose rate while still maintaining an adequate sample concentration for the analysis. A\&PC process knowledge helps simplify the process of keeping the balance between analytical needs and dose limit requirements.

The analytical cells receive vitrification process samples with $\mathrm{Cs}-137$ activity of $7 \mathrm{E}+3 \mu \mathrm{Ci} / \mathrm{g}$ and Sr-90 activity of $6 \mathrm{E}+3 \mu \mathrm{Ci} / \mathrm{g}$. The dose rate of the as-received vitrification sample is approximately $55 \mathrm{R} / \mathrm{hr}$ for a 20 -gram sample. In order to remove the sample and analyze it on various out-of-cell instrumentation, the sample must be diluted so that the dose rate of the sample does not exceed the dose limits. Typically, a 600 to 2000 fold dilution is necessary to reduce the dose rate to acceptable levels.

\subsection{Beta Shields}

The diluted samples are placed in a CRL transfer canister and transferred to a hood or an ICP glovebox. Inside the canister is a polyvinyl chloride (PVC) liner that helps shield the beta radiation. Plexiglass beta shields have been fabricated to contain the sample dilutions at the various instrumentation locations to help shield the beta radiation during sample analysis.

A 7-pack vial holder beta shield was designed to hold seven 20 -mL vials. It is used to transfer sample dilutions from the cell to the ICP glovebox and to store and shield the samples while in the glovebox. The shield design incorporates a removable vial rack to allow easy decontamination of the shield (see figure 78).

Waste from the ICP is collected in a $500-\mathrm{mL}$ bottle inside a cylindrical plexiglass shield in the glovebox (see figure 79). The ICP is capable of analyzing samples manually or using an autosampler. In the manual mode, shielding is accomplished when each sample is placed in a single plexiglass vial holder, which reduces beta radiation exposure to the hands. A beta shield encloses the autosampler rack to provide shielding. The autosampler rack has also been modified to allow sample vials to be opened or closed with one hand, reducing the need for the analyst to place both hands inside the glovebox.

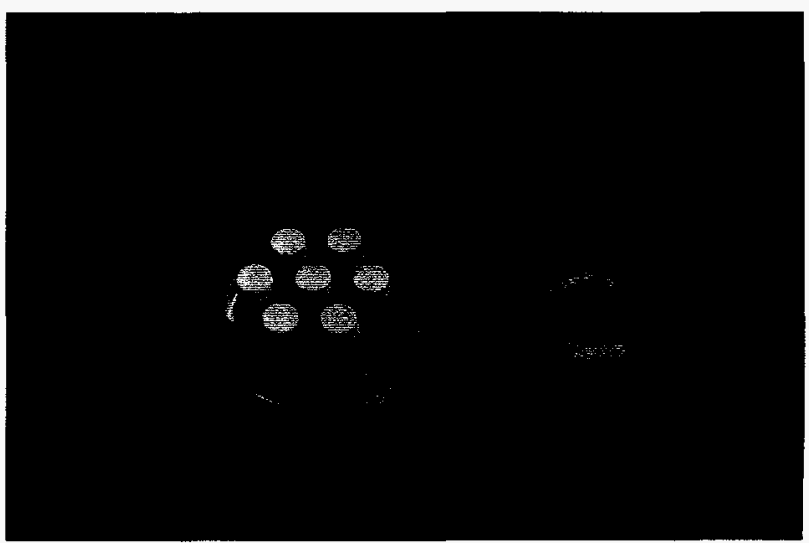

Figure 78. Beta Shield - 7-Pack Vial Holder

The IC and TOC instruments use a single vial holder identical to that used in the ICP glovebox. When the $\mathrm{IC}$ is operated in the autosampler mode, a shielded rack is used to contain $1420-\mathrm{mL}$ vials (see figure 80).

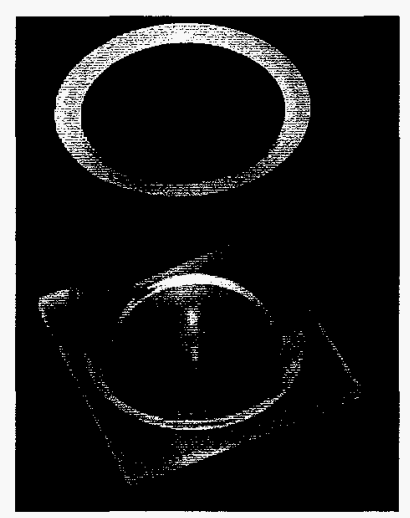

Figure 79. Beta Shield ICP Waste Collection

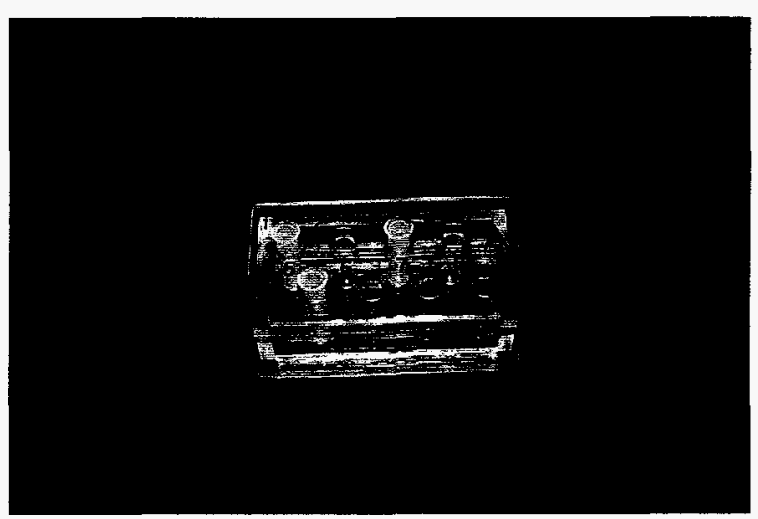

Figure 80. Beta Shield - Ion Chromatography (IC) Auto Sampler Vial Holder 


\subsection{ENVIRONMENTAL CONTROL}

Several control systems in the hot cells prevent emission of radioactive contamination into the work areas or the outdoor environment.

\subsection{Analytical Decontamination Aisle (ADA) Heating, Ventilation, and Air Conditioning (HVAC) Upgrade}

The AC and SSC are kept at 1 to $2 "$ of negative pressure. A flow of approximately 150 cubic feet per minute (cfm) of exhaust ventilation is provided to each cell through a 10" Hastelloy ${ }^{\mathrm{TM}}$ duct. Makeup air for the cells is obtained from the ADA and drawn into each cell. The volume of air entering the cell is controlled by an adjustable damper and the air is filtered prior to entering the cell. Air flows from the Off-gas Aisle (OGA) to the ADA to the individual cells, then is passed through a high-efficiency particulate air (HEPA) filter before it flows out through the main stack, where the exhaust is continually monitored for radioactivity.

The OGA contains many steam lines that cause the air exiting the area to be heated. As a result, the cell temperature can become excessively warm, from $110^{\circ} \mathrm{F}$ to $120^{\circ} \mathrm{F}$. To reduce thermally induced failure of equipment and to provide a stable thermal environment in which to perform in-cell analysis, the air in the ADA is conditioned. A 7.5 ton freon chiller unit was installed on the roof of the Main Plant for this purpose. An air handler was installed in the ADA to cool the air to $70^{\circ} \mathrm{F}$. It operates in a recirculation mode with an operating capacity of $2500 \mathrm{cfm}$. Warm air is drawn from the OGA into the ADA, where the air mixes with the cooled ADA air. The cooled ADA air mixture is drawn into the five ACs, SSC, and SC2. The air cools the cell and helps maintain a stable cell temperature.

\subsection{Floor Shielding}

The floor in front of the cells formerly experienced higher radioactive dose levels than did the rest of the laboratory area due to "shine" coming from a high-radiation area located below the laboratory floor. A steel plate shield, which is one-half inch thick, was placed on the floor to reduce the dose exposure to personnel eorking at the cells. 


\subsection{CONCLUSION}

A\&PC refurbishment of the analytical hot cells; the development of remote techniques, equipment, and tools; and the irnplementation and fine tuning of new procedures have provided the capabilities and flexibility to successfully support the HLW vitrification process.

The ACMUs provided a significant advantage for technology development and training. The work performed there provided the information needed for the design, modification, and fabrication of the apparatus and tools for the analytical cells.

The cell clecontamination and installation of new apparatus were completed by July 1995. Lessons learned after the start of the vitrification campaign resulted in the following changes:

- The remote microwave total solids analyzer was replaced by a thermal oven.

- The remote microwave digestion system was replaced by a thermal oven.

- The dose rate capacity of the 2-gallon cans for radioactive waste in the shield drums was increased by using a smaller bottle (1L) and using grit as a shielding medium around the bottle.

- The ACMUs were modified by adding a transfer cart track for mockup work to meet TCS challenges.

- A small, lightweight, manual "emergency cart" was fabricated and evaluated in the ACMUs. The cart can be placed on the track during a personnel entry and pushed along with the RMs using a pole.

- The remote apparatus for the iron ratio determination was not required due to changing process requirements.

As a result of the work described in this report, the TAT for WI and WGF slurry sample analysis has decreased from 62 hours to 30 hours. This reduction has allowed the vitrification campaign to decrease the batch makeup time period from 204 to a range of 160 to 180 hours, facilitating the production of the 275 glass canister "logs" in a shorter period of time.

The success of the Analytical and Process Chemistry Department in support of the vitrification process is due to the direct involvement and adaptability of all laboratory personnel in each phase of the cell refurbishment, remote method development, and "hot operations." The commitment and support of management, design, Engineering, Maintenance, Radiological Waste, Radiological Control, and Main Plant Operations personnel to provide the best responses to the many unique questions encountered has been essential. 


\subsection{ACRONYMS AND ABBREVIATIONS}

\begin{tabular}{|c|c|}
\hline $\mathrm{ACMU}$ & Analytical Cell Mockup Unit \\
\hline ADA & Analytical Decontamination Aisle \\
\hline $\mathrm{AC}$ & Analytical Cell \\
\hline $\mathrm{A} \& \mathrm{PC}$ & Analytical \& Process Chemistry Department \\
\hline CCD & Charged Coupled Device \\
\hline CFM & Cubic feet per minute \\
\hline $\mathrm{CPC}$ & Chemical Process Cell \\
\hline CPL & Commercial Pneumatic Lift \\
\hline CRL & Central Research Laboratories \\
\hline Cs-137 & Cesium 137 \\
\hline CSS & Cement Solidification System \\
\hline CTS & Component Test Stand \\
\hline DOE & Department of Energy \\
\hline ES & Elemental Shim (second iteration of WGF) \\
\hline FACTS & Functional and Checkout Testing of Systems \\
\hline FL & Front Loading \\
\hline GF & Glass Formers ("cold" chemicals) \\
\hline GM & Geiger-Müller \\
\hline HEPA & High-efficiency Particulate Air (filter) \\
\hline $\mathrm{HF}$ & Hydrofluoric Acid \\
\hline HLW & High-level Waste \\
\hline $\mathrm{HNO}_{3}$ & Nitric Acid \\
\hline $\mathrm{H}_{3} \mathrm{PO}_{4}^{3}$ & Phosphoric Acid \\
\hline $\mathrm{H}_{2}^{3} \mathrm{SO}_{4}^{4}$ & Sulfuric Acid \\
\hline HVAC & Heating, Ventilation, and Air Conditioning \\
\hline IC & Ion Chromatography \\
\hline $\mathrm{ICP}-\mathrm{AES}=\mathrm{ICP}$ & Inductively Coupled Plasma-Atomic Emission Spectroscopy/Spectrometer \\
\hline IH\&S & Industrial Health and Safety \\
\hline IRTS & Integrated Radwaste Treatment System \\
\hline ISA & Ionic Strength Adjuster \\
\hline ISE & Ion-selective Electrode \\
\hline $\mathrm{KOH}$ & Potassium Hydroxide \\
\hline NFS & National Fuel Services Company, Inc. (original site operator) \\
\hline OGA & Off-gas Aisle \\
\hline $\mathrm{PM}$ & Preventive Maintenance \\
\hline PUREX & Plutonium Uranium Extraction \\
\hline PVC & Polyvinyl Chloride \\
\hline QA & Quality Assurance \\
\hline QC & Quality Control \\
\hline RBG & Round-bottomed Glass \\
\hline $\mathrm{RC}$ & Radiological Control \\
\hline REDOX & Oxidation Reduction \\
\hline $\mathrm{RM}$ & Remote Manipulator \\
\hline RWP & Radiation Work Permit \\
\hline RWS & Radiological Waste Support \\
\hline $\mathrm{SAE}$ & Slurry Acceptance Engineer \\
\hline SBS & Submerged Bed Scrubber \\
\hline $\mathrm{SC} 2$ & Sample Cell 2 \\
\hline
\end{tabular}




\subsection{ACRONYMS AND ABBREVIATIONS (continued)}

SF

SGN

SHD

SSC

SU

STS

TAT

TCS

THOREX

TIC

TISAB IV

TOC

TRU

$\% \mathrm{TS}$

$\mathrm{Vac}$

VCL

VTF

WGF

WI

WQR

WVDP

WVNS

$\mathrm{ZnBr}_{2}$
Sugar Feed

Societe Generale pour les Techniques Nouvelles (pneumatic sample transport system)

Shard (radioactive glass from the canister)

Sample Storage Cell

Standard Units

Supernatant Treatment System

Turnaround Time

Transfer Cart System

Thorium Extraction

Total Inorganic Carbon

Total Ionic Strength Adjusting Buffer, Formula IV

Total Organic Carbon

Transuranic

Percentage Total Solids

Volts Alternating Current

Vitrification Cold Lab

Vitrification Test Facility

Waste plus Glass Formers (WI +GF)

Waste Initial (8D-2 HLW \& CFMT heel \& SBS)

Waste Qualification Report

West Valley Demonstration Project

West Valley Nuclear Services Co., Inc.

Zinc Bromide 
Vitrification at the West Valley Demonstration Project 